SFB Is tail risk priced in credit 823 default swap premia?

Christian Meine, Hendrik Supper, Gregor N.F. Weiß

Nr. 24/2013
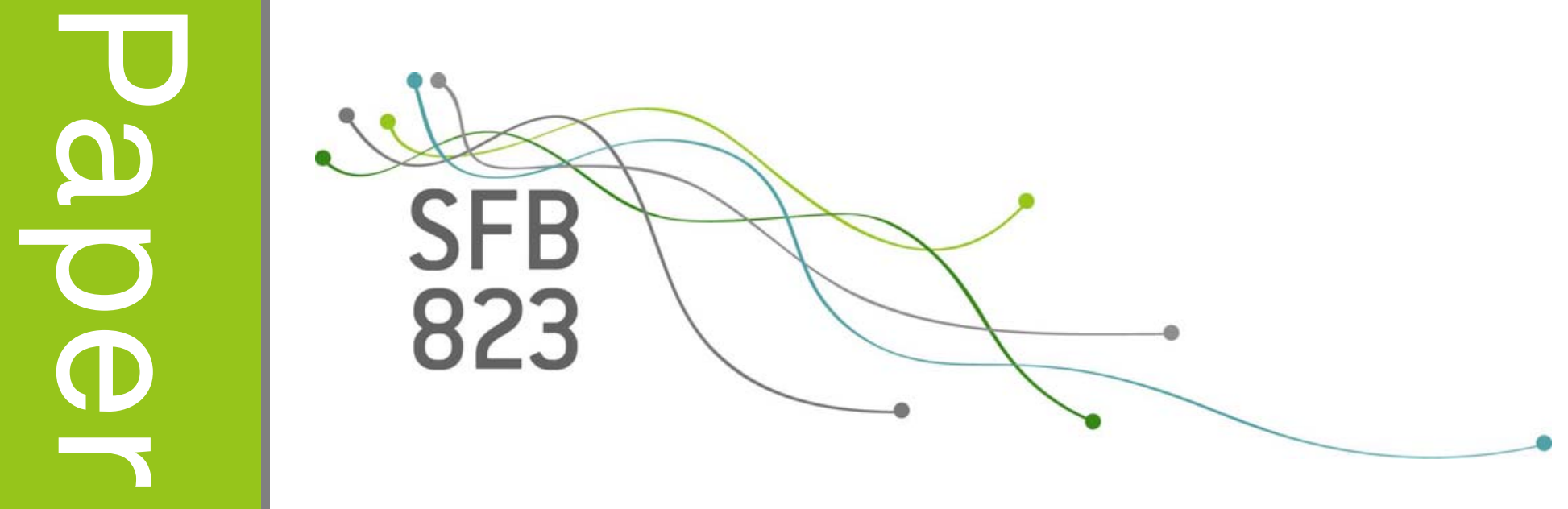



\title{
Is Tail Risk Priced in Credit Default Swap Premia?
}

\author{
Christian Meine * \\ Ruhr-Universität Bochum \\ Hendrik Supper ${ }^{\dagger}$ \\ Technische Universität Dortmund \\ Gregor N.F. Weiß \\ Technische Universität Dortmund
}

June 20, 2013

\begin{abstract}
We show that the propensity of a bank to experience extreme comovements in its credit default swap premia together with the market is priced in the bank's default swap spread during the financial crisis. We measure a bank's CDS tail beta by estimating the upper tail dependence between its default swap spreads and a credit default swap market index. Our study shows that protection sellers receive a premium for bearing the risk of extreme upward comovements in default risk. The economic significance of this effect is large yet limited to the recent financial crisis. Banks in the upper quintile of CDS tail beta have spreads that are on average 140 basis points higher than those of banks in the lower CDS tail beta quintile.
\end{abstract}

Keywords: Credit default swaps, CDS tail beta, asymmetric extreme dependence, tail risk, copulas.

JEL Classification Numbers: G21, C58, G01.

${ }^{*}$ Corresponding author; Address: Universitätsstraße 150, D-44780 Bochum, Germany, telephone: +49 23432 24426, e-mail: christian.meine@rub.de

${ }^{\dagger}$ Address: Otto-Hahn-Str. 6a, D-44227 Dortmund, Germany, telephone: +49 231755 8212, e-mail: hendrik.supper@tu-dortmund.de

¥Address: Otto-Hahn-Str. 6a， D-44221 Dortmund, Germany, telephone: +49 231755 4231, e-mail: gregor.weiss@tu-dortmund.de. Support by the Collaborative Research Center "Statistical Modeling of Nonlinear Dynamic Processes" (SFB 823) of the German Research Foundation (DFG) is gratefully acknowledged. 


\section{Introduction}

Do spreads of single-name credit default swaps (CDS) written on bank names reflect a risk premium for extreme financial disasters? There is increasing empirical evidence that stock market investors receive compensation for bearing the risk of extreme tail events in the financial market (see Bollerslev and Todorov, 2011). Consequently, investors agreeing to sell protection via a credit default swap should just the same receive a premium for bearing the risk of the swap being triggered during periods of financial turmoil. If tail risk is indeed priced in a firm's credit default swap premia, ${ }^{1}$ this effect should be particularly pronounced for banks, because banks face the risk of a bank run by depositors (see Diamond and Dybvig, 1983) and creditors (see Duffie, 2010; Gorton and Metrick, 2012). In this paper, we estimate a bank's upper tail dependence between the returns on its CDS and a relevant CDS market index (referred to as the CDS tail beta) to investigate whether the propensity of an individual bank to jointly surge with the banking sector is priced in the bank's CDS premia. We find that it is: the propensity of a bank's CDS to experience extreme upward comovements with a CDS index for the financial market is a significant determinant of the bank's CDS premia. The economic magnitude of this effect is large as a one standard deviation increase in a bank's CDS tail beta increases its CDS premium by 35 basis points. This result holds after controlling for other theoretical determinants of swap premia.

Many analyses in option pricing have emphasized the finding that investors are crash-averse. As deep out-of-the-money index puts have often been found to have a high implied volatility, investors appear to insure themselves against extreme downward movements of the market when investing in equity markets (see Jackwerth and Rubinstein, 1996; Aït-Sahalia and Lo, 2000; Garleanu et al., 2009). Empirical support for this hypothesis of investors demanding compensation for bearing crash risk is given by Ruenzi and Weigert (2013), who find that a stock's lower tail dependence with respect to the market portfolio is a priced factor in the cross-section of stock returns. Surprisingly, the literature on credit risk still lacks an investigation into the question whether investors selling protection in a CDS contract receive a comparable premium for bearing the risk of the

\footnotetext{
${ }^{1}$ Throughout this paper, we use the terms "CDS premia" and "CDS spreads" synonymously.
} 
reference firm defaulting when default probabilties experience a market-wide increase.

There now exists a substantial body of literature on the determinants of credit spreads. Collin-Dufresne et al. (2001) examine the drivers of corporate bond yield spreads and find that most drivers proposed in theory have little to none explanatory power in regressions of corporate credit spreads. Closely related, Campbell and Taksler (2003) and Cremers et al. (2008) find that idiosyncratic volatility is an economically significant determinant of levels of corporate credit spreads. The analysis of corporate bond yields, however, only offers a distorted picture of a firm's credit risk. As noted by Blanco et al. (2005) and Ericsson et al. (2009), new information is incorporated faster and more accurately into credit default swap premia than into corporate bond yields. Moreover, the latter include further nondefault components (like, e.g., liquidity risk and taxes) and require the specification of a risk-free yield curve model to calculate spreads from bond yields (Duffie and Liu, 2001; Longstaff et al., 2005; Ericsson and Renault, 2006). Yet, we still know relatively little about the fundamental factors driving CDS premia. While studies on the determinants of credit spreads question the explanatory power of observable covariates, Ericsson et al. (2009) show that equity volatility and firm leverage suffice to explain most of the variation in CDS premia over time and across firms. ${ }^{2}$ The theoretical basis for most of these hypothesized determinants is given in the structural model of Merton (1974). In his model, a firm's default probability (and consequently, the value of a corresponding CDS), are influenced by the firm's leverage, equity volatility and the level of the risk-free rate. Especially during times of financial crisis, however, CDS premia could additionally be driven by risk preferences of protection sellers. ${ }^{3}$. If investors were averse to downside risk (see, e.g. Roy, 1952; Kahneman and Tversky, 1979), CDS protection sellers should require a premium for bearing the risk of negative externalities spilling over from other financial institutions to the reference bank. ${ }^{4}$ Anecdotal evidence from the recent financial

\footnotetext{
${ }^{2}$ Using a discrete time no-arbitrage model with observable covariates, Doshi et al. (2013) show that four (observable) covariates extracted from the riskless term structure, the firm's distance-to-default computed using optionimplied volatility, and the VIX suffice to explain CDS spreads.

${ }^{3}$ As noted by Christie (1982) and Collin-Dufresne et al. (2001), however, market value leverage can also increase due to negative stock returns. There is thus a direct link between the pricing of CDS contracts via the model of Merton (1974) and extreme crash risk in equity prices

${ }^{4}$ Recent studies in the literature that incorporate (crash) risk averse investors into standard asset pricing models include, e.g., Shumway (1997); Ang et al. (2006); Ruenzi and Weigert (2013).
} 
crisis strongly supports this notion as banks experienced extreme comovements in their CDS premia following the collapse of Lehman Brothers. In this paper, after carefully controlling for the temporal variation in the tail dependence of CDS spreads, we test and confirm the hypothesis that CDS protection sellers are compensated for the risk of a joint crash in the CDS market.

We measure the aversion of investors to the risk of joint extreme comovements in default probabilities by estimating the upper tail dependence in the CDS spreads of individual banks with respect to a CDS sector index and refer to this as the bank's CDS tail beta. In essence, the upper tail dependence between two random variables measures the probability of both variables to experience comovements in their upper right tail. Traditionally, analyses of systematic risk in portfolio theory and asset pricing have used linear correlation to capture a security's sensitivity to comove with the market (Markowitz, 1959; Sharpe, 1964; Lintner, 1965). In a non-gaussian framework, however, linear correlations cannot fully describe the complete dependence structure in a joint return distribution. Consequently, a growing body of literature has employed methods from extreme value theory and copula theory to study non-linear dependence in asset returns (see, e.g., Longin and Solnik, 2001; Poon et al., 2004; Ruenzi and Weigert, 2013). In this paper, we build on these recent results from the literature and employ the Dynamic Asymmetric Copula (DAC) model of Christoffersen et al. (2012) to estimate the upper tail dependence between the returns on an individual bank's CDS spread and the returns on a CDS bank sector index. We then follow in the footsteps of Collin-Dufresne et al. (2001); Campbell and Taksler (2003); Cremers et al. (2008); Zhang et al. (2009) and Ericsson et al. (2009) and estimate panel regressions of CDS premia with bank fixed effects on known drivers of credit risk as well as on CDS tail beta.

We find that CDS tail beta is a significant determinant of the CDS premia of banks. Banks with higher CDS tail betas exhibit significantly higher CDS spreads. This effect is economically large as banks in the upper quintile of CDS tail betas have an average CDS spread that is 140 basis points higher than the average spread of banks in the lower quintile of CDS tail betas. In our regression analyses, we show that the risk premium protection sellers receive for bearing the risk of a surge in CDS spread returns complements the traditional determinants of CDS premia like, e.g., leverage 
and equity volatility. In our sub-sample analysis, we show that the correlation between banks' CDS premia and CDS tail betas that we find is limited to the crisis years of 2007 to 2010.

The correlation between a bank's CDS tail beta and its CDS premia, however, cannot simply be explained by the bank's systemic relevance for the financial sector. Acharya et al. (2010) show that a bank's Marginal Expected Shortfall (MES in short; the MES is defined as the conditional mean stock return of the bank when the market is plummeting) is a significant determinant of the CDS premia of financial institutions during the financial crisis. ${ }^{5}$ As a result, it could be argued that our CDS tail beta measure is simply another proxy for the systemic relevance of a respective bank for the financial sector. Conceptionally, our measure of CDS tail beta is broadly related to their MES measure yet both measures differ with respect to several key aspects. First, our CDS tail beta constitutes the probability of a joint surge of both the market's and the individual bank's CDS premia, thus measuring the respective right tail of the joint distribution, while MES is based on the left tail of the market's marginal return distribution. Second, the CDS tail beta measures the tail risk in the extreme tail of the joint distribution, while MES only measures systemic risk based on moderately bad days of the market (see Acharya et al., 2010). Consequently, we expect our CDS tail beta to measure the asymptotic probability of an extreme crash in the CDS market that is not captured by measures like, e.g., MES that are based on only moderately bad tail events.

We test this conjecture by including the MES measure of Acharya et al. (2010) estimated using various model specifications as a further explanatory variable in our regressions of CDS premia. The results indicate that the correlation between CDS tail beta and premia remains significant even when including MES in our regressions, irrespective of the model specification used for estimating MES. Our CDS tail beta measure thus complements rather than substitutes this measure of a bank's exposure to systemic risk in pricing models for CDS premia.

Our paper is related to several recent investigations into the pricing of equity and credit derivatives. Most notably, our investigation draws inspiration from the study of Ruenzi and Weigert

\footnotetext{
${ }^{5}$ There now exists a vast number of studies in the financial economics literature on the measurement of systemic risks. Further examples for such measures apart from those used in this study are due to De Jonghe (2010); Adrian and Brunnermeier (2011); Huang et al. (2011); Schwaab et al. (2011); Hautsch et al. (2012); Hovakimian et al. (2012) and White et al. (2012).
} 
(2013) who document a crash risk premium in equity prices. While their study is concerned with the correlation between lower tail dependence and equity prices, our analysis investigates the determinants of CDS premia. ${ }^{6}$ Moreover, in contrast to their work, we account for time variation in the dependence structure of individual and sector-wide CDS premia. Our work is also related to the studies by Ericsson et al. (2009) and Doshi et al. (2013), but we additionally consider a premium for crash risk in the CDS market as an additional explanatory factor in our empirical analysis of CDS premia. Nevertheless, our results do not refute but rather complement the findings by Ericsson et al. (2009). Although we show that CDS tail beta is an economically significant driver of CDS premia in times of financial crisis, the results of Ericsson et al. (2009) remain valid in our sample period before the Subprime crisis. Investors thus seem to demand a risk premium for CDS tail beta when it is needed the most: during a tail event. Finally, our paper is also related to the contemporaneous studies by Oh and Patton (2013) and Christoffersen et al. (2013). The former proposes a new class of copula-based dynamic models for high dimensional conditional distributions to estimate the joint probability of distress from bank CDS premia. Using dynamic copula models, the latter documents that the dependence in default intensities and CDS spreads is highly time-varying and persistent. Both studies, however, do not consider the determinants of CDS premia.

The rest of this paper is organized as follows. Section 2 describes the data and the econometric models we use for estimating CDS tail betas. In Section 3 , we present and discuss the results of our analysis on the determinants of CDS premia. Section 4 concludes.

\section{Modeling extreme CDS spread comovements}

The purpose of this section is to present the data and outline the econometric framework for modeling CDS spread returns as well as their dynamic multivariate dependence structure. We start with a description of the data and a brief study on the stylized facts of CDS spread returns to

\footnotetext{
${ }^{6}$ The link between a firm's stock returns and its credit risk is analyzed in detail by Friewald et al. (forthcoming). Their study, however, is not concerned with the determinants of CDS spreads per se.
} 
identify the correct model specifications.

\subsection{CDS data and stylized facts of CDS spread returns}

To investigate the economic importance of CDS tail beta for the European banking sector, we construct a sample of more than 54,000 daily CDS mid-quotes between January 2004 and September 2010. The data on CDS quotes are retrieved from Credit Market Analysis (CMA) via Thomson Reuters Financial Datastream. For all available major European banks, we also collect daily bid and ask quotes. The respective bid-ask spreads are then calculated as the difference between ask and bid quotes. To ensure accuracy and data consistency, we apply several filtering criteria to our data. The considered CDS series are exclusively written on single-name entities and are denoted in Euro. We further include only those contracts in our final sample that refer to senior debt issues and discard the class of subordinated debt. Additionally, we restrict our analysis solely to contracts exhibiting a five-year term structure, since these are the most frequently traded terms and therefore unlikely to be distorted from low levels of liquidity. Moreover, for a bank to be included in the our sample, we require the bank to be listed on a major stock exchange and have stock price data readily available in Datastream. ${ }^{7}$ Finally, on the individual bank level we exclude all time series with missing values after observing the first quote. Starting with a universe of all European bank names covered by $C M A$, we identify a remaining total of 35 banks matching the above mentioned filtering criteria. ${ }^{8}$ Note that the overall sample size is solely restricted by data availability of both CDS and stock market quotes. To estimate the CDS tail betas of the banks in our sample, we later employ a CDS spread return index that is constructed as the equally-weighted average of individual spread returns across all sample banks. For increased transparency, Appendix 凹provides an overview of the bank names as well as corresponding ticker symbols.

Table I reports summary statistics of daily CDS spreads. Whereas the mean sample spread

\footnotetext{
${ }^{7}$ Note that the subsequent empirical analysis requires CDS as well as stock market quotations. See Section 3 for details. (2013).

${ }^{8}$ A comprehensive overview of bank-specific CDS data available in CMA can also be found in Annaert et al.
} 
is at a comparatively modest level of $91.94 \mathrm{bps}$, the minimum and maximum premia range from $1 \mathrm{bp}$ (EBKOF) up to 1327.86 bps (BILMI), indicating fundamental changes in investors' risk perception during the sample period. In addition, an average standard deviation of more than 100 bps reflects a significant level of volatility in observed CDS spreads. Furthermore, an analysis of the CDS spreads' percentiles and skewness indicates that a great portion of daily spread quotations can be found in the lower tail of the distribution. We find average CDS spreads to be positively skewed suggesting that the pre-crisis period is characterized by lower credit spreads and hence, lower CDS-implied default risk. This is confirmed by the evolution of average spreads over time depicted in Panel (a) of Figure 1, As can be seen from Figure 1, daily CDS spreads remain on low levels between January 2004 until mid-2007. With the commencement of the sub-prime crisis however, a fundamental re-valuation of credit risk took place resulting in highly elevated CDS levels after mid-2007. Additionally, we report the evolution of daily minimum and maximum spread quotations illustrated by the shaded gray area. We find the cross-sectional variation to be rather low in the pre-crisis period but find a substantial widening after mid-2007, suggesting not only a system-wide increase of CDS-implied default risk but also an asymmetric assessment of banks' credit risk during the crisis.

Table 1 presents descriptive statistics on CDS spread log returns. The log returns range from $-77.67 \%$ to $106.63 \%$ on average, reflecting both substantial upward and downward movements in CDS spreads. As we can see from the results on the moments, the log returns are characterized by a negligible mean $(0.15 \%$ on average $)$ and a significant standard deviation ranging from $4.51 \%$ (UNBLF) to $51.25 \%$ (EBKOF). Additionally, the log returns are positively skewed (2.75 on average) and exhibit tail risk, as indicated by a pronounced excess kurtosis. The first-order autocorrelations are negative for most sample banks and $-8.02 \%$ on average. The time evolution of CDS spread log returns is illustrated in Panel (b) of Figure 1. The plot shows that in the beginning of the sample period the average log returns vary between $-10 \%$ and $15 \%$, whereas the shaded area between maximum and minimum observations stays relatively tight around the average returns. As of 2006 (observation 530), the magnitude and volatility of average returns increase and the shaded 
area raises gradually indicating growing cross-sectional variation in CDS spread returns. After the onset of the financial crisis, the shaded area tightens sharply around the average returns in October 2007, whereas the magnitude and volatility of the average returns remain in approximately the same range.

Complementing the analysis of CDS spreads, we also shortly comment on some descriptive statistics of the banks' equity (log) returns presented in Table IA.I $^{9}$ Not surprisingly, returns vary across a wide range of values and, according to the results on percentiles and moments, the stocks possess the usual stylized characteristics of negligible mean log returns $(-0.04 \%$ on average $)$ and non-normally distributed returns with a slight skewness of, on average, -0.43 . The evolution of daily log returns over time is shown in Panel (c) of Figure 1. Underlining our previous findings, the graph exhibits a pattern that is commonly associated with equity return series.

The panels of Figure 2 compare the time evolution of spreads to that of CDS spread log returns and equity returns. The plot given in Panel (a) of Figure 2 does not show any evidence of an increase in the volatility of CDS spreads during the crisis at first glance. However, spread return volatility was extremely high before the crisis with spreads remaining on a very low level. When excluding the pre-crisis period, key events of the financial crisis (like, e.g., the collapse of Lehman Brothers) coincided with significant spikes in CDS spreads and increased spread return volatility. The plot given in Panel (b) further underlines the finding that the average CDS spread and equity return volatility of banks comoved during the financial crisis with both series increasing steeply between 2007 and 2009. CDS spreads decreased after 2009 but started to increase again with the onset of the sovereign debt crisis.

Due to modeling purposes, we will use daily CDS spread log returns to estimate our models and to calculate joint extreme crash risk. Since the time series properties of CDS spread returns are a rather unexplored field in the econometric literature, we will conduct a brief study on the stylized facts of CDS spread $(\log )$ returns in the following. ${ }^{10}$

\footnotetext{
${ }^{9}$ To preserve space, the summary statistics for the equity returns are shown in Table IA.Iin the Internet Appendix to this study.

10 Cont and Kan (2011) undertake a similar study on CDS spread returns for a different set of CDS spreads.
} 
The results of the time series analysis of the CDS spread returns are reported in Table III] In a first step, we check for stationarity of the log returns. To this purpose, we employ the augmented Dickey-Fuller (ADF) test using the general regression equation with a constant and a linear time trend. ${ }^{11}$ The corresponding $p$-values in column 3 of Table $\amalg$ show that the null of a unit root is rejected and all log return series are stationary. Unreported results on additionally conducted PP and KPSS tests support these findings. In the next step, we check for linear serial dependence and employ the Ljung-Box (LB) test with the number of lags equal to 20. The LB test is not rejected for $40 \%(31 \%, 23 \%)$ of the sample banks at the $1 \%(5 \%, 10 \%)$ significance level (see column 5 of Table III). Hence, most log return series are characterized by significant linear serial dependence. Moreover, we perform Engle's (1982) lagrange multiplier (LM) test to check for ARCH effects. To control for linear serial dependence, we firstly estimate an AR model for each return series. ${ }^{12}$ Then, we regress the squared AR residuals on their own history and test the null that all coefficients are equal to zero (no ARCH effects). ${ }^{13}$ The $p$-values in column 7 of Table $\amalg$ show that most return series exhibit ARCH effects: the null of no ARCH effects is rejected for $60 \%$ (66\%) of the sample banks at the $1 \%(5 \%, 10 \%)$ significance level.

Further, we examine the unconditional distribution of CDS spread log returns and check for non-normality and heavy tails. Results on Jarque-Bera (JB) tests are listed in columns 8 and 9 of Table III and show that the null of normally distributed returns is rejected in all cases. Unreported results on Kolmogorov-Smirnov and Shapiro-Wilk tests confirm this finding. To check for heavy tails, we compute tail indices and study quantile plots. We use the well-investigated Hill estimator for the computation of lower and upper tail indices (see Hill, 1975, for details), and present the estimates in columns 10 and 11 of Table $\coprod^{14}$ The tail indices vary considerably across the sample banks, where the mean upper and lower tail indices are respectively given by 2.3 and 3.0, indicating

\footnotetext{
${ }^{11}$ The number of lags included in the regression of the test is chosen to be the upper bound on the rate at which the number of lags grows with the sample size (see Said and Dickey, 1984, for details).

${ }^{12}$ The order of the AR model is chosen such that the null of the $\mathrm{LB}(20)$ test cannot be rejected at the $10 \%$ significance level.

${ }^{13}$ More precisely, we use five lagged values of the squared residuals.

${ }^{14}$ When applying the Hill estimator, one difficulty is given by the appropriate choice of the threshold $k$. Here, we follow Guillou and Hall (2001) and apply their diagnostic procedure with parameters $p=1$ and $c_{\text {crit }}=1.25$ to compute $k$.
} 
that the unconditional distribution of the spread returns is heavy-tailed with heavier left tails on average. An analysis of unreported quantile plots confirms these findings.

As stated by Bera and Higgins (1993) as well as by Bollerslev et al. (1994), fat tailedness in unconditional distributions might be caused by ARCH effects. To check for fat tailedness in the conditional distributions, we compute tail indices for the AR-GARCH residuals of the return series. The unreported results show that, after accounting for ARCH effects, the tail indices remain in the same range and fluctuate around approximately the same means. Hence, the average sample bank exhibits a heavy-tailed conditional spread return distribution with heavier left tails.

Finally, we check for asymmetries in conditional volatility and jointly conduct the Sign Bias Test, the Negative Size Bias Test as well as the Positive Size Bias Test as proposed by Engle and Ng (1993). More precisely, we test the null that the squared AR-GARCH residuals of the return series cannot be predicted by the sign and the magnitude of return shocks. As can be seen from column 13 of Table III, the $p$-values of the test are quite large for all series, indicating that there is no predictive power in the return shocks with regard to the squared AR-GARCH residuals. Hence, we find no evidence of asymmetric conditional volatility in any of the return series.

\subsection{Univariate modeling of CDS spread returns}

We now discuss the marginal models for the CDS spread log returns. According to the previous section, the return series are stationary, autocorrelated and conditionally heteroskedastic. We therefore use an $\operatorname{AR}(m)-\operatorname{GARCH}(p, q)$ model to account for these time series properties, where $m, p, q \in \mathbb{N}$ denote the number of lags considered in the AR and GARCH equations. To additionally account for skewness and fat tails in the conditional distribution, we assume the conditional distributions of the return innovations to follow the skewed $t$ distribution of Hansen (1994). In formal terms, our univariate model approach can be described as follows: with $C D S_{i, t}$ denoting the CDS spread of bank $i$ at time $t(i=1, \ldots, N, t=1, \ldots, T)$, the CDS spread log returns are given 
by

$$
R_{i, t}=\log \left(C D S_{i, t}\right)-\log \left(C D S_{i, t-1}\right)
$$

As mentioned above, the CDS spread index, $C D S_{m, t}$, is calculated as an equally-weighted average of individual spread returns across all sample banks. Hence, the return on the spread index at time $t, R_{m, t}$, is given by

$$
R_{m, t}=\log \left(C D S_{m, t}\right)-\log \left(C D S_{m, t-1}\right), \quad C D S_{m, t}=\frac{1}{N} \sum_{i=1}^{N} C D S_{i, t}
$$

Further, let $\tilde{t}_{\nu, \lambda}$ denote Hansen's (1994) skewed $t$ distribution with $\nu$ degrees of freedom and skewness parameter $\lambda$, and let $\mathcal{F}_{i, t}$ be the information available on the spread return series of bank $i$ up to and including time $t$. Assuming an $\operatorname{AR}(m)-\operatorname{GARCH}(p, q)$ model, the CDS spread log return of bank $i$ at time $t$ follows the dynamic

$$
\begin{aligned}
R_{i, t} & =\mu_{i, t}+\varepsilon_{i, t}=\mu_{i, t}+\sqrt{h_{i, t}} z_{i, t}, \quad z_{i, t} \mid \mathcal{F}_{i, t-1} \sim \tilde{t}_{\nu_{i}, \lambda_{i}} \\
\mu_{i, t} & =\phi_{0, i}+\sum_{j=1}^{m} \phi_{j, i} R_{i, t-j}, \\
h_{i, t} & =\omega_{i}+\sum_{k=1}^{p} \alpha_{k, i} \varepsilon_{i, t-k}^{2}+\sum_{l=1}^{q} \beta_{l, i} h_{i, t-l},
\end{aligned}
$$

where the parameters in the conditional mean and variance equation are restricted to be positive, $2<\nu_{i}<\infty$ and $-1<\lambda_{i}<1$ for all $i=1, \ldots, N^{15}$

Estimation is conducted in two steps: first, we estimate the AR component using conditional least squares and then estimate the GARCH model on the basis of the AR residuals straightforwardly

\footnotetext{
${ }^{15}$ Note that the distribution of return shocks differs across banks, but is constant over time, whereas the return distributions have time varying conditional means and variances.
} 
by maximum likelihood. The log likelihood of the GARCH component for bank $i$ is given by

$$
\log \mathcal{L}\left(\epsilon_{i} ; \theta_{i}\right)=\sum_{t=1}^{T}\left[\log \left(b_{i} c_{i}\right)-\frac{1}{2} \log \left(h_{i}\right)-\frac{\nu_{i}+1}{2} \log \left(1+\frac{1}{\nu_{i}-2}\left(\frac{b_{i} \epsilon_{i, t} h_{i}^{-\frac{1}{2}}+a_{i}}{1+\operatorname{sgn}\left(d_{i}\right) \lambda_{i}}\right)^{2}\right)\right]
$$

where $\epsilon_{i}:=\left(\hat{\varepsilon}_{i, 1}, \ldots, \hat{\varepsilon}_{i, T}\right)^{\top}$ denotes the vector of AR residuals, $\theta_{i}$ is the $(4+m+p+q) \times 1$ vector containing the model parameters (for bank $i$ ), and

$$
a_{i}=4 \lambda_{i} c_{i} \frac{\nu_{i}-2}{\nu_{i}-1}, \quad b_{i}=\sqrt{1+3 \lambda_{i}^{2}-a_{i}^{2}}, \quad c_{i}=\frac{\Gamma\left(\frac{\nu_{i}+1}{2}\right)}{\sqrt{\pi\left(\nu_{i}-2\right)} \Gamma\left(\frac{\nu_{i}}{2}\right)}, \quad d_{i}=\frac{\epsilon_{i, t}}{\sqrt{h_{i}}}+\frac{a_{i}}{b_{i}}
$$

\subsection{Joint modeling of CDS spread returns with the DAC model}

We now turn to the task of modeling the joint distribution of CDS spread (log) returns and the $(\log )$ returns on the CDS spread index. Since we are especially interested in joint extreme movements in individual spreads and the spread index as a potential determinant of individual spreads, we rely on a copula model that allows for tail dependence. Naturally, the multivariate dependence structure changes through time and might be characterized by strong asymmetries in the sense of asymmetric threshold correlations. ${ }^{16}$ To flexibly model the dependence between spreads and our spread index and account for underlying time dynamics as well as multivariate asymmetries, we follow in the footsteps of Christoffersen et al. (2012) by applying their so-called Dynamic Asymmetric Copula (DAC) model to the AR-GARCH filtered spread and index returns.

The DAC model is based on the skewed $t$ copula discussed in Demarta and McNeil (2004), which is parameterized by the correlation matrix of the copula shocks, an asymmetry parameter and a degree of freedom parameter. The correlation matrix of the copula shocks is then modeled by means of a modified version of Engle's (2002) DCC model, which augments the DCC model by a time-varying matrix capturing time trends and other explanatory variables. In this way, the DAC

\footnotetext{
${ }^{16}$ In a recent study, Christoffersen et al. (2013) show that the dependence in CDS spreads is highly time-varying, persistent, and increased significantly in the financial crisis. Multivariate asymmetries in CDS spreads appear to be less important than asymmetries in equity returns but should nevertheless be accounted for in econometric models of spreads.
} 
model accounts for tail dependence, asymmetries and time dynamics in multivariate distributions.

The model takes the following form: let $R_{i, t}$ and $R_{m, t}$ be the CDS spread log return of bank $i$ and the spread index at time $t$, respectively, and let $\hat{z}_{i, t}$ and $\hat{z}_{m, t}$ denote the AR-GARCH residuals, with $u_{i, t}:=F_{i, t}\left(\hat{z}_{i, t}\right)$ and $u_{m, t}:=F_{m, t}\left(\hat{z}_{m, t}\right)$ being the corresponding ranks. Then, the skewed $t$ copula, $C_{t}$, is defined by

$$
C_{t}\left(u_{1, t}, \ldots, u_{N, t} ; P_{t}, \gamma, \eta\right)=t_{P_{t}, \gamma, \eta}\left(t_{\gamma, \eta}^{-1}\left(u_{1, t}\right), \ldots, t_{\gamma, \eta}^{-1}\left(u_{N, t}\right)\right)
$$

where $\gamma$ and $\eta$ denote the asymmetry and degrees of freedom parameters, respectively, and $t_{P_{t}, \gamma, \eta}$ and $t_{\gamma, \eta}^{-1}$ are the multivariate cdf and the univariate inverse cdf of the skewed $t$ distribution discussed in Demarta and McNeil (2004) $){ }^{17} P_{t}$ is the correlation matrix containing the correlations between the copula shocks $z_{i, t}^{c}:=t_{\gamma, \eta}^{-1}\left(u_{i, t}\right)$, and follows the dynamic

$$
P_{t}=\left(1-\psi_{1}-\psi_{2}\right)\left[(1-\kappa) Q+\kappa D_{t}\right]+\psi_{2} P_{t-1}+\psi_{1} \tilde{z}_{t-1}^{c} \tilde{z}_{t-1}^{c \top}
$$

where $\psi_{1}, \psi_{2}$ and $\kappa$ are non-negative parameters, and $\tilde{z}_{t}^{c}:=\left(\tilde{z}_{1, t}^{c}, \ldots, \tilde{z}_{N, t}^{c}\right)^{\top}$ with $\tilde{z}_{i, t}^{c}$ given by $z_{i, t}^{c} \sqrt{P_{i i, t}}$ (see Aielli, 2009, for details). Further, $Q$ is a constant copula correlation matrix calculated as

$$
Q=\frac{T^{-1} \sum_{t=1}^{T} \tilde{z}_{t}^{c} \tilde{z}_{t}^{c \top}-\kappa T^{-1} \sum_{t=1}^{T} D_{t}}{1-\kappa}
$$

and $D_{t}$ is a time trend correlation matrix with trend parameter $\delta$, where the off-diagonal elements are equal to

$$
\frac{\delta^{2} t^{2}}{1+\delta^{2} t^{2}}, \quad t=1, \ldots, T
$$

We refer to Christoffersen et al. (2012) for details on the matrices $Q$ and $D_{t}$. Note, however, that

\footnotetext{
${ }^{17}$ See Demarta and McNeil (2004) for details on the skewed $t$ distribution and the skewed $t$ copula. Note, however, that Hansen's (1994) skewed $t$ distribution (used for the marginals) is different from that discussed in Demarta and McNeil (2004) (used for the joint distribution).
} 
setting $\kappa=0$ yields Engle's (2002) DCC model as applied to copula correlations.

Finally, to ensure that $P_{t}$ remains in the -1 to 1 interval, we normalize $P_{t}$ and use the matrix $\tilde{P}_{t}$ that is defined by

$$
\tilde{P}_{i j, t}=\frac{P_{i j, t}}{\sqrt{P_{i i, t} P_{j j, t}}}, \quad i, j=1, \ldots, N .
$$

The DAC model is estimated straightforwardly by maximum likelihood in our bivariate case. Details of the DAC model can be found in Christoffersen et al. (2012).

\subsection{Estimation results}

We first summarize the estimation results for the univariate $\operatorname{AR}(m)-\operatorname{GARCH}(p, q)$ models. We individually choose the AR lag $m$ for each spread return series such that the LB(20) test cannot be rejected at the $10 \%$ significance level. According to (unreported) preliminary tests, setting the GARCH lags $p$ and $q$ to 1 is sufficient to adequately account for ARCH effects in the AR residuals. The estimation results for the AR-GARCH models are reported in columns 2 to 6 of Table IV ${ }^{18}$ The parameters governing the conditional volatility are given by $\omega, \alpha$ and $\beta$. The $\omega$ parameter is close to zero (0.0002 for the average sample bank) and not listed in the table. The $\alpha$ parameter quantifies the effect of lagged return shocks on current volatility and varies from 0.1377 (EFG) to 0.6600 (MDIBF) (0.3142 on average). Interestingly, volatility in CDS spread returns seems to be affected to a greater extent by news arrival than volatility in stock price returns. ${ }^{19}$ The autoregressive variance parameter, $\beta$, is however dominating in most cases and varies from 0.3286 (MDIBF) to 0.8623 (EFG) (0.6751 for the average sample bank). As indicated by the fourth column, volatility is highly persistent for all spread return series. The parameter estimates for the conditional distribution of the return innovations show that the skewed $t$ GARCH model fully accounts for the evidenced fat tailedness (as indicated by the degrees of freedom parameter being equal to 5.36 on

\footnotetext{
${ }^{18}$ Note that the results on the AR processes are fairly standard and, therefore, have been omitted to preserve space.

${ }^{19}$ Typically, $\alpha$ is between 0.01 and 0.2 for stock price returns (see, e.g., Christoffersen et al., 2012; Engle, 2002; Kang et al., 2010).
} 
average) and picks up much of the skewness found in Table

The (unreported) results on the $\mathrm{LB}(20)$ tests confirm the good fit of the marginal models and indicate that there is no autocorrelation left in the AR-GARCH residuals (with the $p$-value being equal to 0.5816 on average). Further, we conduct $\operatorname{LB}(20)$ tests on the absolute residuals as well as Engle's (1982) ARCH LM test to evaluate the performance of the GARCH component. The average $p$-values of the two tests are 0.6451 as well as 0.8951 , respectively, indicating that the AR-GARCH models pick up the persistence in absolute spread returns and adequately account for ARCH effects. Hence, the marginal models generate white-noise residuals so that the theoretical requirements for the application of the DAC model are met.

The parameter estimates for the DAC model are reported in columns 7 to 12 of Table IV The first four columns of the DAC estimates refer to the parameters characterizing the conditional correlation dynamics of the copula shocks. The conditional correlation matrix mean-reverts at time $t$ to a slowly varying component, $(1-\kappa) Q+\kappa D_{t}$, which is a weighted average of the constant matrix $Q$ (containing average copula correlations) and the time-varying matrix $D_{t}$ (accommodating for time trends in copula correlations). The $\psi_{2}$ and $\psi_{1}$ parameters capture the impact of lagged copula correlations as well as the cross-product of lagged copula shocks on current copula correlations, respectively, where $\psi_{1}+\psi_{2}$ yields the persistence in dependence and $1-\psi_{1}-\psi_{2}$ governs the speed of mean-reversion. As we can see from the estimates, the autoregressive parameter, $\psi_{2}$, ranges from 0.7587 (IKB) to 0.9887 (UNBLF) and is 0.9399 on average, dominating the $\psi_{1}$ parameter for all banks in the sample. As indicated by the third column of the DAC estimates, the persistence in the dependence structure is high in all models, implying slow mean-reversion in copula correlations. The next column refers to the long-run copula correlations and reports the parameter estimates characterizing the matrix $D_{t}$. To identify the portion of the increase in long-run correlations that is due to the time trend component, we follow Christoffersen et al. (2012) and report $\kappa D_{12, T}{ }^{20}$ The increases are positive for all banks in the sample and are 0.3281 on average, indicating that our sample period is characterized by a strong upward trend in copula correlations. This is con-

\footnotetext{
${ }^{20}$ Note that the increase due to the time trend component can be calculated as $\left.\kappa D_{12, t}\right|_{t=T}-\left.\kappa D_{12, t}\right|_{t=0}=$ $\kappa D_{12, T}=\kappa \delta^{2} T^{2} /\left(1+\delta^{2} T^{2}\right)$, see Christoffersen et al. (2012).
} 
firmed by Panels (a) and (b) of Figure 3. Panel (a) plots average daily dynamic copula correlations (solid line) along with the range between the smoothed series of minimum and maximum correlations (shaded area) as well as the average constant correlations (dashed line). As we can see from the panels, the dynamic correlations are close to the constant correlations in the beginning of the sample and have been on a slight downward trend as of mid-2005, falling below the constant correlations prior to the financial crisis. With the onset of the financial crisis in 2007, however, the copula correlations have been trending upwards, increasing considerably from $20 \%$ in 2007 to $60 \%$ in 2010 . Hence, the average dynamic correlations are below the constant correlations in the pre-crisis period, and are higher in the end of our sample period, reflecting the importance of considering the evolution and time trends of the general dependence level in the DAC framework. A more detailed analysis of the dynamic copula correlations per country is presented in the Internet Appendix. The light-gray lines and bars in the panels of Figure IA.1 show the country-wise average daily and cumulative quarterly dynamic copula correlations, respectively, and illustrate the cross-sectional differences in the time evolution of correlations. Except for the panels of Austria and Greece, the country-wise panels confirm the above findings and only show slight differences in the magnitude of the correlations and the evolution of the trend across the countries included in our sample.

In our empirical study, we investigate whether the propensity of an individual bank to jointly crash with the banking sector is priced in the bank's CDS premia. To this purpose, we introduce the upper tail dependence between individual spread returns and returns on the spread index as a potential determinant of individual spreads and call this determinant CDS tail beta. In our DAC model framework, bank's $i$ CDS tail beta at time $t$ can be measured via the probability limit

$$
\text { TailBeta }_{i, t}:=\lim _{\xi \rightarrow 1} \mathbb{P}\left(u_{i, t} \geq \xi \mid u_{m, t} \geq \xi\right)=\lim _{\xi \rightarrow 1} \frac{1-2 \xi+C_{t}\left(\xi, \xi ; P_{t}, \gamma, \eta\right)}{1-\xi}
$$

Panels (c) and (d) of Figure 3 show the time evolution of the average daily and quarterly tail betas for our sample period, respectively, where the average is taken across the individual tail betas of 
the 35 sample banks. As we can see from the panels, the time evolution and trend patterns of tail betas are similar to those of copula correlations. Since the beginning of the sample in 2004, tail betas have been on a slight downward trend, reaching its minimum of 5\% in mid-2007. With the onset of the financial crisis, the downward trend abruptly turns into a strong upward trend, and tail betas increase dramatically up to $25 \%$. As can be seen from the quarterly tail betas in Panel (d), the downward trend comes to a halt in the second quarter of 2007. Further, much of the following sharp upward trend is captured in the last two quarters in 2007 and the first three quarters in 2008. In the sequel, the trend corrects and returns to its 2008 levels in the second quarter of 2010. As for copula correlations, we plot the time evolution of country-wise average daily as well as cumulative quarterly tail betas to identify cross-country differences in magnitudes and time trends of tail betas. The results are shown by the dark-gray lines and bars in Figure IA.1 and lead to the same conclusions as the results for country-wise copula correlations.

\section{Empirical analysis}

We aim to answer the question to what extent, if any, tail risk is a priced factor in bank-specific CDS contracts. This section briefly outlines the empirical model and presents our main results. Robustness checks are given at the end of this section.

\subsection{Main dependent and independent variables}

We begin our analysis by briefly reviewing the theoretical determinants of default risk and CDS spreads that are frequently stated in the literature. All variable definitions and data sources are provided in Appendix $\amalg$

In the seminal framework of Merton (1974), a firm's default probability is determined by the firm's leverage (or its value), its asset volatility and the risk-free rate. An increase in the firm's leverage (and conversely, a decrease in firm value) is associated with higher default risk and thus higher CDS spreads. Due to limited balance sheet data, the leverage ratio cannot be 
measured directly. Moreover, especially off-balance sheet items may not be captured by conventional balance sheet-based proxies of leverage. For this reason, we follow Christie (1982) and Collin-Dufresne et al. (2001) and proxy a bank's change in firm value by using quarterly arithmetic stock returns. Data on daily equity prices are obtained from Datastream for all 35 banks in our sample and we expect our variable Firm value to be negatively correlated with CDS spreads.

Next, we turn to the expected causal relation between asset volatility and CDS spreads. In theory, higher levels of asset volatility should be associated with higher default probabilities. As a consequence, we expect asset volatility and CDS spreads to be positively correlated. In line with Alexander and Kaeck (2008), we use the variable Volatility defined as end-of-quarter values of the VSTOXX implied volatility index to proxy for unobservable asset volatility. ${ }^{21}$ The VSTOXX index is inferred from EURO STOXX 50 realtime option prices and mirrors expectations of market participants with respect to future levels of volatility.

Turning to the risk-free rate, increases in the risk-free rate should theoretically lead to lower CDS spreads, since the asset value process recedes from the default barrier. We employ a shortterm 1-year Euro swap rate as our variable Risk-free interest rate as, e.g., Longstaff et al. (2005) argue that swap rates represent adequate marked-based estimates of the risk-free rate. Nevertheless, we are aware of the fact that short-term interest rates may also reflect the stance of monetary policy and may therefore affect bank business models. Accordingly, we expect the sign of the coefficient on the risk-free rate to be unrestricted. Both the VSTOXX volatility index and short-term swap rates are retrieved from Datastream.

Complementing the factors proposed in Merton's model, several further factors have been suggested in the recent literature as potential drivers of default risk and CDS spreads. First, the theoretical and empirical results of Bongaerts et al. (2011) predict and confirm that CDS spreads contain a premium for the contract's marketability. Similar to the results of Campbell and Taksler (2003) and Longstaff et al. (2005) for credit spreads, CDS spreads should thus in part be driven by their illiquidity (see also Annaert et al., 2013). To measure liquidity, we collect end-of-quarter bid-ask

\footnotetext{
${ }^{21}$ Benkert (2004) provides evidence in favor of option-implied volatilities over historic volatility measures as option-implied volatilities explain a greater amount of variation in CDS spreads than there empirical counterparts.
} 
quotes (in basis points) from Datastream and expect our variable Liquidity defined as the bid-ask spread of a bank's CDS to be positively correlated with CDS spreads.

Additionally, CDS spreads could also be driven by the business climate of the bank's home country. There is ample evidence in the empirical literature (see, e.g., Longstaff et al., 2005; Zhang et al.,2009) that credit risk premia are sensitive to changes in the business climate in which a firm operates. We thus include end-of-quarter values of the S\&P 500 index as our variable Business climate in our regressions to account for general stock market momentum. Positive index changes are associated with declining default probabilities and increasing recovery rates, and should therefore be negatively correlated with CDS spreads. Another factor that could affect the pricing of credit protection is the overall stance of the economy as proxied by the growth of the economy. In the context of our analysis, GDP growth is a relevant control variable because recent studies like, e.g., the one by the Committee on the Global Financial System (CGFS) (2011) suggest that banks are particularly exposed to their home sovereign as well as to domestic credit markets. At the country level, GDP growth is likely to be accompanied with increasing borrowers' solvency and a lower overall risk exposure of financial institutions to their domestic market. Consequently, we associate increasing growth rates with declining bank-specific default risk premia. Data on quarterly GDP growth rates are obtained from the OECD.

Finally, we also employ the slope of the yield curve as a further explanatory variable in our regression analyses. Here, we use the yield curve slope as an indicator for the country-wide future economic activity of a bank's home country. Our variable Slope is defined as a country's respective 10-year minus 2-year government bond benchmark yields. Data on government bond yields are taken from Datastream. In theory, spot rates converge to their long-term counterparts, thereby increasing the risk-neutral drift of the asset value process making default less likely to occur (see Longstaff et al., 2005). Nevertheless, also monetary policy measures may be reflected in the slope coefficient. Hence, we expect the direction of the effect of the yield curve slope on CDS spreads to be unrestricted.

Table $V$ reports sample summary statistics. Mean CDS spreads and CDS spread returns across 
our full sample are 93.89 bps and -1\%, respectively. Estimates for the banks' CDS tail betas vary between zero and 0.55 with the mean CDS tail beta being 0.14. Log returns on the banks' stocks in our sample exhibit the usual stylized facts. Similar to CDS tail beta, equity tail betas also vary considerably around the mean of 0.33 with a minimum value of zero and a maximum of 0.96 . Our proxy for the change in a bank's firm value is zero on average with values ranging from -79\% to 230\%. Liquidity of CDS contracts also varies considerably with the mean spread between CDS bid and ask quotes being $9.56 \mathrm{bps}$. Finally, the estimates for the four variants of MES as our proxy for a bank's systemic relevance show that the banks in our sample are rather heterogeneous with respect to their exposure to system-wide tail events. The 5th percentile of the MES estimates is at a low $1 \%$ (0\% for the static MES), yet higher percentiles range up to 5\% and $14 \%$. Our sample of European banks thus seems to include both systemically irrelevant institutions as well as banks with a high exposure to systemic crashes.

Table IA.II in the Internet Appendix divides our sample of banks into the top and bottom quartiles of CDS spreads. The difference in the mean CDS spread between the two groups is by construction extremely large. Banks in the top CDS spread quartile had a mean spread of 271.76 bps while in contrast, banks in the lower quartile had an average CDS spread of only 10.41 bps. The difference in mean CDS spread returns is not significant between the two groups. However, a simple comparison of mean CDS tail betas in the top and bottom spread quartiles hints at a systematic positive correlation between CDS spreads and CDS tail betas. Banks in the upper CDS spread quartile possess a mean CDS tail beta that is more than twice as high $(0.18)$ than in the lower quartile (0.07). ${ }^{22}$

\footnotetext{
${ }^{22}$ Further evidence for the explanatory power of CDS tail betas is presented in Figure IA.2 in the Internet Appendix in which we show scatter plots of banks' CDS spreads against the bank stocks' CDS tail betas, CDS bid-ask spreads, and changes in firm value, respectively. The linear trend lines in these simple scatter plots underline our conjecture that CDS tail beta, along with the determinants from Merton's model, could be an economically significant driver of default risk.
} 


\subsection{Regression results}

To analyze the suspected correlation between CDS spreads and CDS tail betas in more detail, and to account for correlations between our explanatory variables, we next turn to univariate and multiple regressions of CDS spreads.

\subsubsection{Univariate regressions}

We begin our regression analysis by first examining the isolated explanatory power of the main independent and control variables excluding our new CDS tail beta factor. Panel A of Table VI reports the estimated coefficients of these univariate models. All variables are implemented in levels and the univariate regression results are obtained via pooled ordinary least squares (OLS) estimations. The results from these univariate regressions are for the most part in line with our expectations. Most strikingly, however, the coefficient on the risk-free interest rate is negative and large in magnitude. While the correlation between short term interest rates and CDS spreads could possibly be driven by two forces working in the opposite direction, the results in column 2 suggest that interest rates are more likely to reflect a tightened monetary policy stance than an increase in the risk-neutral drift rate. Considering that our sample comprises banks only, the comparably large coefficients on the risk-free interest rate and the yield curve slope may indeed reflect the high sensitivity of banks to measures of monetary policy. Similar evidence emerges from looking at Panel B of Table VI where the univariate models are estimated in first differences. Among others,

Collin-Dufresne et al. (2001) and Ericsson et al. (2009) point out that the dependent variable and some regressors may be integrated. Except for the coefficient on Slope, all results from the firstdifference regressions remain statistically and economically significant and are also consistent with the results obtained from the regressions in levels.

\subsubsection{Is tail risk priced in CDS contracts?}

We now turn to a panel regression analysis of all 35 bank names and utilize both the crosssectional and the time series characteristics of our data set to analyze the correlation between CDS 
spreads and tail risk. Table VII reports the results from our baseline bank fixed effect regressions. ${ }^{23}$ The results presented in column 1 verify that, consistent with our expectations, firm value and changes in implied volatility are significant drivers of CDS levels and enter the regression significant at the $1 \%$ level, respectively. The effect of an increase in the interest rate is significant and negative. In the second specification, we investigate the isolated effect of our variable of interest, CDS tail beta, on CDS spreads. In column 2 we present evidence that CDS tail beta is indeed a priced factor in CDS contracts. Sellers of credit protection are concerned about bank names that are more likely to fail, given an extreme market-wide increase in default probabilities. The estimated coefficient is both economically and statistically highly significant. In the univariate case, a one standard deviation higher CDS tail beta is associated with an increase in CDS spread levels by almost 71 bps $(5.904 \times 0.12)$.

These results are confirmed by univariate sorts based on CDS tail beta. For each bank in the sample, we first rank the time series of CDS spread observations into quintiles with respect to CDS tail beta, and then compute the average CDS spread for each tail beta quintile. Table IA.III in the Internet Appendix reports the results and shows that, for most banks, CDS spreads are monotonically increasing in CDS tail beta. The last column contains the difference between high and low tail beta quintile spreads and shows that spreads in high tail beta quintiles are, for the most part, considerably higher than spreads in low tail beta quintiles. The average difference is equal to 140.05 bps and significantly different from zero at the $1 \%$ level.

In column 3 of Table VII, we turn to our baseline model. When additionally controlling for the variables motivated by Merton's model (column 1), we obtain similarly convincing results. Although the coefficient on CDS tail beta decreases slightly, the correlation between tail risk and CDS spreads is still economically and statistically highly significant. Now, a one standard deviation higher CDS tail beta accounts for a 48 bps $(4.030 \times 0.12)$ increase in spread levels. Compared to column 1 , the adjusted $\mathrm{R}^{2}$ increases by more than 6 percentage points after controlling for CDS tail beta.

\footnotetext{
${ }^{23}$ Note that the Hausman test favors fixed over random effects.
} 
To eliminate as many confounding factors as possible, the specifications (4) to (7) include several controls suggested in the previous section. In column 4, we test the robustness of the found correlation between CDS tail beta and CDS spreads to the additional inclusions of changes in the CDS contract's liquidity. Our variable Liquidity enters regression (4) positively and significantly at the $5 \%$ level with the coefficient on $C D S$ tail beta remaining economically and statistically significant.

Further controlling for the business climate, the GDP growth rate, and the yield curve slope, however, we find that all three variables enter the respective regressions with negative coefficients. More precisely, accounting for changes in the general business climate increases the adjusted $\mathrm{R}^{2}$, although with the inclusion of business climate, the coefficients on the changes in firm value and asset volatility are statistically insignificant. Given the reduction in the significance of both variables Firm value and Volatility, a potential concern here might be that the results are driven by a certain degree of multicollinearity, i.e., high correlations between our proxy for business climate and other explanatory variables. To address this concern, we compute variance inflation factors (VIF) for all explanatory variables included in the regression. Given that the highest factor value is 2.89 for Business climate, we believe that multicollinearity is not a serious concern throughout our regression models. Column 6 shows that the coefficient on GDP growth is significant at the $1 \%$ level and large in magnitude. Controlling for the growth rate of the GDP increases the adjusted $\mathrm{R}^{2}$ up to $37 \%$. Although the coefficient on CDS tail beta is slightly smaller (2.922) in magnitude compared to the baseline model in column 3 (4.030), the correlation between tail risk and CDS spreads remains highly significant. Finally, in the last column of Table VII, we report estimates on all the included control variables and consider this specification to be our benchmark model. The coefficient on the slope of the yield curve is negative but insignificant. Significance is also reduced with respect to the control for the general business climate and all variables from Merton's model are significant at least at the $10 \%$ level. Most importantly, however, CDS tail beta is both statistically and economically highly significant in this regression specification using the full set of control variables. Overall, the regression results provide strong support for the hypothesis that 
CDS investors are indeed crash averse and hence, demand a risk premium-type markup for bank names with a large exposure to the market during extreme events.

\subsubsection{Is the pricing of tail risk crisis-dependent?}

The analyses we have conducted so far present strong empirical evidence that CDS tail beta explains a significant part of the variation in CDS spread levels that is not captured by other previously identified determinants of CDS spreads. Next, we address the question whether this positive correlation between CDS tail beta and CDS spreads is constant over time or whether it changes between economic regimes. To test these conjectures, we re-estimate our benchmark regression from Table VII separately for the periods before and during the recent financial crisis. We intuitively expect the awareness of CDS investors of extreme market-wide distress to be far less pronounced in the pre-crisis regime. The argument behind this assumption is straightforward. First, Figure 3 provides visual evidence that after the onset of the subprime crisis, market correlations as well as extreme dependence in CDS spreads increased significantly. Second, the mid-2007 beginning of the financial crisis coincided with a significant build-up of systemic risks in the global financial sector (see International Monetary Fund, April, 2010) and increased uncertainty among investors concerning the financial health of global banks. As a result, we expect the sensitivity of sellers of CDS protection to market-wide surges in CDS spreads to be higher after the onset of the crisis and particularly pronounced after the failure of Lehman Brothers in September 2008. ${ }^{24}$

To test the hypothesis that the perception of CDS tail risk varies throughout the sample period, we divide our sample into two sub-samples. The first sub-sample covers the pre-crisis period from January 2004 to June 2007. We consider the crisis to have started in the third quarter of 2007 and to have lasted until September 2010. Results on the regressions for the two sub-samples are presented in Table VIII.

A comparison of the two estimated regressions presented in Table VIII clearly supports the hypothesis that CDS tail risk is only a relevant factor during the crisis period. The estimated coef-

\footnotetext{
${ }^{24}$ This view is underlined, e.g., by the International Monetary Fund (April, 2009) which argued that the events at Lehman Brothers and AIG increased system-wide conditional risk.
} 
ficient on CDS tail beta in column 2 is positive and highly statistically significant at the $1 \%$ level. Compared to the full-sample benchmark model, the coefficient on our main explanatory variable increases by approximately 1.5 percentage points when using the crisis subsample for estimating the model. After mid-2007, a 1\% point increase in CDS tail beta indicates a 4.4 bps increase in CDS spreads. The strong correlation between CDS tail beta and CDS premia lends strong support to the hypothesis that market participants adjust their individual risk assessment with respect to system-wide risk contemporaneously. Note that the significance of all other coefficients remains unchanged and in line with theory. Note also that the overall explanatory power increases sharply when turning from pre-crisis to crisis periods as evidenced by the sharp increase in the adjusted $\mathrm{R}^{2}$-squared. Perhaps not surprisingly, when turning to the pre-crisis period the empirical results show that CDS tail beta is only an economically and statistically significant driver of bank-specific spread levels in times of financial turmoils. Although positive, the coefficient on CDS tail beta is small in magnitude and statistically insignificant. Interestingly, almost all other explanatory variables lose their statistical significance as well. This finding may be due to the fact that before the start of the crisis, the within-variation of almost all variables is extremely low over time and crosssectionally. Surprisingly but consistent with theory, the short-term interest rate is a priced factor and has significant explanatory power at the $1 \%$ level. Again, this may indicate that the stance of monetary policy was a significant driver of bank risk between 2004 and mid-2007.

\subsubsection{Are CDS spreads linearly increasing in CDS tail beta?}

So far, our regression models imply that CDS spreads are linearly increasing in a respective bank's CDS tail beta. Some commentators of the recent financial crisis, however, have argued that some banks became too important or too big to fail prior to the crisis. If true, sellers of credit protection could have relied on government assistance for these banks in times of financial distress. Consequently, CDS investors insuring debt of banks that qualify for implicit or explicit government assistance could be less exposed to market crash risk, since the probability of default 
and the associated cost of distress are lower for these banks. ${ }^{25}$ Schweikhard and Tsesmelidakis (2011) show that during the recent financial crisis, market participants indeed may have treated equity and debt differently in the presence of implicit or explicit government guarantees, with creditors being favoured over equity investors.

Therefore, we verify the hypothesis that CDS investors, similar to the assessment of systemically important banks, may assign individual risk weights according to the exposure of an individual bank to the market during extreme events. Put differently, given that the system as a whole is in distress, banks with high market exposures, i.e., high values for CDS tail beta, are more likely to default but could, on the other hand, also be considered to be more relevant than others. As a result, more systemically relevant banks could be assigned a higher likelihood of receiving government assistance. This translates to our measure of tail risk as follows. We have reason to believe that the relation between CDS tail beta and CDS spreads is not linear, but rather inversely u-shaped. This functional relation would then imply lower tail risk premiums as government assistance for systemically important banks is implicitly priced in CDS premia.

In order to formally test this hypothesis, we include the squared term of CDS tail beta in our benchmark regression of CDS spreads and thus allow for non-linear dependence between the two variables. Column 1 of Table $\amalg$ X reports estimates for the extended non-linear regression model. When estimated together with its squared counterpart, the coefficient on CDS tail beta is significant at the $1 \%$ level and higher as compared to our benchmark specification. The estimated coefficient on the squared value, however, is negative and also significant at the $1 \%$ level. Thus, the results support our hypothesis that a non-linear model provides a better fit to our data than the linear model. Note that all remaining controls keep the expected sign on their coefficients. Consistent with our conjecture, we find evidence that under the assumption of implicit and explicit government guarantees, CDS investors indeed differentiate with respect to the individual bank's exposure to the market, given the market returns are in the extreme right tail of the distribution.

\footnotetext{
${ }^{25}$ In support of this view, Gandhi and Lustig (forthcoming) find bank stocks to exhibit a size effect due to the pricing of government guarantees for large, systemically relevant banks. They conjecture and empirically confirm that stocks of large banks have lower risk-adjusted returns than small ones.
} 
Accordingly, sellers of credit protection demand lower compensation for bearing the risk of extreme market downturns, possibly relying on government assistance during times of market-wide financial distress.

\subsubsection{Are CDS spreads sensitive to crashes in equity markets?}

Although our findings are consistent with risk aversion of CDS investors, we now consider an alternative source of joint crash risk. It could be argued that sellers of credit protection do not price an individual bank's exposure with respect to the CDS market, but rather consider the exposure of the bank to stock market crashes as a determinant of default risk. ${ }^{26}$ Hence, in the following we repeat our benchmark regression this time using the lower tail dependence (LTD) coefficient estimated between the respective equity return series and the return on the stock price index.

We define our variable Equity tail beta as the equity LTD coefficient and simply calculate the stock price index as the daily equally-weighted average stock return over all 35 banks. ${ }^{27}$ Equity tail beta is estimated using the DAC model of Christoffersen et al. (2012). To generate white-noise residuals, we first apply the NGARCH model of Engle and Ng (1993) to the univariate return series assuming that the return innovations follow a skewed $t$ distribution (see Hansen, 1994). ${ }^{28}$ In a second step, we then estimate bivariate DAC models on the basis of the NGARCH filtered equity return series with each estimation employing the filtered returns on the corresponding bank's equity prices and the price index. Finally, equity tail betas are estimated from the DAC models using numerical integration.

As one would expect, for the banks included in our sample the results in column 2 of Table IX show that a $1 \%$ point increase in a banks' equity tail beta is associated with a 4 bps increase in CDS spread levels. The results from column 2 have important implications. Sellers of credit protection do not only price CDS implied tail risk but also the extent to which a bank's stock is

\footnotetext{
${ }^{26}$ This argument is in spirit of the theoretical model of Acharya et al. (2010). They associate systemic risk with an undercapitalization of a bank when the market as a whole is undercapitalized.

${ }^{27}$ Ruenzi and Weigert (2013) refer to stocks with high values of LTD as crash-sensitive stocks.

${ }^{28}$ More precisely, to account for serial correlation in the return series, we apply the NGARCH model to the residuals from autoregressive models of order two, see Christoffersen et al. (2012) for details.
} 
exposed to the market during times of distress. Summarizing our results so far, we find that both, CDS- and equity-implied tail risk are priced in CDS contracts. For investors relying on implicit or explicit government assistance, the effect of CDS tail beta on spread levels is diminishing when banks' market exposures increase.

Further, we investigate whether we can also identify diminishing risk premia according to banks' equity tail beta. The discussion above suggests that no such effect should be identifiable for equity tail beta since creditors are favoured over equity investors in case of a bank receiving government assistance. Indeed, the results in column 3 of Table $\amalg X$ show that, when the squared terms of the equity tail beta are estimated together with their non-squared counterparts, the coefficient on the squared values is insignificant. The results show that investors price stock price sensitivities into CDS premia but, in contrast to CDS markets, do not implicitly rely on government support.

Finally, we investigate the robustness of CDS tail beta to the inclusion of equity tail beta and estimate panel regressions with CDS and equity tail beta as well as our other controls as explanatory variables. The results are reported in column 4 of Table $\llbracket \mathrm{X}$ and show that the coefficient on CDS tail beta remains highly statistically and economically significant when estimated together with the controls and equity tail beta. The coefficient on the latter is also statistically significant and implies a considerable economic effect of similar magnitude as above. Hence, sellers of CDS protection price extreme tail risk in both CDS markets and in equity markets.

\subsection{Robustness Checks}

In addition to the regressions discussed in Section 3.2, we investigate the robustness of our results to the inclusion of further control variables in this section. More precisely, we test the hypothesis that CDS tail beta complements other measures of a bank's upside, systematic and systemic risk. 


\subsubsection{Is the impact of CDS tail beta driven by upside risk aversion?}

In the spirit of Ruenzi and Weigert (2013) we distinguish investors' crash aversion as measured by CDS tail beta from general upside risk aversion expressed in terms of traditional correlationbased risk measures. Since the strong relation between CDS spreads and CDS tail beta documented in the preceding sections could be driven by differences in linear risk measures like, e.g., CAPMtype beta, upside beta, and coskewness, in the following robustness check we separate the impact of CDS tail beta on CDS spreads from the impact of linear risk measures. To this purpose, we perform double-sorts and panel regressions on the basis of the above mentioned correlation-based risk measures, and show that CDS tail beta is robust with respect to linear effects in CDS spread comovements.

The correlation-based risk measures include regular beta, upside beta as proposed by Ang et al. (2006), as well as coskewness (see Kraus and Litzenberger, 1976; Harvey and Siddique, 2000), and are computed on the basis of daily CDS spread log returns via rolling windows of 100 data points. Upside beta is defined to be regular beta conditional on the CDS spread index return being above its median. Since focusing upside beta more on the right tail could potentially account for effects similar to CDS tail beta, we consider alternative definitions and additionally calculate upside betas as betas conditional on the CDS spread index return being above its $80 \%, 90 \%$, and $95 \%$ quantile. $^{29}$

The time evolution of beta, upside betas, and coskewness is depicted in the panels of Figure 4. The panels on the left-hand side show the time evolution of the linear risk measures, averaged across all banks in the sample, whereas the panels on the right-hand side compare this time evolution to that of CDS tail betas in terms of risk measure and tail beta indices. As can be seen from the right-hand side panels, average beta and upside betas range from -5 to 5 and exhibit a rather stationary behaviour during the sample period. In contrast to, e.g., copula correlations and CDS tail beta, there are neither observable patterns in the time evolution like upward or downward

\footnotetext{
${ }^{29}$ Note that this approach is in line with Ruenzi and Weigert (2013) who, in contrast, calculate different specifications of downside beta on the basis of quantiles in the left tail of the market return distribution.
} 
trends nor significant peaks corresponding to key events during the sample period. Interestingly, the range between the 10th and the 90th percentile tightens sharply around the beginning of the financial crisis, whereas the averages remain on normal levels outside the range. Average coskewness, on the other hand, varies between -50 to 50, whereas the range between the 10th and 90th percentile evolves tightly around the average.

In a first step, we conduct double-sorts based on CDS tail beta and the linear risk measures, respectively, in which we analyze the impact of CDS tail beta on CDS spreads after controlling for one of the alternative risk measures at a time. More precisely, we first rank the time series of CDS spread observations into quintiles with respect to beta, upside betas, and coskewness, respectively, for each bank in the sample. Then, within each of these quintiles, we sort the corresponding CDS spreads by CDS tail beta. Finally, we calculate the mean CDS spread for each quintile and average across all banks in the sample.

The results of the double-sorts are reported in Table $\mathrm{X}$ Panel A shows average daily spreads double-sorted on CDS tail beta and regular beta. In all CDS tail beta quintiles, the CDS spreads associated with high beta risk are considerably higher than the spreads associated with low beta risk, with the difference between high and low beta CDS spreads being equal to 79.53 bps on average. More importantly, however, in all beta quintiles, we document a nearly monotonic increase in CDS spreads from low to high CDS tail beta quintiles, where the difference between high and low tail beta quintile spreads is economically large and ranges from 26.25 to $135.73 \mathrm{bps}$. Except for the first beta quintile, these differences are statistically significant at the $1 \%$ and $5 \%$ level as well. Consequently, the risk associated with regular beta is different from the risk associated with CDS tail beta and cannot account for the premium sellers of credit protection receive for engaging in CDS contracts on bank names with high CDS tail betas.

Panels B to $\mathrm{F}$ of Table $\mathrm{X}$ report results for the double-sorts based on various specifications of upside beta. As we can see from the panels, the results are qualitatively similar to those for regular beta reported in Panel A. In most CDS tail beta quintiles, CDS spreads associated with lower upside beta tend to be lower than CDS spreads associated with high upside beta, indicating 
that general upside risk aversion may be reflected in CDS spreads. Turning to the impact of CDS tail beta, we find that, in all upside beta quintiles, there is a strong positive relatio between CDS tail beta quintile and CDS spreads, and the difference between high and low tail beta quintile spreads is of similar magnitude and statistically significant at the $1 \%$ and $5 \%$ level. Hence, the risk associated with upside beta has to be distinguished from the risk associated with CDS tail beta and has a different impact on CDS spreads, irrespective of the particular definition of upside beta.

Finally, we investigate the impact of CDS tail on CDS spreads after explicitly controlling for the impact of the risk associated with coskewness. The results are reported in Panel G and indicate that coskewness risk cannot account for the increased CDS spreads associated with high CDS tail beta. In all coskewness quintiles, the CDS spreads of low tail beta quintiles are significantly lower than the spreads of high tail beta quintiles. The differences between high and low tail beta quintile spreads range from 88.57 to 163.84 bps (116.60 bps on average) and are statistically significant at the $1 \%$ level.

In summary, the double-sorts provide strong evidence that the impact of CDS tail beta on CDS spreads is different from the impact of alternative linear risk measures, i.e., the significant positive relation between tail beta and spreads cannot be explained by traditional, correlationbased measures of risk. Consequently, investors' crash aversion needs to be distinguished from general upside risk aversion. In double-sorts, however, we can only control for one CDS spread characteristic at a time. Therefore, in the following we will include the alternative risk measures in multivariate panel regressions and examine their impact on CDS spreads when considering CDS tail beta and the control variables introduced at the beginning of the section.

The results of the panel regressions are reported in Table $X \mathbb{X}$ and confirm the above findings that CDS tail beta is robust to linear comovements and moderately extreme events. In regression (1), we introduce regular beta as a further explanatory variable, whereas in regressions (2) to (5) we respectively include the different specifications of upside beta. Finally, in regression (6), we consider coskewness in addition to CDS tail beta and the control variables. Expectedly, the coefficient on CDS coskewness enters this regression significantly at the $1 \%$ level with a negative 
sign. As we can see from the results on the different regressions, all coefficients of the alternative risk measures are statistically insignificant when estimated together with CDS tail beta and the control variables. Further, compared to the outcomes of our benchmark regression (7) in Table VII. the coefficients on CDS tail beta and the control variables slightly vary in magnitude but remain constant with respect to their sign and significance. Regarding CDS tail beta, the coefficients in the alternative regressions (1) to (5) vary from 2.919 (specification (3)) to 3.406 (specification (1)) and are 3.060 on average, whereas the CDS tail beta coefficient in benchmark regression (7) is equal to 2.929 . The coefficients remain statistically significant at the $1 \%$ level, and the economic effect is of similar magnitude: in regressions (1) to (5) a one standard deviation higher CDS tail beta increases CDS spread levels by 36.72 bps on average $(3.060 \times 0.12)$. According to benchmark regression (7), on the other hand, the effect is a 35.15 higher CDS spread $(2.929 \times 0.12)$ for a one standard deviation higher CDS tail beta. The results on the coefficients of the control variables merely differ slightly across the different regression specifications as well.

Overall, including the alternative linear risk measures in multivariate panel regressions shows that the linear impact of correlation-based risk measures on CDS spreads is not significant. Hence, the impact of CDS tail beta on CDS spreads is different from the impact of linear risk measures and cannot be explained by linear comovement in spreads.

Interestingly, the results on our regression analysis are in a slight contrast to the results on the double-sorts at first glance. As documented above, in all CDS tail beta quintiles, low beta and upside beta quintile spreads tend to be lower than high beta and upside beta quintile spreads, indicating a positive relation between linear risk measures and CDS spreads after controlling for tail risk. The regression analysis, on the contrary, comes to the conclusion that there is no significant impact of linear risk measures on CDS spreads. At this point, we need to consider that our panel regressions only capture linear impacts of the explanatory variables on the dependent variable. Double-sorts, however, allow us to control for any potential non-linear impact. Therefore, the results of our double-sorts and regressions are not contradictory, but indicate that, after controlling for tail risk, the impact of correlation-based risk measures on CDS spreads is, if at all, of non-linear 
nature.

\subsubsection{Is the impact of CDS tail beta driven by systemic risk exposure?}

As stated by Acharya et al. (2010), a bank's systemic relevance for the financial sector is reflected in CDS spreads during the recent financial crisis. More precisely, they show that a bank's Marginal Expected Shortfall (defined as the conditional mean equity return of the bank when the market is plummeting) is a significant determinant of financial institutions' crisis spreads. Consequently, CDS tail beta could simply be another proxy for a bank's exposure to systemic risk and its impact on CDS spreads could be driven by differences in systemic risk measures like, e.g., Marginal Expected Shortfall. Hence, in the following, we distinguish crash aversion from systemic risk exposure and examine, whether the impact of the former remains significant after controlling for the impact of the latter. As above, we first conduct double-sorts based on CDS tail beta and MES, and then run multivariate panel regressions including MES as a further explanatory variable.

MES is estimated on the basis of equity returns from alternative models including the static MES according to Acharya et al. (2010) as well as various dynamic model specifications proposed in Brownlees and Engle (2012). Static MES is computed non-parametrically from rolling windows of 100 data points, and the dynamic MES models include the VCT model, the Dynamic Conditional Beta model as well as the Dynmaic Conditional Copula model that is based on Patton's (2006) dynmaic t-copula. ${ }^{30}$

Figure 5]depicts the time evolution of average MES for each of the above models and compares it to the time evlolution of CDS tail beta. Panel (a) combines the estimates of the different MES models and shows that the time series profile of the estimates is rather similar across the models. The general pattern in the time evolution is the same for all models: starting with fairly moderate levels of, on average, $1 \%$ to $4 \%$ in the pre-crisis period, MES experienced sharp increases at the onset of the financial crisis. From the beginning in mid-2007 up to 2009, MES increased from 2\% to more than $8 \%$, indicating a significant surge in the average exposure of banks to systemic tail

\footnotetext{
${ }^{30}$ Further details and a formal description of the different MES models can be found in Acharya et al. (2010) and Brownlees and Engle (2012).
} 
events. The dramatic increase was followed by a strong downward trend, with MES decreasing significantly to pre-crisis levels. In the first quarter of 2010, however, dynamic MES peaked again and temporarily returned to levels of more than $7 \%$, whereas static MES was characterized by a rather constant evolution. As we can see from Panels (b) to (e), both CDS tail beta and MES were characterized by a sharp increase as of the onset of the crisis in 2007. In contrast to MES, though, CDS tail beta experienced a strong upward trend rather than a temporary surge.

Table XII reports the results on double-sorts based on CDS tail beta and the different MES specifications. As can be seen from the panels of the table, the results are qualitatively and quantitatively rather similar: in all CDS tail beta quintiles, low MES quintile spreads tend to be lower than high MES quintile spreads, irrespective of the specific MES model. Hence, there is a strong positive relation between MES and CDS spreads even after controlling for tail risk, indicating that systemic risk may be a priced factor. More importantly for our purposes, turning to CDS tail beta, we document a nearly monotonic increase in CDS spreads from low to high CDS tail beta quintiles for most MES quintiles, where the difference between high and low CDS tail beta quintile spreads is economically large and statistically significant for the most part. Consequently, systemic risk is different from the risk associated with CDS tail beta and cannot explain the significantly positive correlation between CDS tail beta and CDS spreads. Since, in double-sorts, we can only control for one variable at a time, in the following we include MES in multivariate panel regressions.

The regression results are reported in specification (7) of Table XI As the time series profile of MES and the regression outcomes are rather similar across the different MES model specifications, we merely show results for the static MES as initially proposed by Acharya et al. (2010). Column (7) of Table XI lists the estimated coefficients of the panel regression including CDS tail beta, static MES, and control variables as explanatory variables. Similar to Acharya et al. (2010), we find evidence that MES is a significant driver of CDS spreads, with the corresponding coefficient being highly significant at the $1 \%$ level and implying a large economic effect: a one standard deviation higher MES is associated with a 33 bps $(11.000 \times 0.03)$ higher CDS spread. Nevertheless, the coefficient of CDS tail beta is still significant at the $1 \%$ level, although it declines slightly in value. 
The economic effect remains large as well, with a one standard deviation higher CDS tail beta implying a 22 bps $(1.848 \times 0.12)$ higher CDS spread.

Overall, including MES in multivariate panel regressions confirms our findings from the double-sorts and shows that the impact of CDS tail beta on CDS spreads is different from the impact of MES. Hence, crash aversion has to be distinguished from systemic risk, and CDS tail beta is indeed a distinct factor priced in CDS spreads.

\section{Conclusion}

We find that during the recent financial crisis, credit default swap spreads of European banks included a premium for the bank's CDS tail beta as measured by the upper tail dependence between the returns on default swaps written on individual bank names and an equally-weighted index of bank CDS. Investors selling protection against the default of a bank receive a premium if the swap's reference entity possesses a higher sensitivity to sector-wide increases in average CDS spreads. This effect is economically large and its direction is in line with our economic intuition. Banks in the upper quintile of CDS tail beta have spreads that are on average 140 basis points higher than those of banks in the lower CDS tail beta quintile. The high CDS spreads of banks possessing high CDS tail betas can neither be explained by traditional factors from Merton's model nor by alternative measures of systematic, tail or systemic risk. Consequently, our study contributes significantly to the open question on which factors can explain the large fraction of variation in spread differences that is not captured by traditional determinants of credit default. However, the explanatory power of CDS tail beta is restricted to our sub-sample of bank-quarters during the financial crisis. Thus, investors appear to be sensitive to crash risk when already facing a sectorwide crisis.

Our results confirm and extend previous findings from the empirical literature on the determi-

nants of CDS spreads. While we confirm the results of Ericsson et al. (2009) on the explanatory power of the Merton factors, our new CDS tail beta factor has high explanatory power increasing 
the adjusted $\mathrm{R}^{2}$ in our regressions of CDS spreads from $24 \%$ to $32 \%$. Furthermore, our results are also consistent with the findings of Acharya et al. (2010) that CDS spreads of banks are driven by measures of systemic risk exposure. However, our new measure of CDS tail beta complements rather than substitutes other measures of moderate or extreme tail risk. Finally, extending the results of Ruenzi and Weigert (2013), we also document a strong positive correlation between equity tail beta and CDS spreads.

This study focuses solely on the pricing of CDS tail beta in the CDS spreads of banks. A natural extension of our study would include an analysis of non-financial firms before and during the financial crisis. Theory predicts that the correlation between CDS tail risk and CDS spreads is particularly strong for banks as they are more vulnerable to runs of creditors and depositors during financial crises. Yet, non-financial firms should just the same be sensitive to turmoil in the overall CDS market and we would expect CDS tail beta to be priced in non-financial firms' CDS spreads as well. Furthermore, a natural extension of our initial question is whether CDS premia are also correlated with the propensity of the CDS premia to surge together with the CDS spread of sovereign bonds. We leave this question for future work. 


\section{Appendix}

\section{Appendix I: Sample banks.}

The appendix lists all sample banks. Shown are the company name as it appears in the Worldscope data item WC06001. Ticker symbols are taken from Bloomberg.

\begin{tabular}{ll}
\hline Bank & Ticker symbol \\
\hline Allied Irish Banks & AIBSF \\
Alpha Bank & ALPHA \\
Banca Italease & BILMI \\
Banca Monte dei Paschi di Siena & BMDPF \\
Banca Popolare di Milano & BPMLF \\
Banca Popolare Italiana & BPI \\
Banco Bilbao Vizcaya Argentaria & BBVA \\
Banco Comercial Português & BPCGF \\
Banco Espírito Santo & BKESF \\
Banco Pastor & BCPSF \\
Banco Popular Espanol & BPESF \\
Banco Português de Investimento & BBPI \\
Banco Sabadell & SAB \\
Banco Santander Central Hispano & SAN \\
Bank of Ireland & IRLBF \\
Bankinter & BKT \\
BNP Paribas & BNP \\
Commerzbank & CBK \\
Crédit Agricole & ACA \\
Deutsche Bank & DBK \\
Dexia Group & DEXB \\
EFG Eurobank Ergasias & EFG \\
Erste Group Bank & EBKOF \\
Fortis & FSVVF \\
IKB Deutsche Industriebank & IKB \\
ING Bank & ING \\
Intesa Sanpaolo & IITSF \\
Irish Life and Permanent & ILB \\
KBC Group & KBC \\
Mediobanca & MDIBF \\
Natixis & KN \\
Société Générale & GLE \\
UBI Banca & UBI \\
Unibail Holding & UNBLF \\
Unicredito Italiano & CRIH \\
\hline & \\
&
\end{tabular}




\section{Appendix II: Variable definitions and data sources}

The appendix presents definitions as well as data sources for all dependent and independent variables that are used in the empirical study. The bank CDS and equity data are taken from the Thomson Reuters Datastream database. The country control variables are taken from Datastream and from the OECD statistics Database.

\begin{tabular}{|c|c|c|}
\hline Variable name & Definition & Data source \\
\hline CDS spreads & $\begin{array}{l}\text { Daily end-of-quarter CDS spreads, denoted in basis points and obtained from Credit Mar- } \\
\text { ket Analysis (CMA). }\end{array}$ & CMA, Datastream. \\
\hline Volatility & End-of-quarter VSTOXX implied volatility index values. & Datastream. \\
\hline Risk-free interest rate & 1-year Euro interest rate swap ISDA mid-market rate, denoted in per cent. & ISDA, Datastream. \\
\hline CDS tail beta & $\begin{array}{l}\text { End-of-Quarter upper tail dependence (UTD) coefficients estimated between the banks' } \\
\text { CDS spread return series and the returns on the spread index. UTD coefficients } \\
\text { are computed from the Dynamic Asymmetric Copula (DAC) model as proposed in } \\
\text { Christoffersen et al. (2012). UTD time series are filtered using a simple moving average } \\
\text { including a lag of the past } 20 \text { trading days. }\end{array}$ & Datastream, own calc. \\
\hline Firm value & Quarterly arithmetic bank stock returns denoted in per cent. & Datastream, own calc. \\
\hline Liquidity & $\begin{array}{l}\text { Daily CDS bid-ask spread. The proxy for liquidity is calculated as the difference between } \\
\text { daily CDS ask and bid quotes. }\end{array}$ & $\begin{array}{l}\text { Datastream, CMA, own } \\
\text { calc. }\end{array}$ \\
\hline Business climate & End-of-quarter values of the S\&P 500 index. & Datastream, own calc. \\
\hline GDP growth & Country-level GDP growth rates in comparison to previous quarter, denoted in per cent. & OECD statistics Database. \\
\hline Slope & A country's respective 10-year minus 2-year government bond benchmark yields. & Datastream. \\
\hline Beta & $\begin{array}{l}\text { Realized regular beta calculated on the basis of daily CDS spread log returns from rolling } \\
\text { windows of } 100 \text { data points according to the definition } \beta:=\frac{\operatorname{cov}\left(R_{i, t}, R_{m, t}\right)}{\operatorname{var}\left(R_{m, t}\right)} \text {. }\end{array}$ & Datastream, own calc. \\
\hline $\begin{array}{l}\text { Upside beta (median, } \\
80 \%, 90 \%, 95 \%)\end{array}$ & $\begin{array}{l}\text { Realized upside beta defined as regular beta conditional on the CDS index return being } \\
\text { above its median ( } 50 \% \text { quantile) and its } 80 \%, 90 \% \text {, and } 95 \% \text { quantiles, where the compu- } \\
\text { tation is based on daily CDS spread log returns and implemented via rolling windows of } \\
100 \text { data points. With } r_{m, t}^{q} \text { denoting the respective return quantile, the formal definition } \\
\text { is given by } \beta_{q \%}:=\frac{\operatorname{cov}\left(R_{i, t}, R_{m, t} \mid R_{m, t}>R_{m, t}^{q}\right)}{\operatorname{var}\left(R_{m, t} \mid R_{m, t}>R_{m, t}^{q}\right)} \text {. }\end{array}$ & Datastream, own calc. \\
\hline Coskewness & $\begin{array}{l}\text { Realized coskewness based on daily CDS spread log returns and computed from rolling } \\
\text { windows of } 100 \text { data points according to Coskewness }=\frac{\mathbb{E}\left[\left(R_{i, t}-\mu_{i, t}\right)\left(R_{m, t}-\mu_{m, t}\right)^{3}\right]}{\sqrt{\operatorname{var}\left(R_{i, t}\right)} \operatorname{var}\left(R_{m, t}\right)^{3 / 2}}\end{array}$ & Datastream, own calc. \\
\hline MES & $\begin{array}{l}\text { Marginal Expected Shortfall calculated from alternative models including the static MES } \\
\text { according to Acharya et al. (2010) as well as various dynamic model specifications pro- } \\
\text { posed in Brownlees and Engle (2012). Static MES is computed non-parametrically from } \\
\text { rolling windows of } 100 \text { data points, and the dynamic MES models include the VCT } \\
\text { model, the Dynamic Conditional Beta model as well as the Dynamic Conditional Copula } \\
\text { model that is based on Patton's } 2006 \text { ) dynamic } t \text {-copula (see Brownlees and Engle, 2012, } \\
\text { for details). }\end{array}$ & Datastream, own calc. \\
\hline Equity tail beta & $\begin{array}{l}\text { End-of-Quarter lower tail dependence (LTD) coefficients estimated between the banks' } \\
\text { equity return series and the returns on the stock price index. LTD coefficients } \\
\text { are computed from the Dynamic Asymmetric Copula (DAC) model as proposed in } \\
\text { Christoffersen et al. (2012). LTD time series are filtered using a simple moving average } \\
\text { including a lag of the past } 20 \text { trading days. }\end{array}$ & Datastream, own calc. \\
\hline
\end{tabular}




\section{References}

Acharya, V. V., L. H. Pedersen, T. Philippon, And M. Richardson (2010): "Measuring Systemic Risk," Working paper, New York University.

Adrian, T. And M. K. Brunnermeier (2011): “CoVaR,” Federal Reserve Bank of New York Staff Reports 348.

AiElli, G. P. (2009): "Dynamic Conditional Correlations: On Properties and Estimation,” Working Paper.

AÏT-SAHAliA, Y. AND A. Lo (2000): “Nonparametric risk management and implied risk aversion," Journal of Econometrics, 94, 9-51.

AlEXANDER, C. AND A. KAECK (2008): "Regime dependent determinants of credit default swap spreads," Journal of Banking an Finance, 32, 1008-1021.

Ang, A., J. Chen, And Y. XING (2006): “Downside risk," Review of Financial Studies, 19, 1191-1239.

Annaert, J., M. De Ceuster, P. Van Roy, And C. Vespro (2013): "What determines Euro area bank CDS spreads," Journal of International Money and Finance, 32, 444-461.

BENKERT, C. (2004): “Explaining credit default swap premia,” Journal of Futures Markets, 24, 71-92.

BerA, A. K. And M. L. Higgins (1993): “ARCH Models: Properties, Estimation and Testing," Journal of Economic Surveys, 7, 305-362.

Blanco, R., S. Brennan, And I. Marsh (2005): “An Empirical Analysis of the Dynamic Relation between Investment-Grade Bonds and Credit Default Swaps," Journal of Finance, 60(5), 2255-2281.

Bollerslev, T., R. F. Engle, And D. B. Nelson (1994): “ARCH Models," in Handbook of Econometrics, ed. by R. F. Engle and D. L. McFadden, Amsterdam: Elsevier, North-Holland, 2959-3038.

Bollerslev, T. And V. Todorov (2011): "Tails, fears, and risk premia," Journal of Finance, $66,2165-2211$.

Bongaerts, D., F. DE JONG, AND J. DRIESSEN (2011): "Derivative pricing with liquidity risk: theory and evidence from the credit default swap market," Journal of Finance, 66, 203-240.

BrownleEs, C. T. And R. Engle (2012): "Volatility, Correlation and Tails for Systemic Risk Measurement," Working Paper.

CAMPBEll, J. AND G. TAKSLER (2003): "Equity Volatility and Corporate Bond Yields," Journal of Finance, 58, 2321-2349. 
Christie, A. A. (1982): "The stochastic behavior of common stock variances. Value, leverage and interest rate effects," Journal of Financial Economics, 10, 407-432.

Christoffersen, P., V. Errunza, K. Jacobs, And H. Langlois (2012): "Is the Potential for International Diversification Disappearing? A Dynamic Copula Approach," Review of Financial Studies, 25, 3711-3751.

Christoffersen, P., K. Jacobs, X. Jin, And H. Langlois (2013): "Dynamic Dependence in Corporate Credit," Working Paper.

Collin-Dufresne, P., R. S. Goldstein, And J. S. Martin (2001): “The Determinants of Credit Spread Changes," Journal of Finance, 56(6), 2177-2207.

Committee on the Global Financial System (CGFS) (2011): “The Impact of Sovereign Credit Risk on Bank Funding Conditions," CGFS Papers.

CONT, R. AND Y. H. KAN (2011): "Statistical modeling of credit default swap portfolios," Working paper.

Cremers, M., J. Driessen, P. Maenhout, And D. Weinbaum (2008): "Individual StockOption Prices and Credit Spreads," Journal of Banking and Finance, 32(12), 2706-2715.

De Jonghe, O. (2010): "Back to the Basics in Banking? A Micro-Analysis of Banking System Stability," Journal of Financial Intermediation, 19, 387-417.

Demarta, S. AND A. J. MCNeIL (2004): “The $t$ Copula and Related Copulas," International Statistical Review, 73, 111-129.

Diamond, D. W. And P. H. Dybvig (1983): "Bank Runs, Deposit Insurance, and Liquidity," Journal of Political Economy, 91, 401-419.

Doshi, H., J. Ericsson, K. Jacobs, And S. M. Turnbull (2013): "Pricing Credit Default Swaps with Observable Covariates," Review of Financial Studies, doi:10.1093/rfs/hht015.

DufFIE, D. (2010): "The failure mechanics of dealer banks," Journal of Economic Perspectives, 24(1), 51-72.

DufFIE, D. AND J. LiU (2001): “Floating-Fixed Credit Spreads," Financial Analysts Journal, 57, $76-87$.

EngLE, R. F. (1982): "Autoregressive Conditional Heteroscedasticity with Estimates of the Variance of United Kingdom Inflation,” Econometrica, 50, 987-1007.

(2002): "Dynamic Conditional Correlation: A Simple Class of Multivariate GARCH Models," Journal of Business and Economic Statistics, 20, 339-350.

ENGLE, R. F. AND V. K. NG (1993): "Measuring and Testing the Impact of News on Volatility," Journal of Finance, 48, 1749-1778. 
ERICsson, J., K. JacoBS, AND R. Oviedo (2009): “The Determinants of Credit Default Swap Premia," Journal of Financial and Quantitative Analysis, 44(1), 109-132.

ERICSSON, J. AND O. RENAUlt (2006): "Liquidity and credit risk," Journal of Finance, 61, 2219-2250.

Friewald, N., C. WAGner, AND J. ZEChner (forthcoming): “The Cross-Section of Credit Risk Premia and Equity Returns," Journal of Finance.

GANDHI, P. AND H. Lustig (forthcoming): "Size Anomalies in Bank Stock Returns," Journal of Finance.

Garleanu, N., L. Pedersen, And A. Poteshman (2009): “Demand-based option pricing," Review of Financial Studies, 22, 4259-4299.

Gorton, G. And A. Metrick (2012): "Securitized banking and the run on repo," Journal of Financial Economics, 104, 425-451.

Guillou, A. AND P. Hall (2001): "A diagnostic for selecting the threshold in extreme value analysis," Journal of the Royal Statistical Society (Series B), 63, 293-305.

HAnsen, B. E. (1994): “Autoregressive Conditional Density Estimation,” International Economic Review, 35, 705-730.

HaRvey, C. AND A. SidDiQue (2000): “Conditional skewness in asset pricing tests," Journal of Finance, 55, 1263-1295.

Hautsch, N., J. Schaumburg, And M. Schienle (2012): "Financial Network Systemic Risk Contributions," Discussion Paper 2012-053, CRC 649, Humboldt-Universität zu Berlin.

HiLL, B. M. (1975): "A simple general approach to inference about the tail of a distribution," The Annals of Statistics, 3, 1163-1174.

Hovakimian, A., E. Kane, And L. Laeven (2012): "Variation in Systemic Risk at US Banks During 1974-2010,” NBER Working Paper No. 18043.

Huang, X., H. Zhou, And H. Zhu (2011): “Systemic Risk Contribution,” Finance and Economics Discussion Series, board of Governors of the Federal Reserve System.

International Monetary Fund, I. (April, 2009): "Responding to the Financial Crisis and Measuring Systemic Risk." Global Financial Stability Report.

(April, 2010): "Meeting New Challenges to Stability and Building a Safer System," Global Financial Stability Report.

JACKWERTH, J. AND M. RUBINSTEIN (1996): "Recovering probability distributions from option prices," Journal of Finance, 51, 1611-1631.

KAhneman, D. AND A. TVERSKy (1979): "Prospect theory: an analysis of decision under risk," Econometrica, 47, 263-291. 
KAnG, B. U., F. In, G. KIM, And T. S. KIM (2010): "A Longer Look at the Asymmetric Dependence between Hedge Funds and the Equity Market," Journal of Financial and Quantitative Analysis, 45, 763-789.

KRAUS, A. AND R. LitZENBERGER (1976): "Skewness preference and the valuation of risk assets," Journal of Finance, 31, 1085-1100.

LINTNER, J. (1965): “The valuation of risk assets and the selection of risky investments in stock portfolios and capital budgets," Review of Economics and Statistics, 47, 13-37.

LONGIN, F. AND B. SOLNIK (2001): "Extreme correlation of international equity markets," Journal of Finance, 56, 649-676.

Longstaff, F. A., S. Mithal, And E. Neis (2005): “Corporate Yield Spreads: Default Risk Or Liquidity? New Evidence From The Credit Default Swap Market,” Journal of Finance, 60(5), 2213-2253.

Markowitz, H. (1959): Portfolio selection, Yale University Press.

Merton, R. C. (1974): "On the pricing of corporate debt: The risk structure of interest rates," Journal of Finance, 29, 449-479.

OH, D. H. And A. J. PATton (2013): “Time-Varying Systemic Risk: Evidence from a Dynamic Copula Model of CDS Spreads," Working Paper.

Patton, A. J. (2006): “Modelling Asymmetric Exchange Rate Dependence," International Economic Review, 47, 527-556.

Poon, S., M. Rockinger, And J. TAWn (2004): "Extreme value dependence in financial markets: diagnostics, models, and financial implications," Review of Financial Studies, 17, 581-610.

RoY, A. (1952): "Safety first and the holdings of assets," Econometrica, 20, 431-449.

Ruenzi, S. AND F. WeIGERT (2013): “Crash Sensitivity and the Cross-Section of Expected Stock Returns," Working Paper.

SAID, S. E. AND D. A. DiCKEY (1984): “Testing for unit roots in autoregressive-moving average models of unknown order," Biometrika, 71, 599-607.

SchwaAB, B., S.-J. Koopman, And A. LuCAS (2011): "Systemic risk diagnostics, coincident indicators and early warning signals,” Technical report.

SCHWEIKHARD, F. A. AND Z. TSESMELIDAKIS (2011): “The Impact of Government Interventions on CDS and Equity Markets," Working paper.

SHARPE, W. (1964): "Capital asset prices: a theory of market equilibrium under conditions of risk," Journal of Finance, 19, 425-442.

SHumWAY, T. (1997): “Explaining returns with loss aversion,” Unpublished Working Paper, University of Michigan. 
White, H., T.-H. KIM, AND S. Manganelli (2012): "VAR for VaR: Measuring Tail Dependence Using Multivariate Regression Quantiles," European Central Bank Working Paper.

Zhang, B., H. ZhOU, AND H. Zhu (2009): "Explaining Credit Default Swap Spreads with the Equity Volatility and Jump Risks of Individual Firms," Review of Financial Studies, 22, 50995131. 
Figures 
Figure 1: Time evolution of CDS spreads, CDS spread returns and equity returns.

The panels of this figure show, respectively, the time evolution of CDS spreads, CDS spread (log) returns and equity $(\log )$ returns over the sample period from January 2004 to October 2010. In each of the panels, the black line refers to the average across all 35 sample banks, whereas the shaded area represents the span between maximum and minimum spread/return values and shows the range of values that is covered for each day of the sample. To facilitate visual inspection, we smooth the shaded area by applying moving averages to the maximum and minimum spread/return series. Equity returns and CDS spread log returns are measured in \%, CDS spreads are denominated in basis points (bps).

(a) CDS spreads

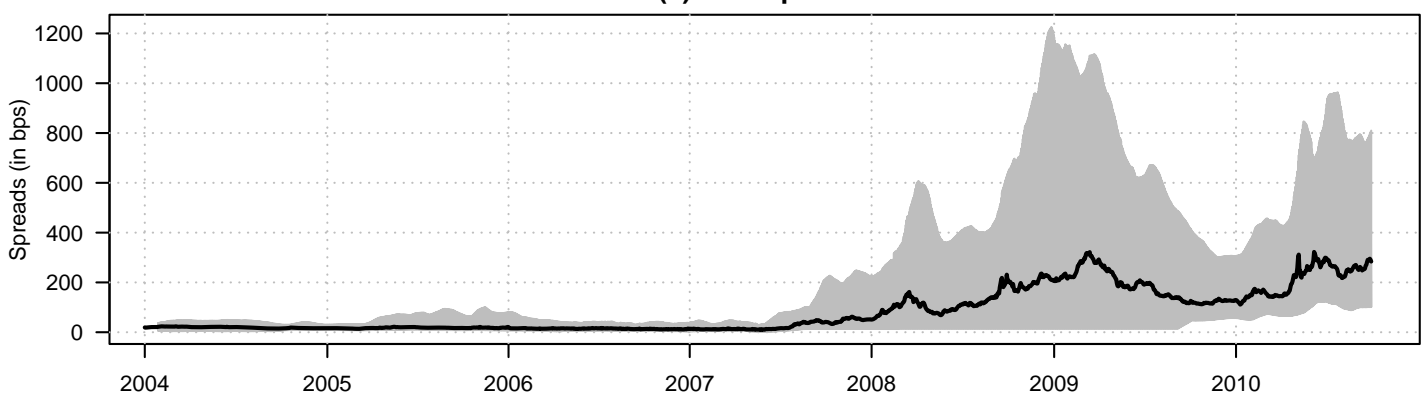

(b) CDS spread log returns

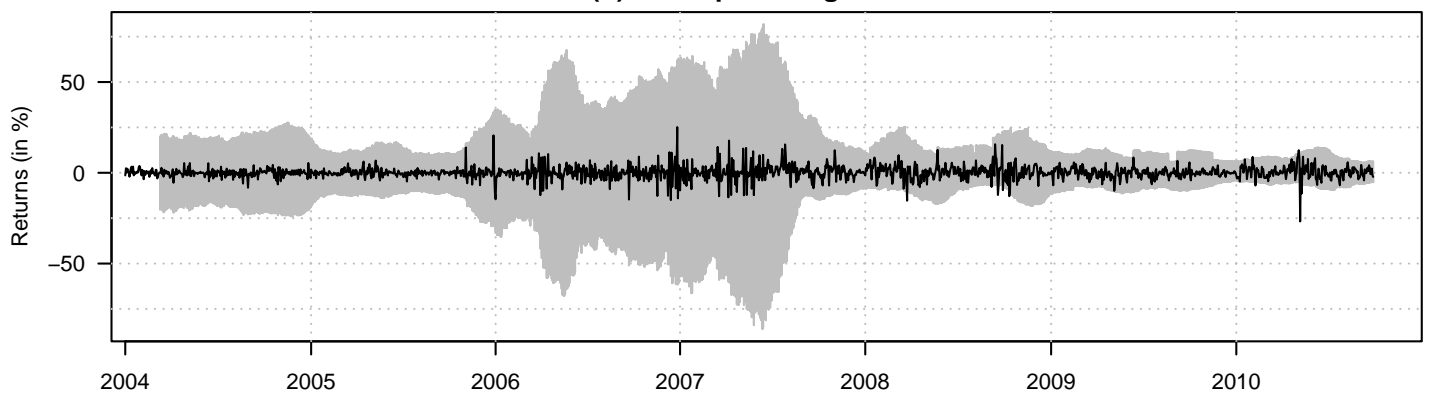

(c) Equity log returns

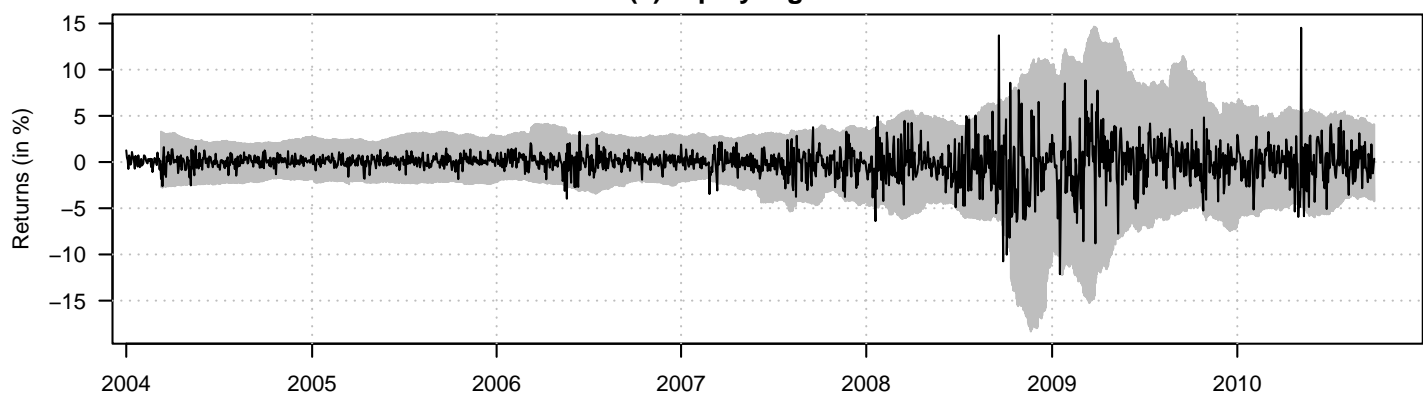


Figure 2: CDS spreads versus CDS spread returns and equity returns.

The panels of this figure compare the time evolution of CDS spreads to the time evolution of CDS spread log returns and equity log returns, respectively, over the sample period from January 2004 to October 2010. The black line refers to the average CDS spread across all 35 banks and is scaled according to the right-hand y-axis, whereas the gray lines show the average equity/CDS spread log returns and are scaled according to the y-axis on the left-hand side. Equity returns and CDS spread returns are measured in \%, CDS spreads are denominated in basis points (bps).

(a) CDS spreads vs. CDS spread log returns

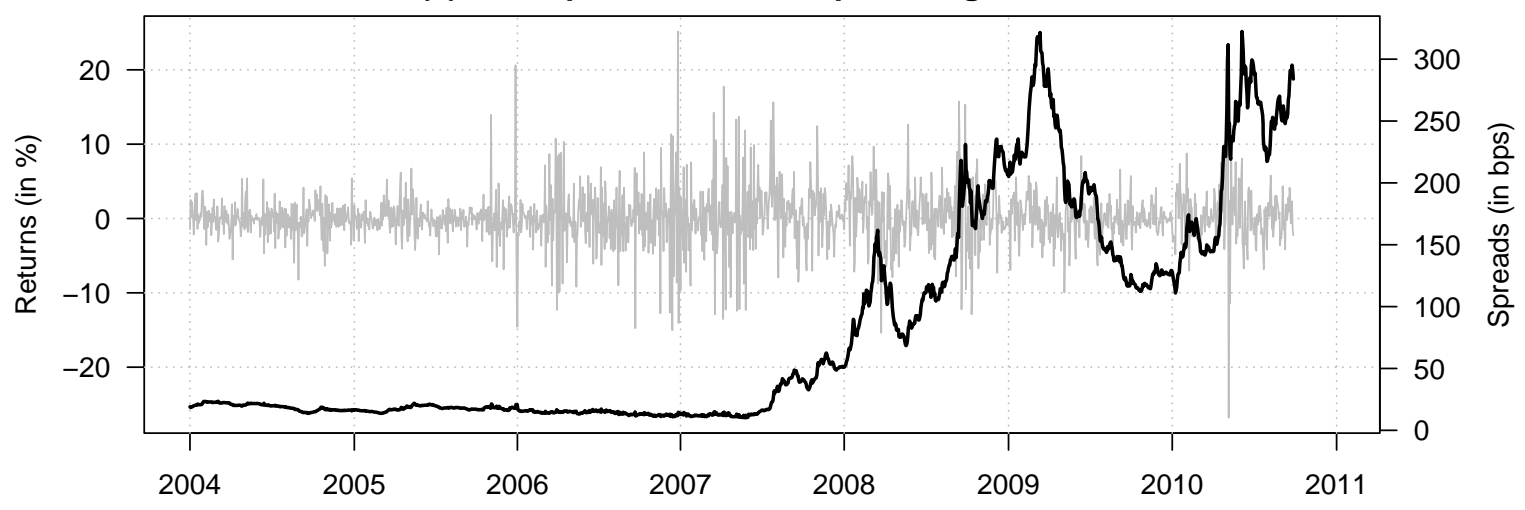

(b) CDS spreads vs. equity log returns

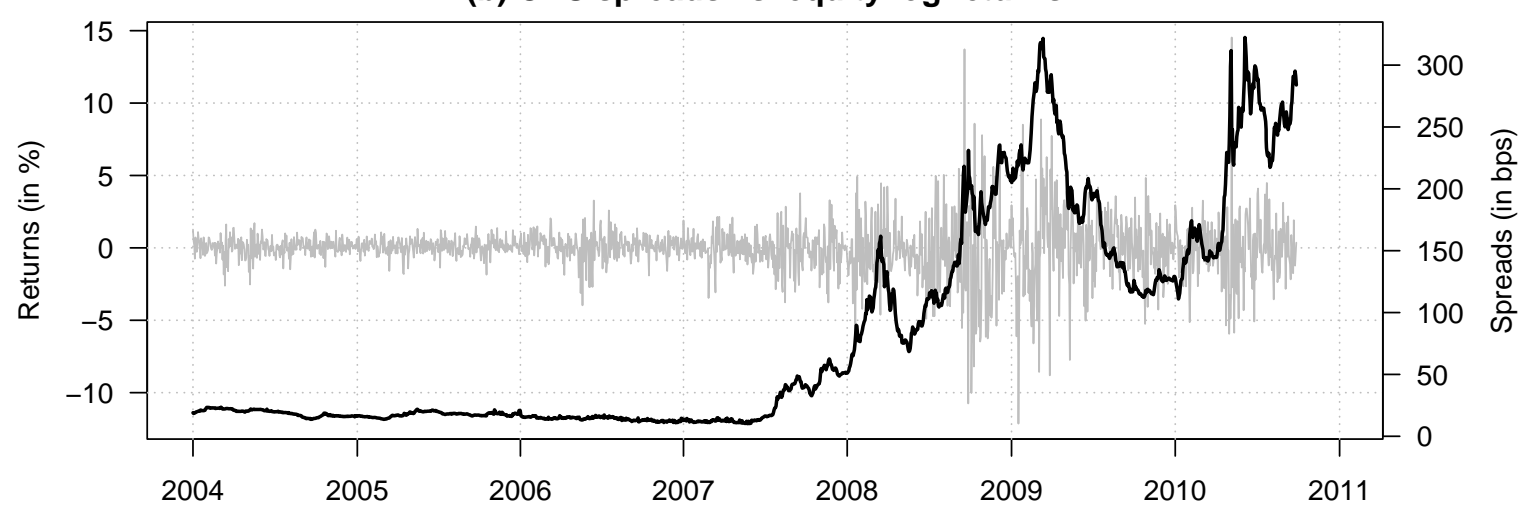


Figure 3: Copula correlations and CDS tail betas.

The panels of this figure show the time evolution of average daily/quarterly dynamic copula correlations and CDS tail betas (denominated in \%). The sample period contains daily data from January 2004 to October 2010 and the average is taken across all 35 sample banks. The daily panels show the average daily dynamic (solid line) and constant (dashed line) copula correlations, the average daily CDS tail betas (solid line) as well as the minimum/maximum range for correlations and tail betas, smoothed by a moving average (gray area). The quarterly panels show the average quarterly copula correlations and tail betas, where each quarter in the sample period is represented by a bar. (Pre-)crisis quarters are colored in (light) gray. Copula correlations and CDS tail betas are estimated from the Dynamic Asymmetric Copula (DAC) model, where the tail betas are approximated by numerical integration using $\xi=0.001$ (see Christoffersen et al., 2012, for details).

(a) Average daily copula correlations

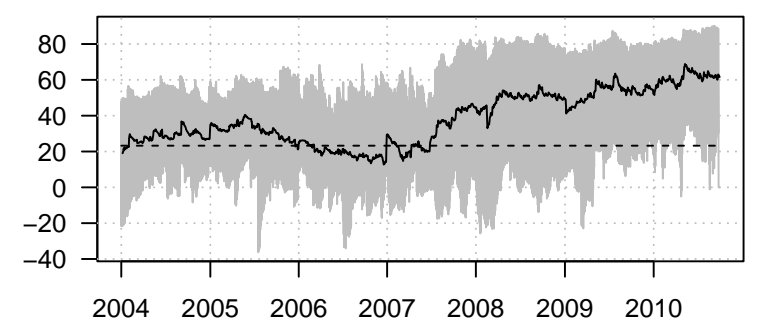

(c) Average daily tail betas

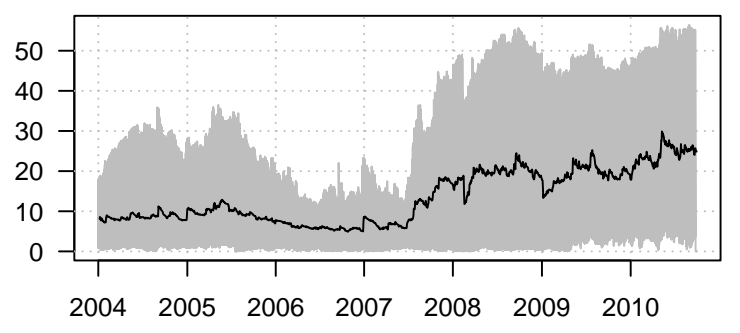

Dynamic copula correlations/tail betas (in \%) Constant copula correlations (in \%) $\mathrm{Min} /$ Max range (b) Average quarterly copula correlations

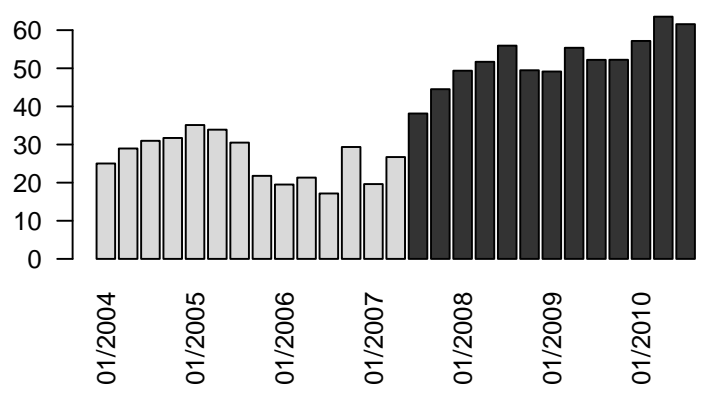

(d) Average quarterly tail betas

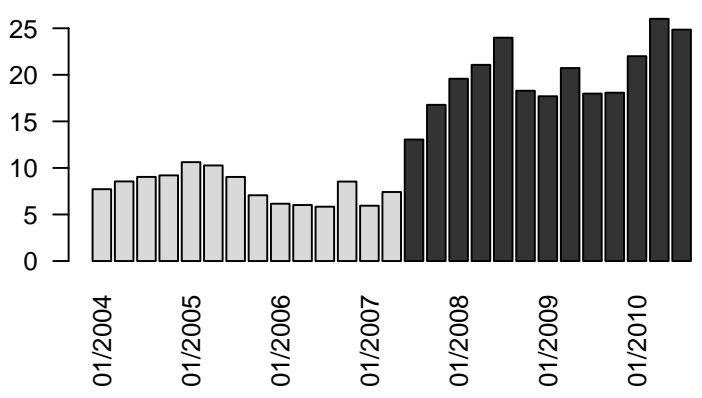


Figure 4: Alternative risk measures and CDS tail beta.

The panels of the figure depict the time evolution of average realized alternative risk measures and compare it to the time evolution of average realized CDS tail beta. The alternative risk measures considered in our study are regular beta, different specifications of upside beta as well as coskewness. More precisely, upside betas are calculated as betas conditional on the CDS index return being above its median and its $80 \%, 90 \%$ and $95 \%$ quantile. The realized alternative risk measures are computed from rolling windows of 100 data points using the definitions listed in Appendix [II. where the sample period contains daily data from January 2004 to October 2010 and the average is taken across all banks in the sample. The panels on the left-hand side show the time evolution of average realized alternative risk measures (black lines) as well as the range between their 10th and 90th percentiles (shaded areas). The right-hand side panels compare this time evolution to that of average realized CDS tail betas in terms of risk measure and tail beta indices calculated by expressing each observation in a specific time series as a percentage of the first observation in that time series. The black lines refer to the time series of the corresponding risk measure index, where the lightgray shaded areas refer to upside deviations from the tail beta index, and the dark-gray shaded areas depict downside deviations. CDS tail betas are simulated from the DAC model, where the tail betas are approximated by numerical integration using $\xi=0.001$ (see Christoffersen et al., 2012, for details).

(a) Beta

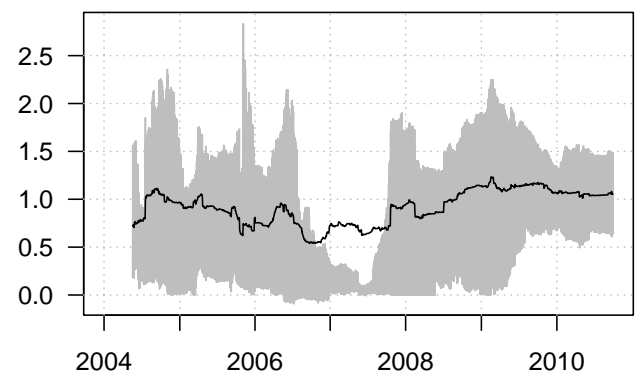

(c) Upside beta (50\%)

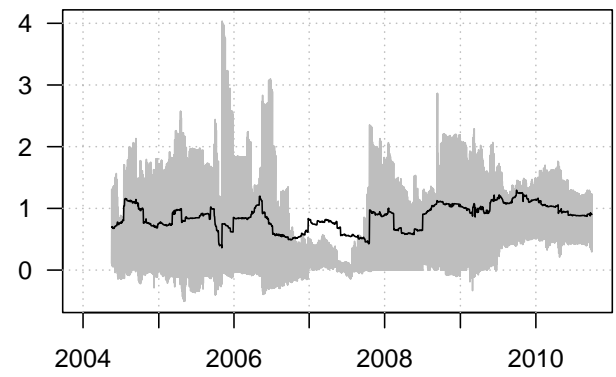

(e) Upside beta (80\%)

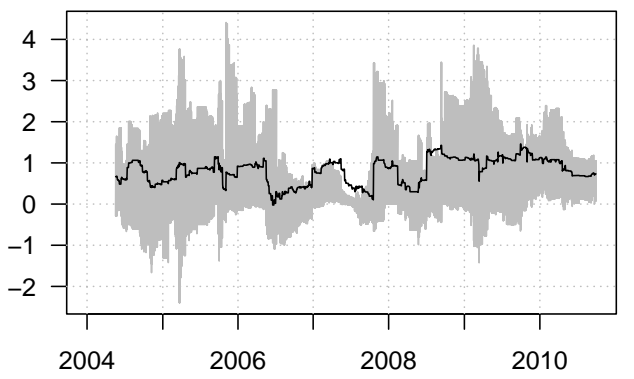

(b) Beta index vs. tail beta index

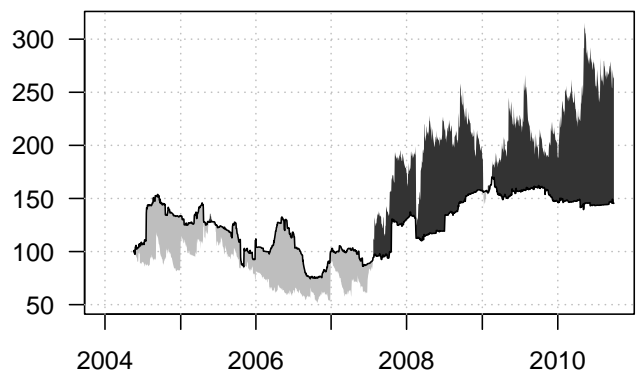

(d) Upside beta index vs. tail beta index

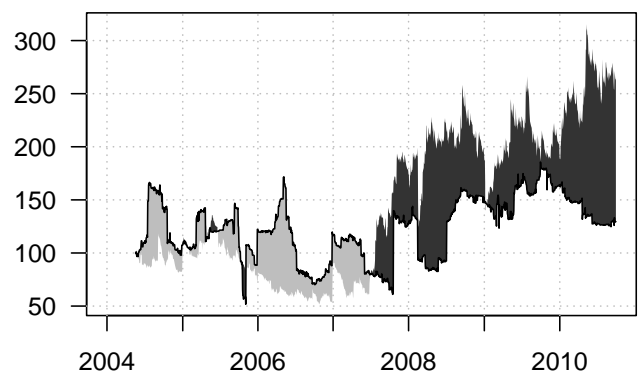

(f) Upside beta index vs. tail beta index

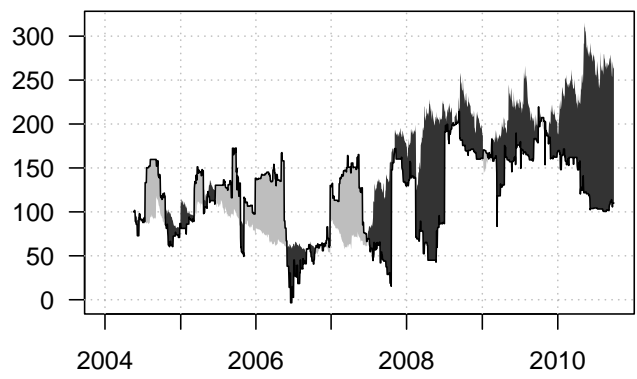


Figure 4: Alternative risk measures (continued).

(g) Upside beta (90\%)

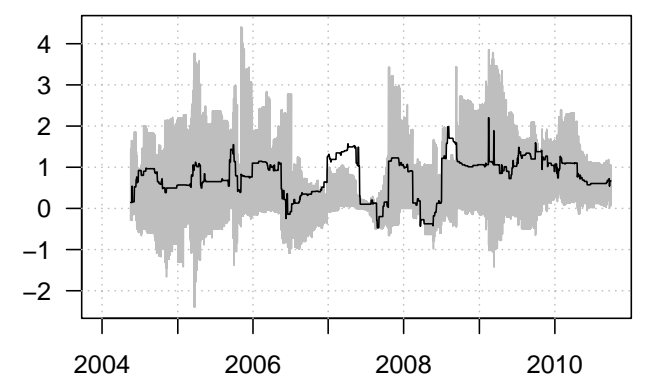

(i) Upside beta (95\%)

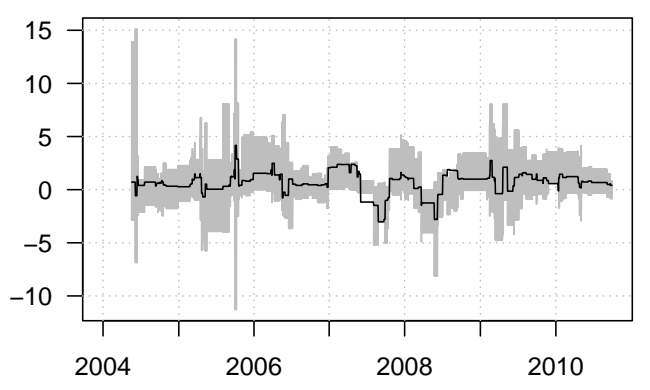

(k) Coskewness

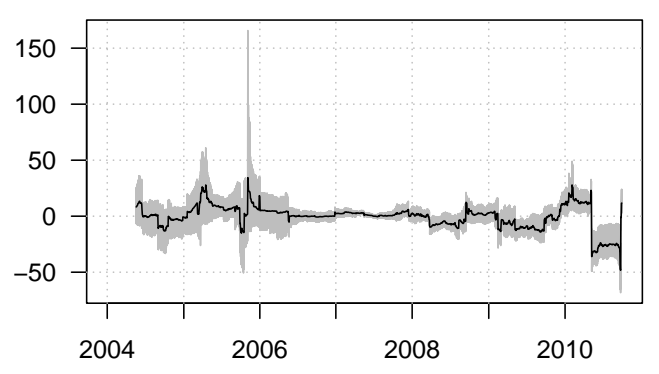

(h) Upside beta index vs. tail beta index

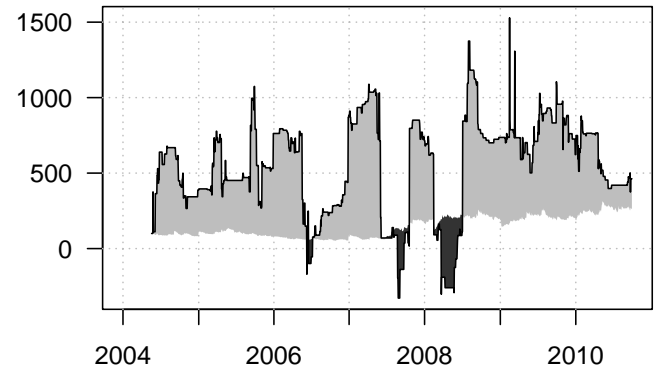

(j) Upside beta index vs. tail beta index

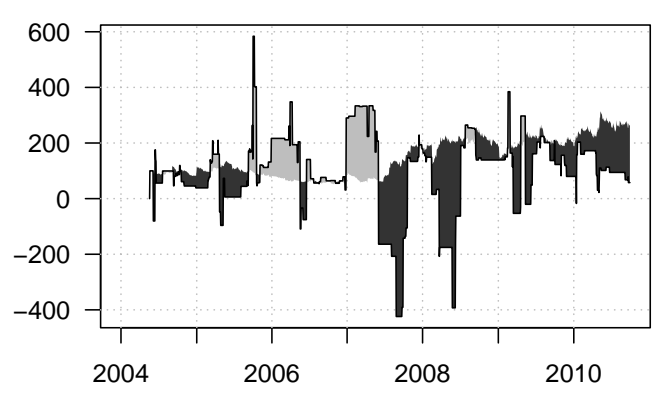

(I) Coskewness index vs. tail beta index

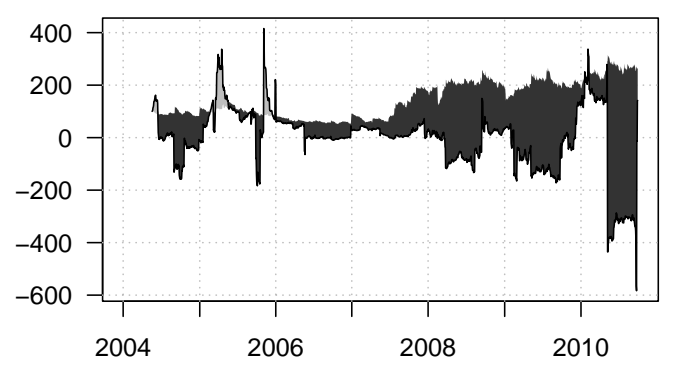




\section{Figure 5: MES models and CDS tail beta.}

The panels of the figure show the time evolution of average Marginal Expected Shortfall (MES) and compare it to the time evolution of average CDS tail beta. Average MES is calculated from alternative models including the static MES according to Acharya et al. (2010) as well as various dynamic model specifications proposed in Brownlees and Engle (2012). Static MES is computed non-parametrically from rolling windows of 100 data points, and the dynamic MES models include the VCT model, the Dynamic Conditional Beta model as well as the Dynamic Conditional Copula model that is based on Patton's (2006) dynamic $t$-copula (see Brownlees and Engle, 2012, for details). The sample period contains daily data from January 2004 to October 2010 and the average is taken across all banks in the sample. The first panel depicts the time evolution of the different MES specifications, whereas the following panels compare this time evolution to that of CDS tail beta, with the light-gray shaded areas showing the MES range between the 10th and 90th percentile and with the dark-gray coloured lines referring to CDS tail beta. CDS tail betas are simulated from the DAC model, where the tail betas are approximated by numerical integration using $\xi=0.001$ (see Christoffersen et al., 2012, for details).

\section{(a) MES models}

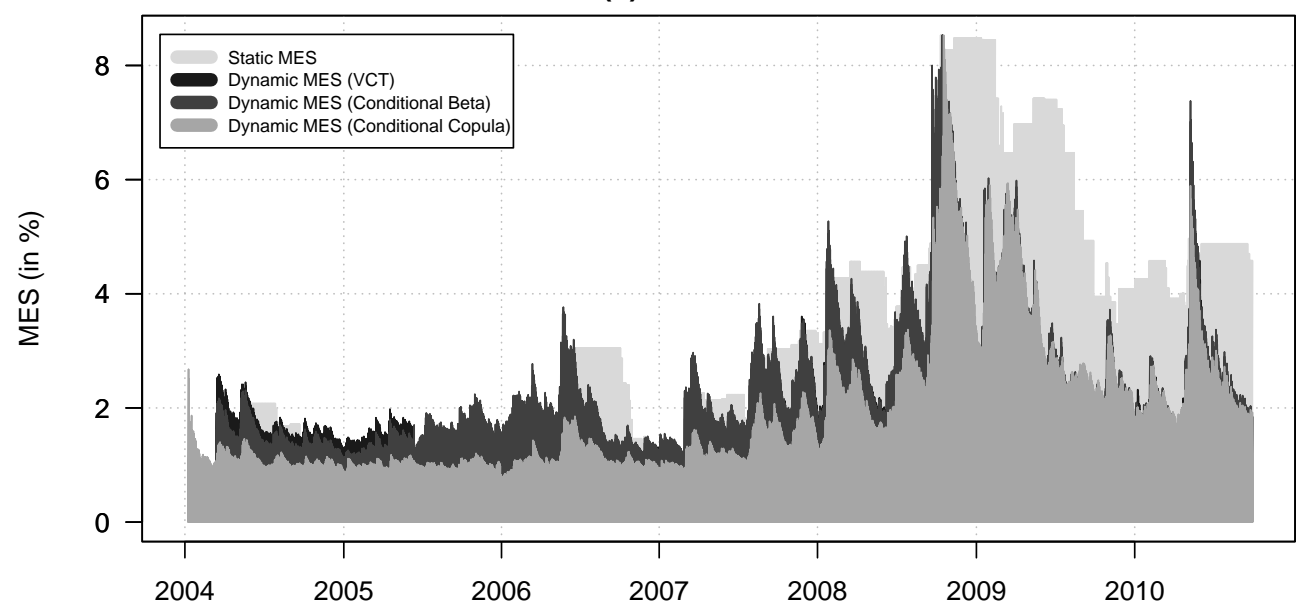

(b) CDS tail beta vs. static MES

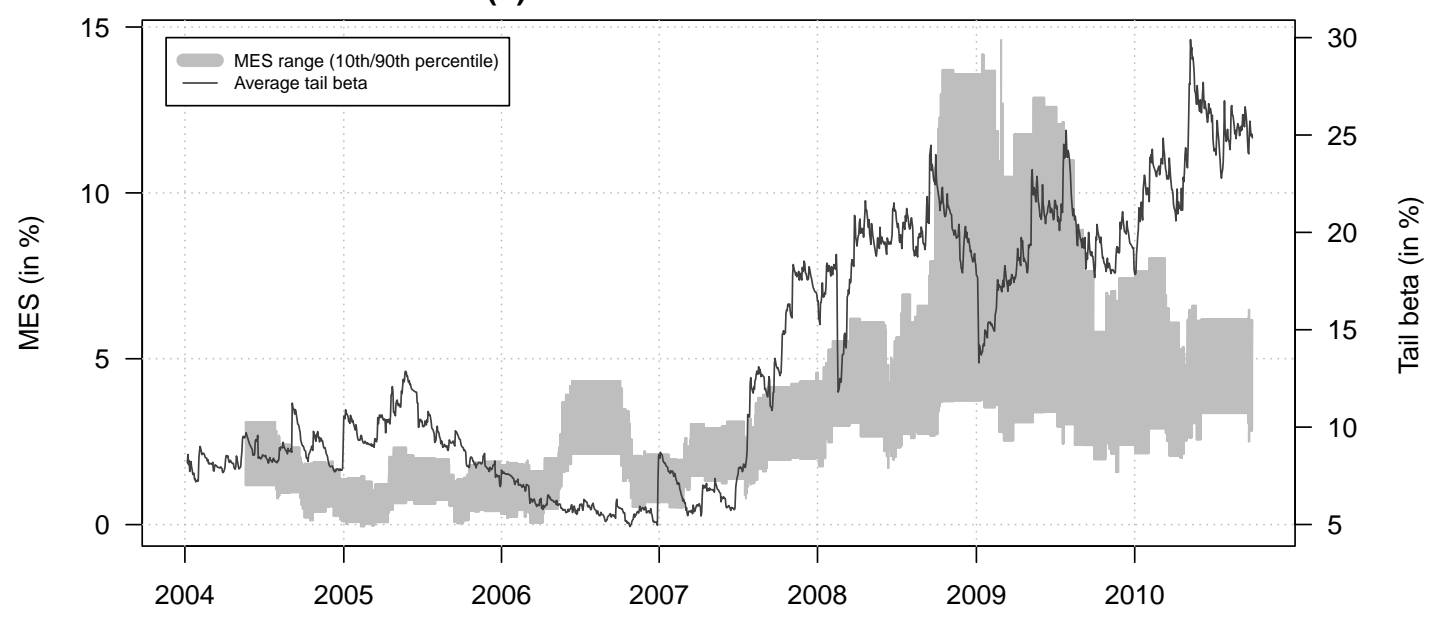


Figure 8: MES models and CDS tail beta (continued).

(c) CDS tail beta vs. dynamic MES (VCT)

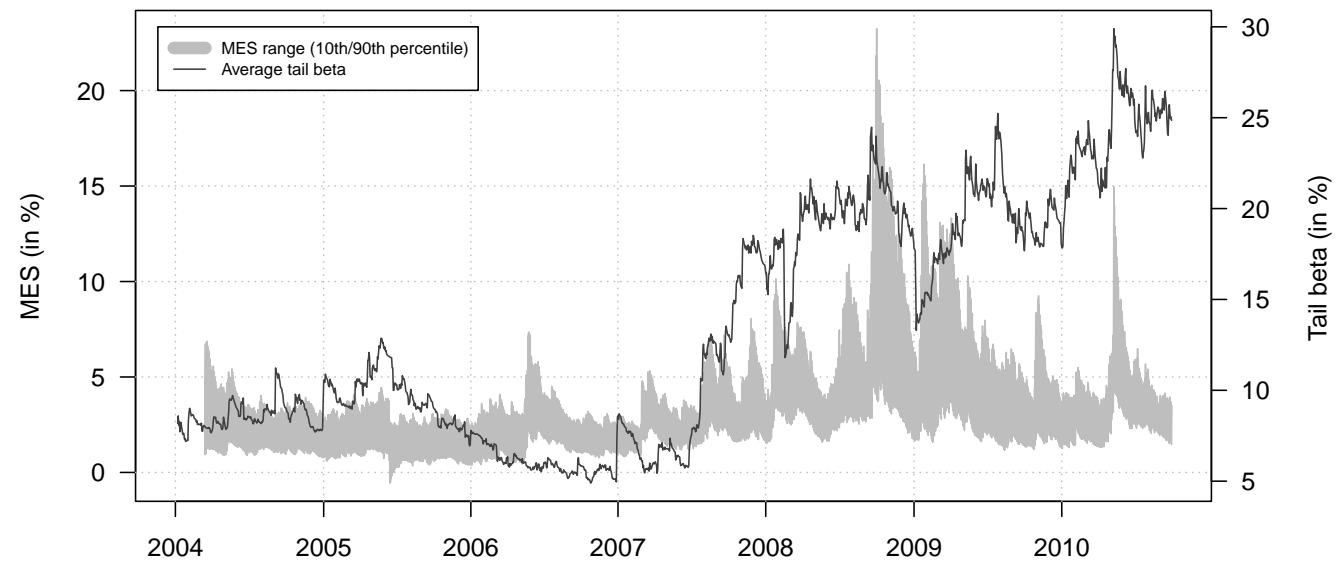

(d) CDS tail beta vs. dynamic MES (Conditional Beta)

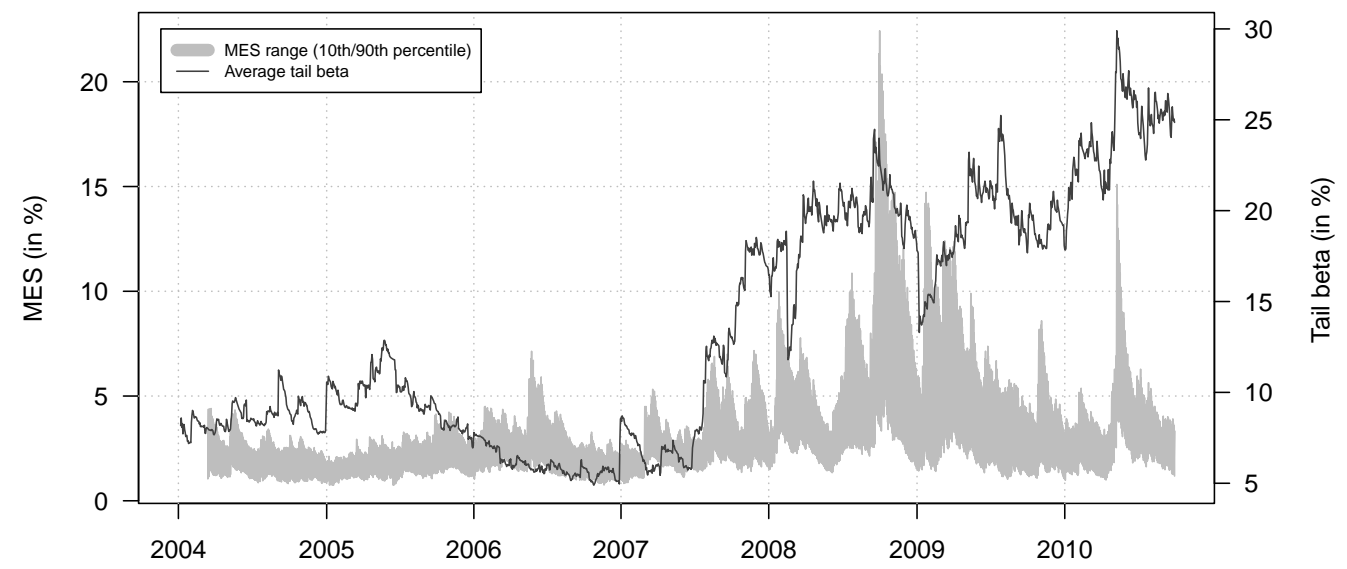

(e) CDS tail beta vs. dynamic MES (Conditional Copula)

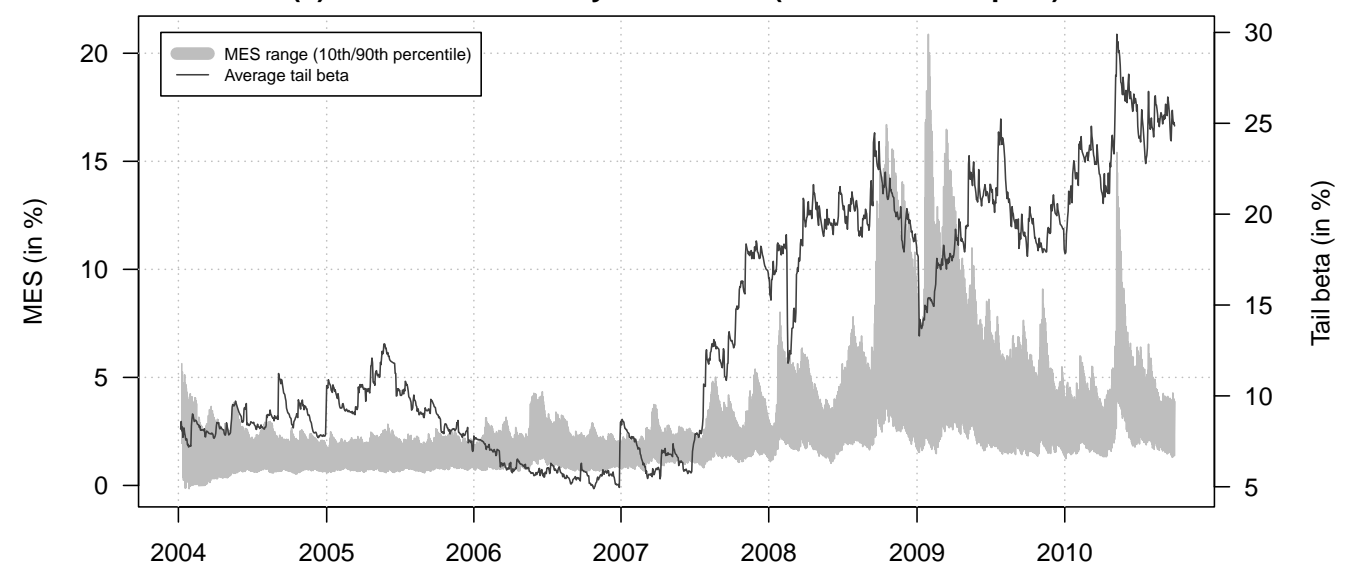




\section{Tables}


$\overrightarrow{0}$.

可

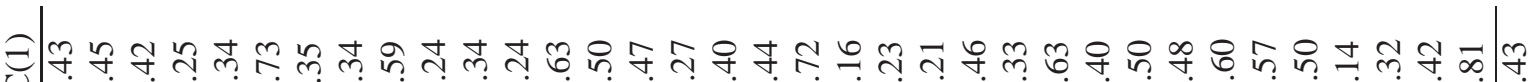
४ু 至 离

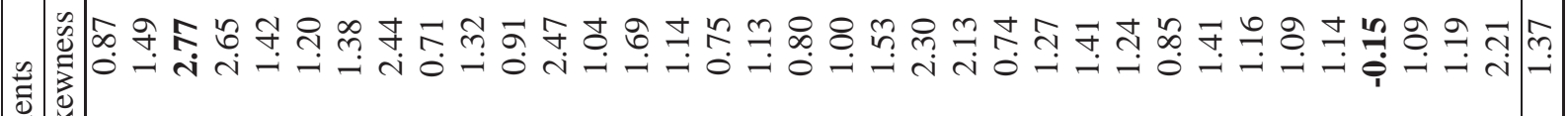

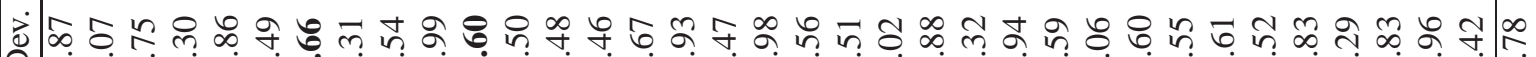

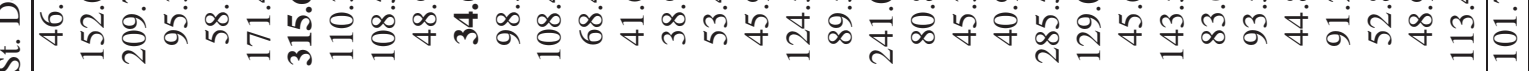

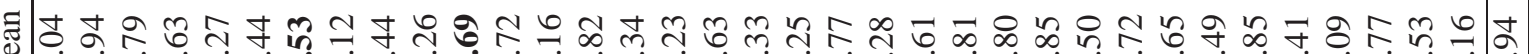

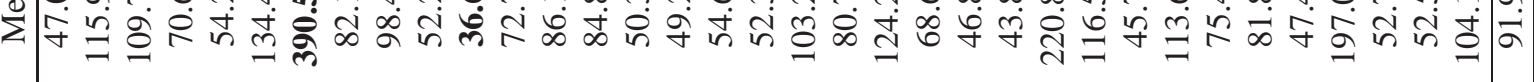

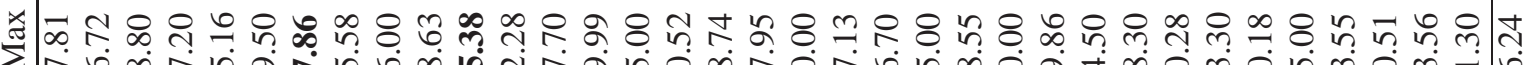

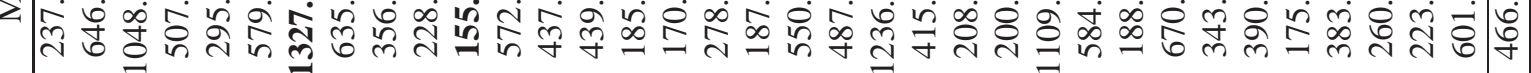
풍으

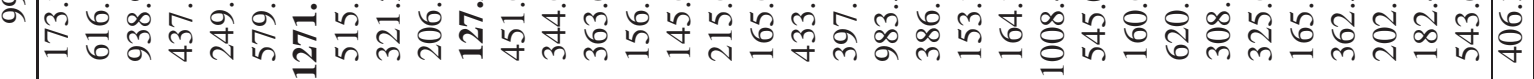
해

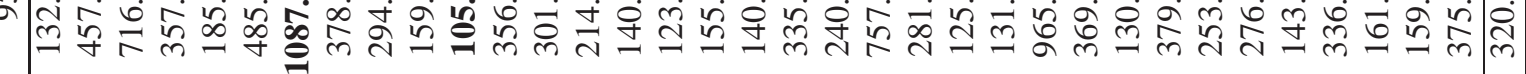
๒

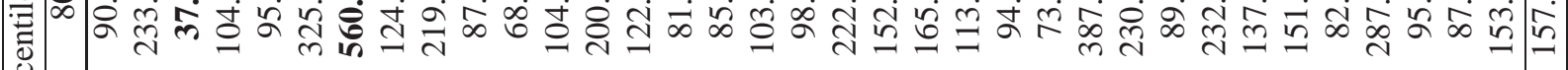
政 ฯ

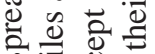

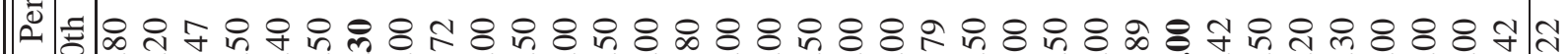
식

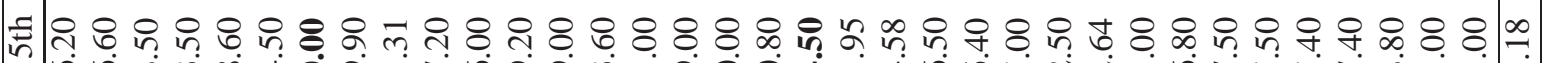
这. जे

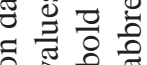
¿ $\Xi \Xi$

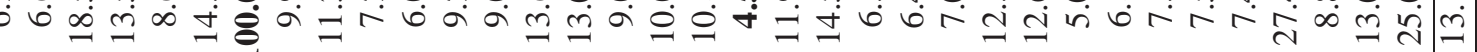

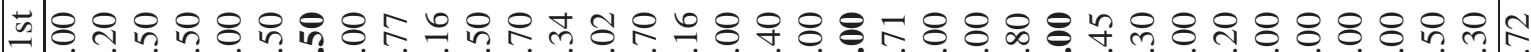

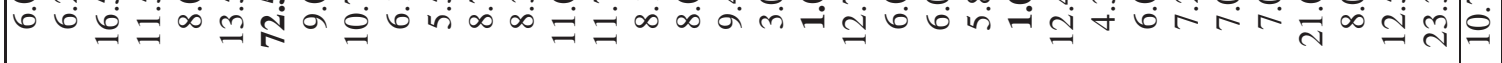

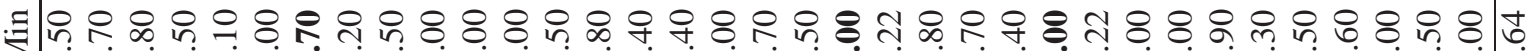

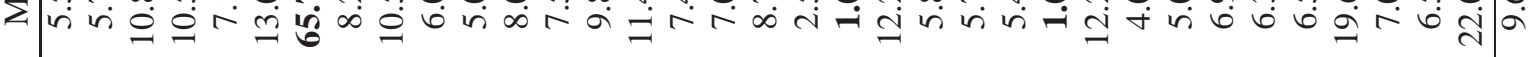

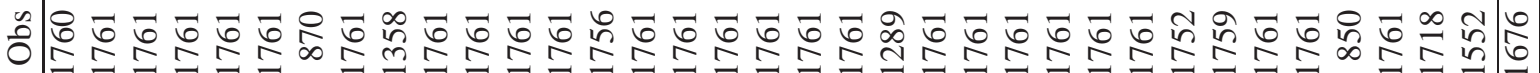

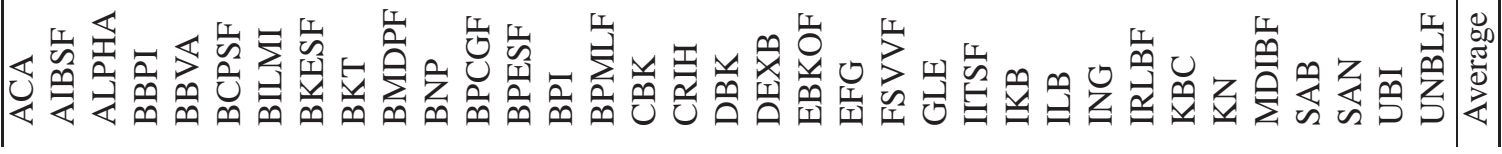


春

호의

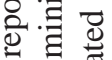

을

원

范

응

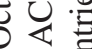

究

पे స

눙

룽

要要

츠응

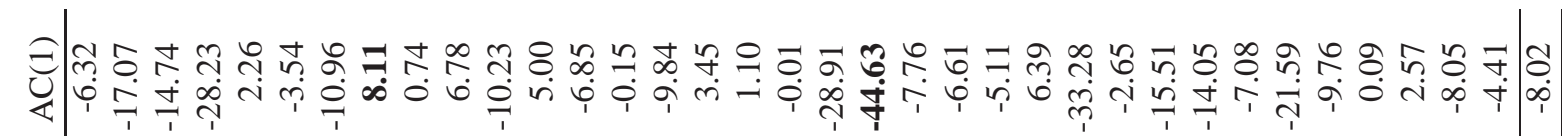

ظஷ

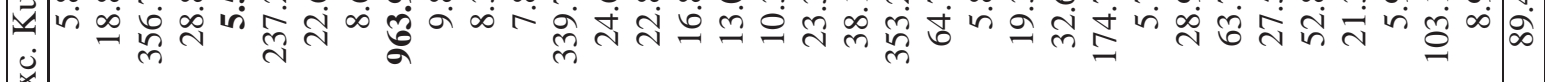
x

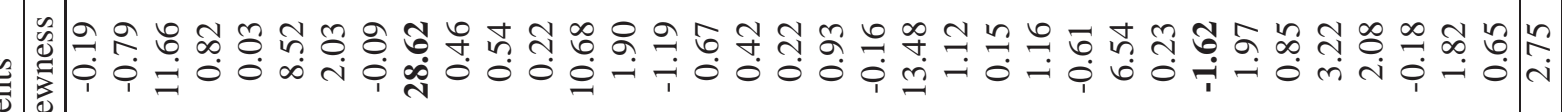

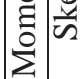

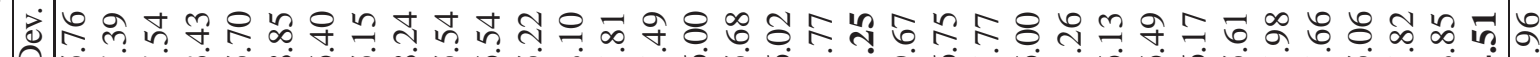

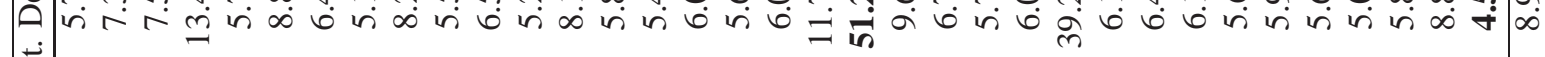
$\vec{n}$

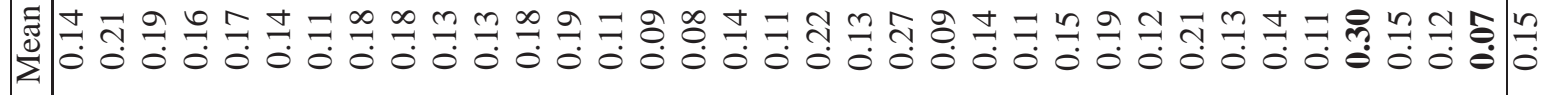

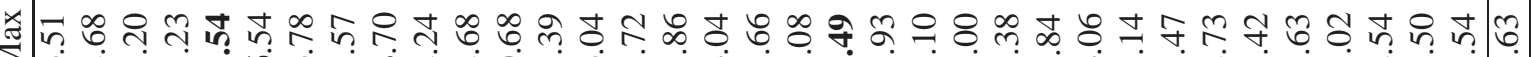

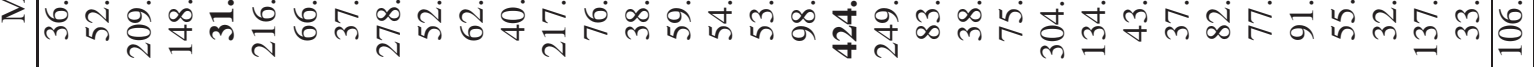

혜 엇

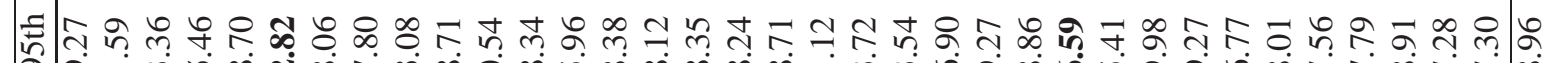

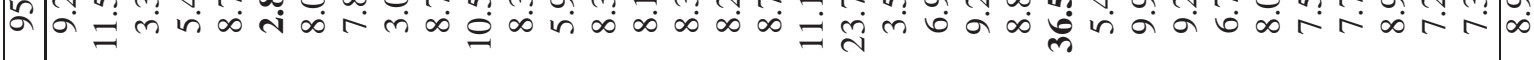

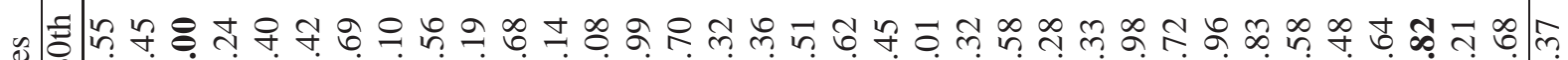

矛部央 صل

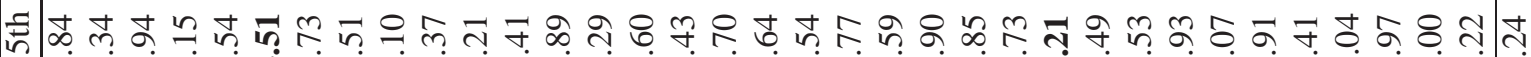

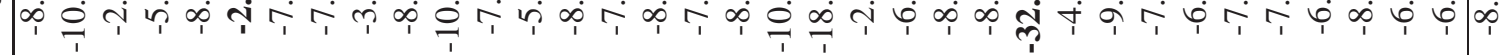

항ำ 국에

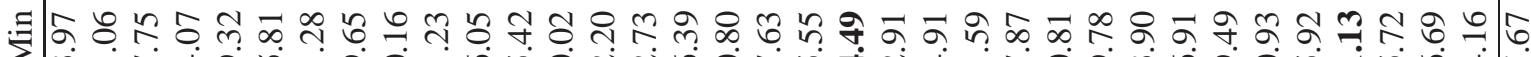
य क्षे क्ष के

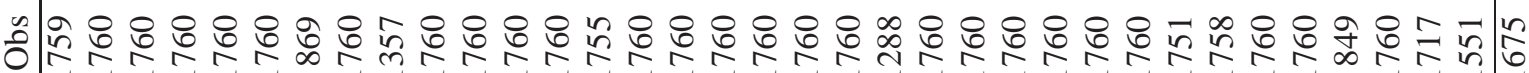

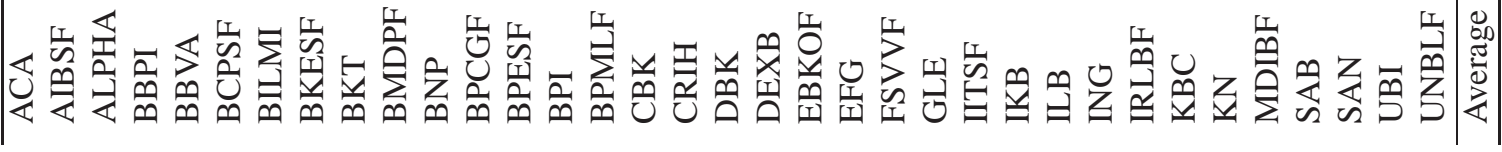




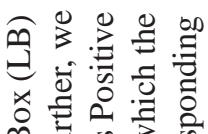

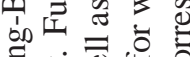
$\Xi$ ¿ ส \pm क 0 خ气山 छ ठี

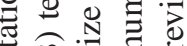
杄 थ ส 2 .

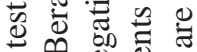
ص d I 过氙焉

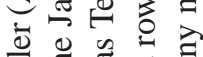

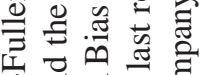
空 产的记

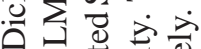
己 氖矛 ฮ్ర ह

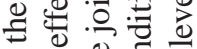
피웡 눙 $\stackrel{\Xi}{0}$ \& 0 $\stackrel{2}{2} \stackrel{\Xi}{0}$ 菏范的 $\dot{\Xi} \stackrel{\Xi}{\Xi}$

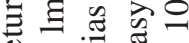

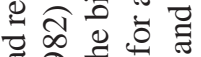
으 的 낭에 월 㖉语 त्र ส \&

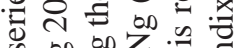

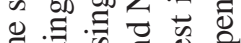

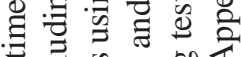
त की 0 की 4

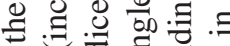
ธี ญ네 웡

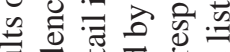
氙 응 ڤ 응으윷

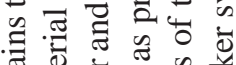

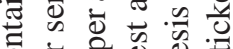
ธี

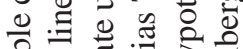
ज्ञै

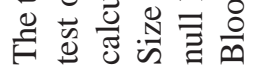

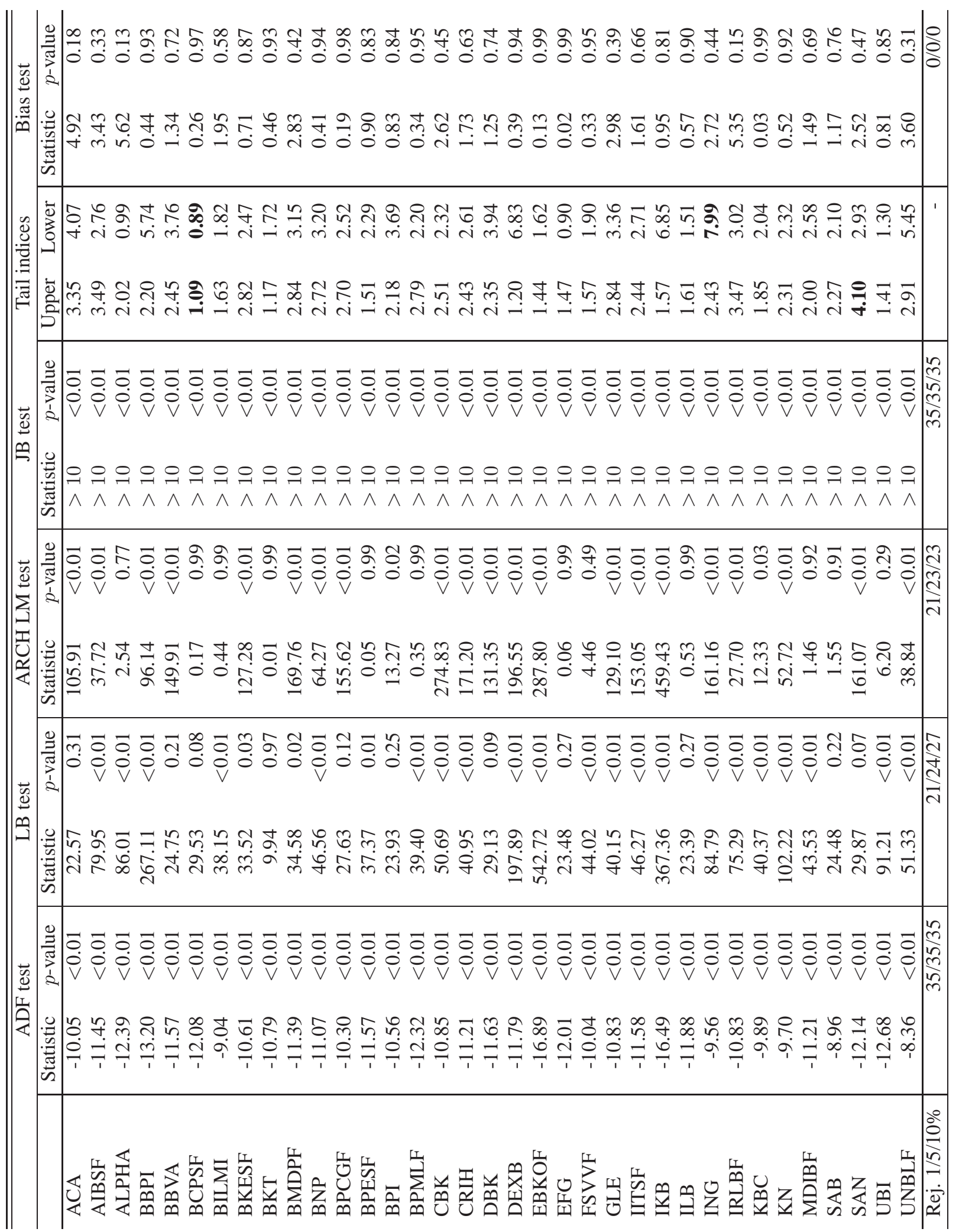




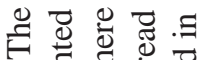

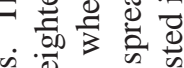

के के

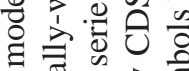

哥

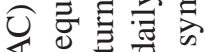

跑

ส

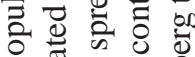

U

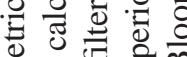

.

름ㄷㅇ

安等

눙

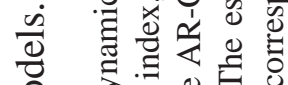

긍

๑

के

政

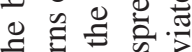

$\exists$ 舟

를 월

त व

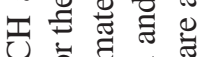

บ

过记

ए

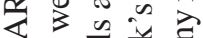

ฯ क षे है

늘

$\geq$ 呵

三䓃

\&

पै

田 $\dot{0} 0$

的表五

प

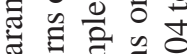

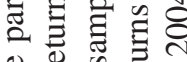

正

tᄒ

¿ के

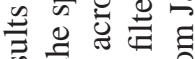

\%

홀

등 릉

플

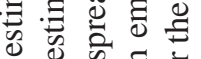

등 훙

正

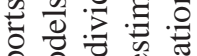

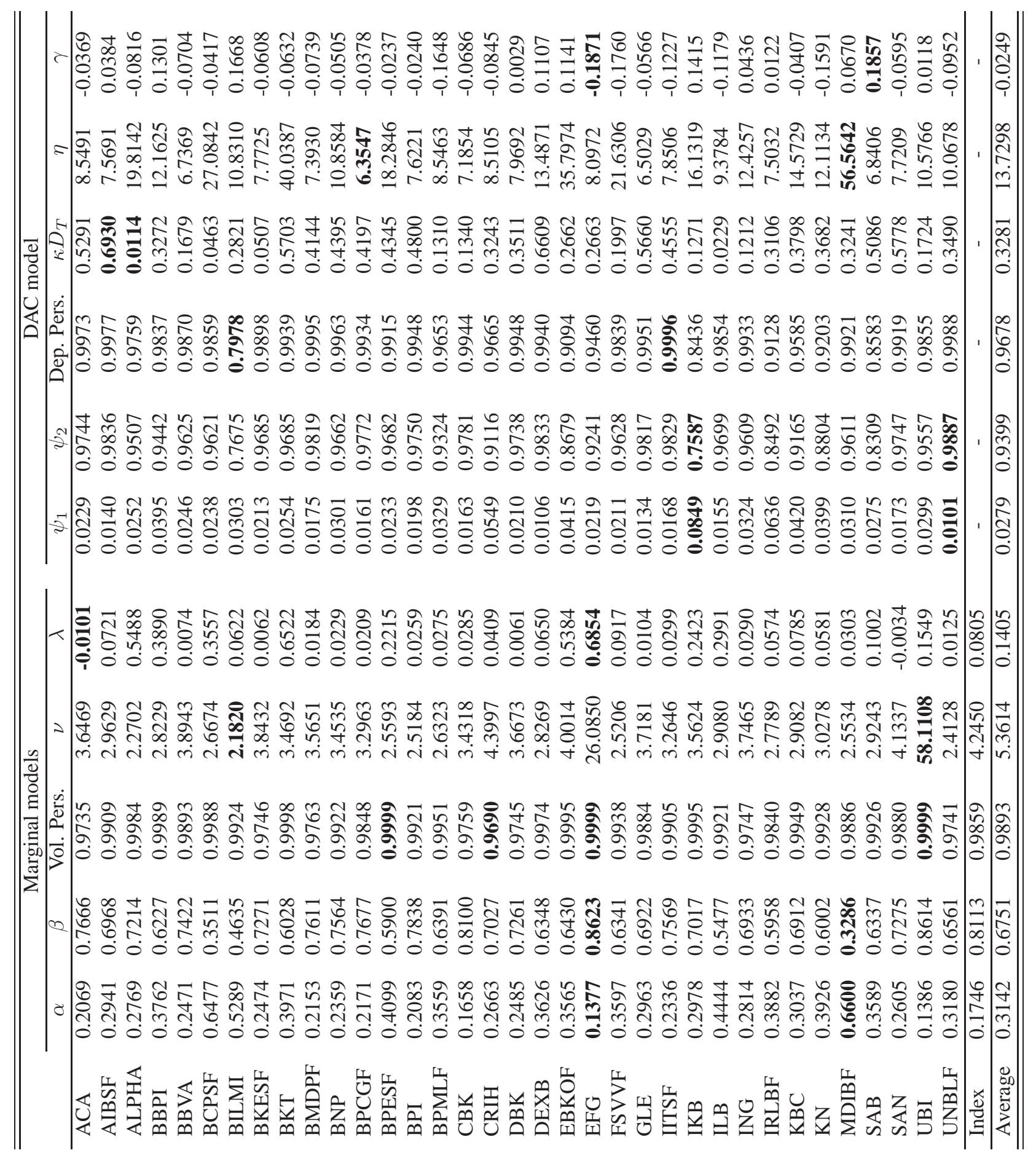

巳 $\Xi \stackrel{0}{0}$

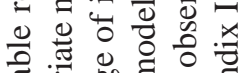

ज्ञ

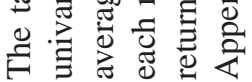




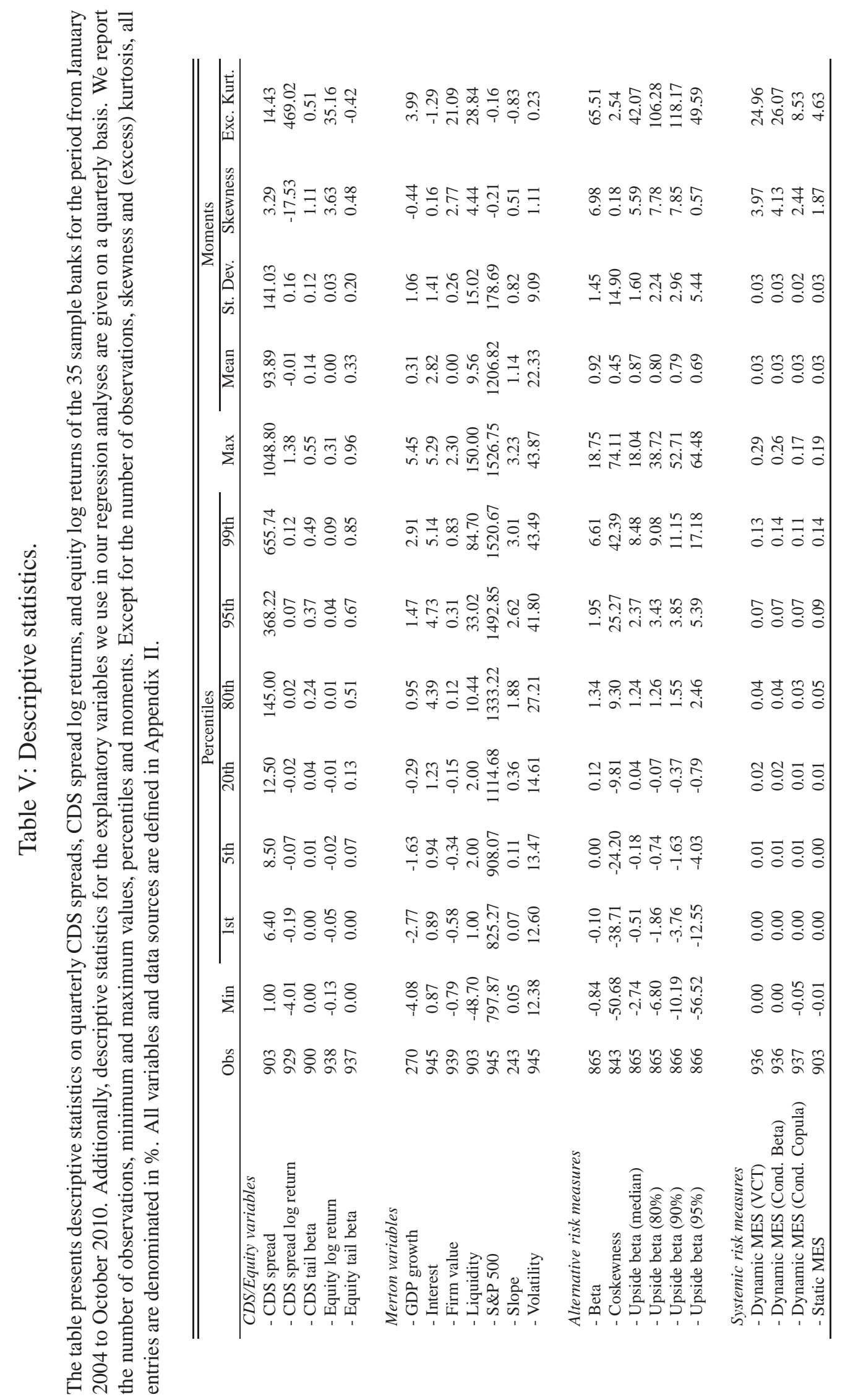




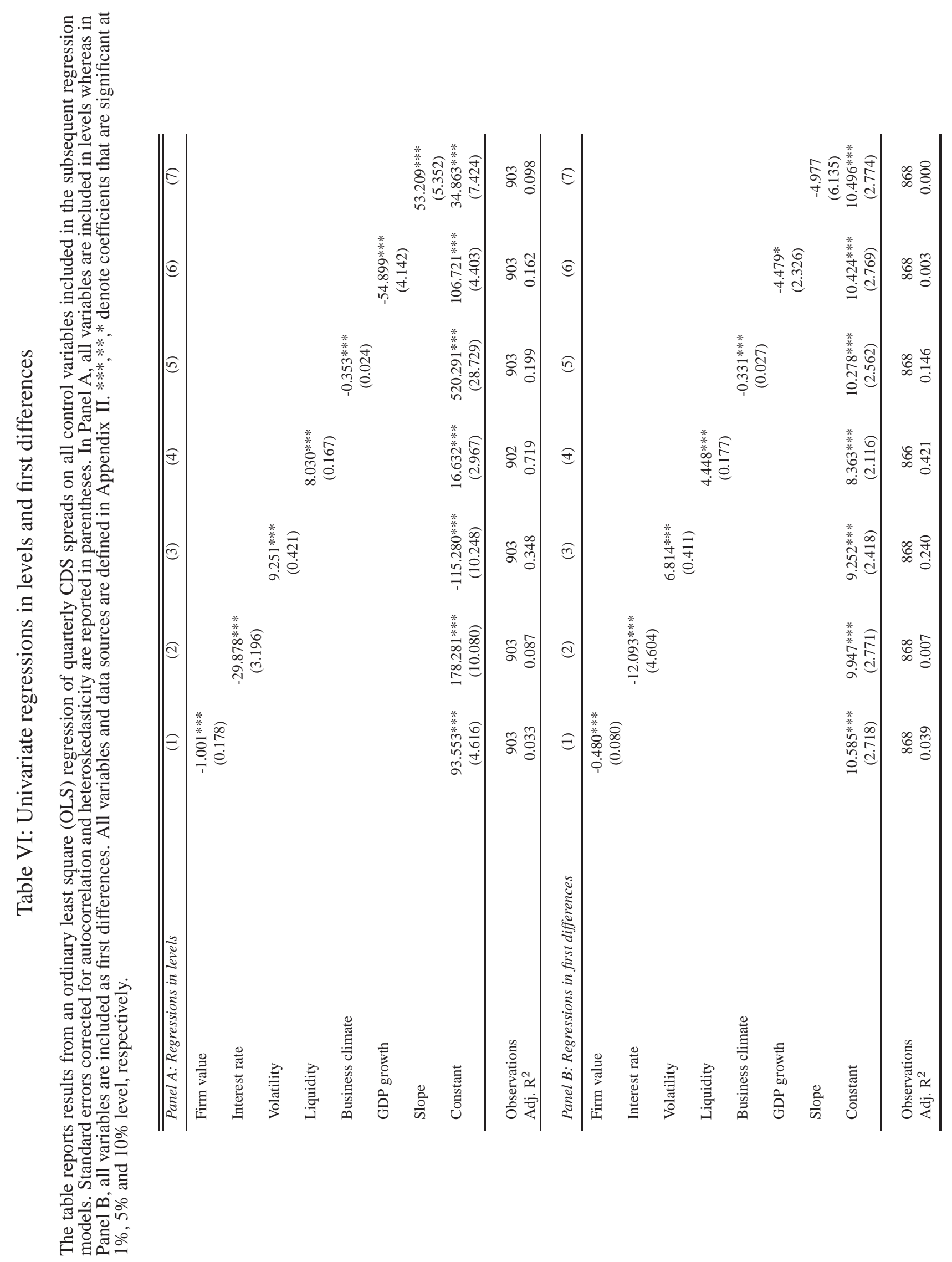




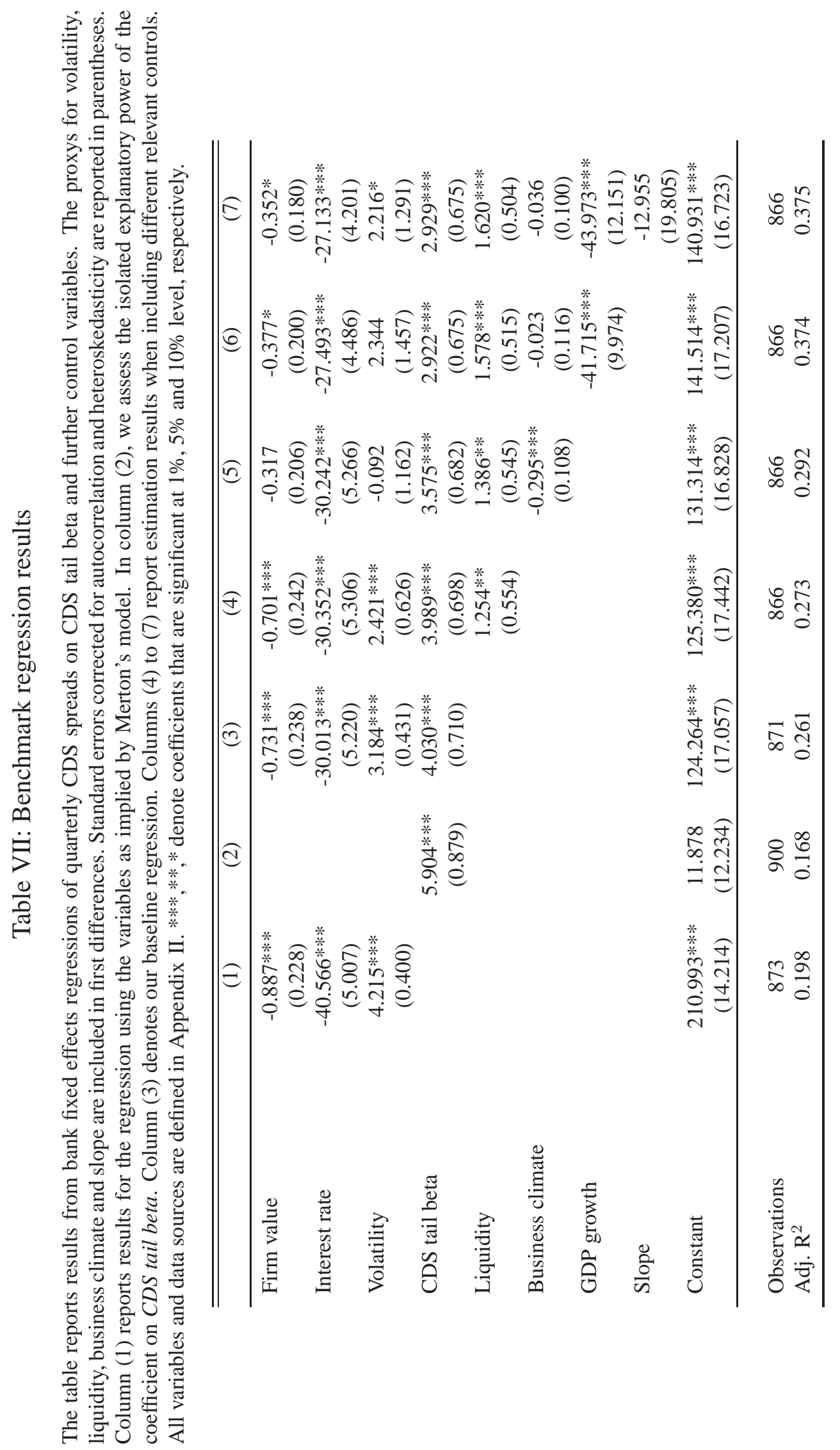




\section{Table VIII: Crisis vs. pre-crisis period}

The table reports results from a sub-sample analysis where we regress quarterly CDS spreads on CDS tail beta and on further control variables. The proxys for volatility, liquidity, business climate and slope are included in first differences. Standard errors corrected for autocorrelation and heteroskedasticity are reported in parentheses. Column (1) repeats our benchmark regression fom Tabel VII for the pre-crisis period lasting from Q1-2004 to Q2-2007. The commencement of the crisis is fixed to Q3 2007. Column two reports estimation results from the crsisi period, i.e. Q3-2007 to Q3-2010. All variables and data sources are defined in Appendix ஹ***,**, denote coefficients that are significant at $1 \%, 5 \%$ and $10 \%$ level, respectively.

\begin{tabular}{lcc}
\hline \hline & Pre-crisis & Crisis \\
\hline Firm value & -0.025 & -0.152 \\
& $(0.024)$ & $(0.166)$ \\
Interest rate & $-1.827^{* * *}$ & $-25.839^{* * *}$ \\
& $(0.513)$ & $(4.000)$ \\
Volatility & -0.060 & 2.189 \\
& $(0.131)$ & $(1.550)$ \\
CDS tail beta & 0.371 & $4.433^{* * *}$ \\
& $(0.245)$ & $(1.004)$ \\
Liquidity & 0.484 & $1.606^{* * *}$ \\
& $(0.312)$ & $(0.496)$ \\
Business climate & 0.000 & -0.011 \\
& $(0.004)$ & $(0.128)$ \\
GDP growth & 0.411 & $-49.719^{* * *}$ \\
& $(0.350)$ & $(16.821)$ \\
Slope & 0.177 & -32.117 \\
& $(0.411)$ & $(21.775)$ \\
Constant & $18.811^{* * *}$ & $137.958^{* * *}$ \\
& $(2.581)$ & $(22.662)$ \\
\hline \multirow{2}{*}{ Observations } & & \\
Adj. $\mathrm{R}^{2}$ & 413 & 453 \\
\hline
\end{tabular}


Table IX: Testing for the functional form of the relation between CDS spreads and CDS tail beta

The table reports results from a bank fixed effects regression of quarterly CDS spreads on CDS tail beta and further control variables. The proxys for volatility, liquidity, business climate and slope are included in first differences. Standard errors corrected for autocorrelation and heteroskedasticity are reported in parentheses. Column (1) reports results form our benchmark regression, this time including the squared term of CDS tail beta. In column (2) we assess the isolated explanatory power of the coefficient on Equity tail beta. Finally, Column (3) shows results results when including Equity tail beta as well as its squared term. All variables and data sources are defined in Appendix II $* * *, * *, *$ denote coefficients that are significant at $1 \%, 5 \%$ and $10 \%$ level, respectively.

\begin{tabular}{|c|c|c|c|c|}
\hline & 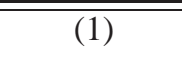 & 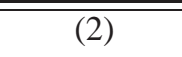 & 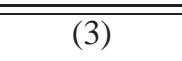 & $\overline{(4)}$ \\
\hline Firm value & $\begin{array}{l}-0.343^{*} \\
(0.179)\end{array}$ & $\begin{array}{c}-0.307^{*} \\
(0.169)\end{array}$ & $\begin{array}{l}-0.300^{*} \\
(0.168)\end{array}$ & $\begin{array}{c}-0.303 * \\
(0.169)\end{array}$ \\
\hline Interest rate & $\begin{array}{c}-25.116^{* * * *} \\
(4.068)\end{array}$ & $\begin{array}{c}-32.620 * * * \\
(4.296)\end{array}$ & $\begin{array}{c}-32.581 * * * \\
(4.357)\end{array}$ & $\begin{array}{c}-28.228 * * * \\
(4.234)\end{array}$ \\
\hline Volatility & $\begin{array}{l}2.308^{*} \\
(1.286)\end{array}$ & $\begin{array}{c}1.192 \\
(1.311)\end{array}$ & $\begin{array}{c}1.228 \\
(1.305)\end{array}$ & $\begin{array}{c}1.367 \\
(1.278)\end{array}$ \\
\hline CDS tail beta & $\begin{array}{c}7.956 * * * \\
(1.933)\end{array}$ & & & $\begin{array}{c}2.065^{* * * *} \\
(0.617)\end{array}$ \\
\hline$(\mathrm{CDS} \text { tail beta })^{2}$ & $\begin{array}{c}-11.165^{* * *} \\
(3.463)\end{array}$ & & & \\
\hline Equity tail beta & & $\begin{array}{c}4.155 * * * \\
(0.760)\end{array}$ & $\begin{array}{c}6.053 * * * \\
(2.052)\end{array}$ & $\begin{array}{c}3.015 * * * \\
(0.701)\end{array}$ \\
\hline (Equity tail beta) $^{2}$ & & & $\begin{array}{l}-0.024 \\
(0.019)\end{array}$ & \\
\hline Liquidity & $\begin{array}{c}1.522 * * * \\
(0.500)\end{array}$ & $\begin{array}{c}1.736 * * * \\
(0.496)\end{array}$ & $\begin{array}{c}1.733 * * * \\
(0.493)\end{array}$ & $\begin{array}{c}1.675^{* * * *} * \\
(0.500)\end{array}$ \\
\hline Business climate & $\begin{array}{l}-0.032 \\
(0.099)\end{array}$ & $\begin{array}{l}-0.090 \\
(0.100)\end{array}$ & $\begin{array}{l}-0.091 \\
(0.100)\end{array}$ & $\begin{array}{l}-0.056 \\
(0.098)\end{array}$ \\
\hline GDP growth & $\begin{array}{c}-42.001 * * * \\
(12.196)\end{array}$ & $\begin{array}{c}-47.533 * * * \\
(11.262)\end{array}$ & $\begin{array}{c}-47.464 * * * \\
(11.258)\end{array}$ & $\begin{array}{c}-45.005^{* * * *} \\
(11.838)\end{array}$ \\
\hline Slope & $\begin{array}{l}-12.969 \\
(19.528)\end{array}$ & $\begin{array}{l}-21.169 \\
(19.778)\end{array}$ & $\begin{array}{l}-21.111 \\
(19.705)\end{array}$ & $\begin{array}{l}-19.189 \\
(20.096)\end{array}$ \\
\hline Constant & $\begin{array}{c}102.294 * * * \\
(20.511)\end{array}$ & $\begin{array}{r}59.817 * * \\
(27.627) \\
\end{array}$ & $\begin{array}{c}32.877 \\
(43.898) \\
\end{array}$ & $\begin{array}{l}55.700^{*} \\
(28.557) \\
\end{array}$ \\
\hline $\begin{array}{l}\text { Observations } \\
\text { Adi } R^{2}\end{array}$ & $\begin{array}{c}866 \\
0387\end{array}$ & 866 & $\begin{array}{l}866 \\
0378\end{array}$ & 866 \\
\hline
\end{tabular}


Table X: Dependent portfolio sorts: CDS tail beta and alternative risk measures.

This table reports average daily CDS spreads double-sorted on CDS tail beta and realized regular beta (Panel A), realized upside beta (median, 80\%, 90\% and 95\%, Panels B-F), and realized coskewness (Panel G). In a first step, we rank the time series of CDS spread observations into quintiles (1-5) with respect to beta, upside beta, and coskewness, respectively, for each bank in the sample. Then, within each of these quintiles, we sort the corresponding CDS spreads by CDS tail beta resulting in a total of 875 quintiles. In the last step, we calculate the mean CDS spread for each quintile and finally average across all banks in the sample. The last row reports the difference between the average CDS spreads of the fifth and the first tail beta quintile for each beta, upside beta, and coskewness quintile with corresponding significance levels, where $t$-statistics are in parantheses and ${ }^{* * *},{ }^{* *}$, and ${ }^{*}$ indicate significance at the $1 \%, 5 \%$ and $10 \%$ significance level, respectively. CDS tail betas are simulated from the DAC model, realized betas, upside betas and coskewness are computed from rolling windows of 100 data points according to the definitions listed in Appendix ПI. To account for daily fluctuations, the double-sorts are based on smoothed versions of the original variables, obtained by applying a simple moving average filter with a lag of 20 trading days. The sample period contains daily data from January 2004 to October 2010 for 35 European banks.

Panel A: Beta $(\beta)$ vs. CDS tail beta.

\begin{tabular}{c|ccccc|c}
\hline \hline & 1 Low $\beta$ & 2 & 3 & 4 & 5 High $\beta$ & Average \\
\hline 1 Low tail beta & 55.43 & 44.10 & 54.39 & 70.00 & 109.99 & 66.78 \\
2 & 45.45 & 45.82 & 79.31 & 103.57 & 123.70 & 79.57 \\
3 & 44.12 & 51.79 & 94.77 & 150.65 & 132.42 & 94.75 \\
4 & 57.83 & 61.31 & 123.44 & 178.67 & 146.03 & 113.45 \\
5 High tail beta & 81.69 & 78.05 & 137.94 & 205.72 & 170.04 & 134.69 \\
\hline \multirow{2}{*}{ High - Low } & 26.25 & $33.96^{* * *}$ & $83.55^{* * *}$ & $135.73^{* * *}$ & $60.04^{* *}$ & \multirow{2}{*}{67.91} \\
& $(1.44)$ & $(4.21)$ & $(6.01)$ & $(4.99)$ & $(2.21)$ & \\
\hline
\end{tabular}

Panel B: Upside beta (50\%) vs. CDS tail beta.

\begin{tabular}{c|ccccc|c}
\hline \hline & 1 Low $\beta_{50 \%}^{+}$ & 2 & 3 & 4 & 5 High $\beta_{50 \%}^{+}$ & Average \\
\hline 1 Low tail beta & 47.57 & 49.58 & 43.99 & 59.40 & 81.83 & 56.47 \\
2 & 42.12 & 48.15 & 63.72 & 115.56 & 109.89 & 75.89 \\
3 & 46.57 & 42.07 & 96.93 & 130.83 & 147.37 & 92.75 \\
4 & 56.54 & 65.41 & 132.87 & 169.90 & 173.02 & 119.55 \\
5 High tail beta & 95.55 & 91.69 & 148.69 & 200.21 & 188.35 & 144.90 \\
\hline \multirow{2}{*}{ High - Low } & $47.98^{* *}$ & $42.11^{* *}$ & $104.70^{* * *}$ & $140.81^{* * *}$ & $106.52^{* * *}$ & \multirow{2}{*}{88.42} \\
& $(2.72)$ & $(2.44)$ & $(6.66)$ & $(5.66)$ & $(4.19)$ & \\
\hline
\end{tabular}


Panel D: Upside beta (80\%) vs. CDS tail beta.

\begin{tabular}{c|ccccc|c}
\hline \hline & 1 Low $\beta_{80 \%}^{+}$ & 2 & 3 & 4 & 5 High $\beta_{80 \%}^{+}$ & Average \\
\hline 1 Low tail beta & 44.01 & 62.28 & 48.99 & 47.81 & 56.61 & 51.94 \\
2 & 57.17 & 60.83 & 51.93 & 67.01 & 112.02 & 69.79 \\
3 & 69.30 & 82.09 & 68.97 & 119.82 & 145.61 & 97.16 \\
4 & 75.81 & 113.94 & 99.53 & 162.99 & 169.17 & 124.29 \\
& 110.96 & 133.52 & 149.65 & 203.22 & 167.26 & 152.92 \\
\hline H High tail beta & $66.96^{* * *}$ & $71.24^{* * *}$ & $100.66^{* * *}$ & $155.41^{* * *}$ & $110.66^{* * *}$ & \multirow{2}{*}{100.98} \\
\hline \multirow{2}{*}{ High - Low } & $(4.15)$ & $(3.11)$ & $(5.50)$ & $(6.25)$ & $(4.45)$ & \\
& & & & & & \\
\hline
\end{tabular}

Panel E: Upside beta (90\%) vs. CDS tail beta.

\begin{tabular}{c|ccccc|c}
\hline \hline & 1 Low $\beta_{90 \%}^{+}$ & 2 & 3 & 4 & 5 High $\beta_{90 \%}^{+}$ & Average \\
\hline 1 Low tail beta & 42.66 & 57.80 & 58.85 & 38.77 & 50.70 & 49.76 \\
2 & 69.41 & 67.24 & 64.11 & 50.66 & 91.79 & 68.64 \\
3 & 74.23 & 72.52 & 90.69 & 76.78 & 131.20 & 89.08 \\
4 & 130.63 & 118.90 & 116.13 & 115.40 & 167.24 & 129.66 \\
5 High tail beta & 150.63 & 145.29 & 143.88 & 161.02 & 184.67 & 157.10 \\
\hline \multirow{2}{*}{ High - Low } & $107.97^{* * *}$ & $87.48^{* * *}$ & $85.03^{* * *}$ & $122.25^{* * *}$ & $133.97^{* * *}$ & \multirow{2}{*}{107.34} \\
& $(5.75)$ & $(4.13)$ & $(3.54)$ & $(8.71)$ & $(4.56)$ & \\
\hline
\end{tabular}

Panel F: Upside beta (95\%) vs. CDS tail beta.

\begin{tabular}{c|ccccc|c}
\hline \hline & 1 Low $\beta_{95 \%}^{+}$ & 2 & 3 & 4 & 5 High $\beta_{95 \%}^{+}$ & Average \\
\hline 1 Low tail beta & 58.87 & 43.57 & 53.90 & 38.17 & 45.59 & 48.02 \\
2 & 76.42 & 49.45 & 59.09 & 56.07 & 62.80 & 60.77 \\
3 & 89.50 & 63.48 & 82.11 & 91.08 & 109.95 & 87.22 \\
4 & 125.21 & 96.26 & 131.52 & 133.61 & 176.27 & 132.58 \\
& 150.81 & 157.84 & 151.82 & 157.50 & 186.66 & 160.93 \\
\hline High tail beta & $91.94^{* * *}$ & $114.27^{* * *}$ & $97.92^{* * *}$ & $119.33^{* * *}$ & $141.07^{* * *}$ & \multirow{2}{*}{112.90} \\
\hline \multirow{2}{*}{ High - Low } & $(4.25)$ & $(6.43)$ & $(6.33)$ & $(6.66)$ & $(4.85)$ & \\
\hline
\end{tabular}

Panel G: Coskewness vs. CDS tail beta.

\begin{tabular}{c|ccccc|c}
\hline \hline & 1 Low coskew & 2 & 3 & 4 & 5 High coskew & Average \\
\hline 1 Low tail beta & 57.85 & 51.62 & 44.89 & 35.56 & 64.10 & 50.81 \\
2 & 97.42 & 85.64 & 37.24 & 44.45 & 55.26 & 64.00 \\
3 & 127.62 & 129.04 & 56.33 & 58.24 & 81.59 & 90.56 \\
4 & 180.40 & 136.78 & 102.40 & 118.68 & 134.57 & 134.56 \\
5 High tail beta & 221.70 & 144.38 & 133.46 & 156.24 & 181.25 & 167.41 \\
\hline \multirow{2}{*}{ High - Low } & $163.84^{* * *}$ & $92.76^{* * *}$ & $88.57^{* * *}$ & $120.68^{* * *}$ & $117.14^{* * *}$ & \multirow{2}{*}{116.60} \\
& $(5.19)$ & $(3.21)$ & $(6.39)$ & $(5.33)$ & $(5.02)$ & \\
\hline
\end{tabular}




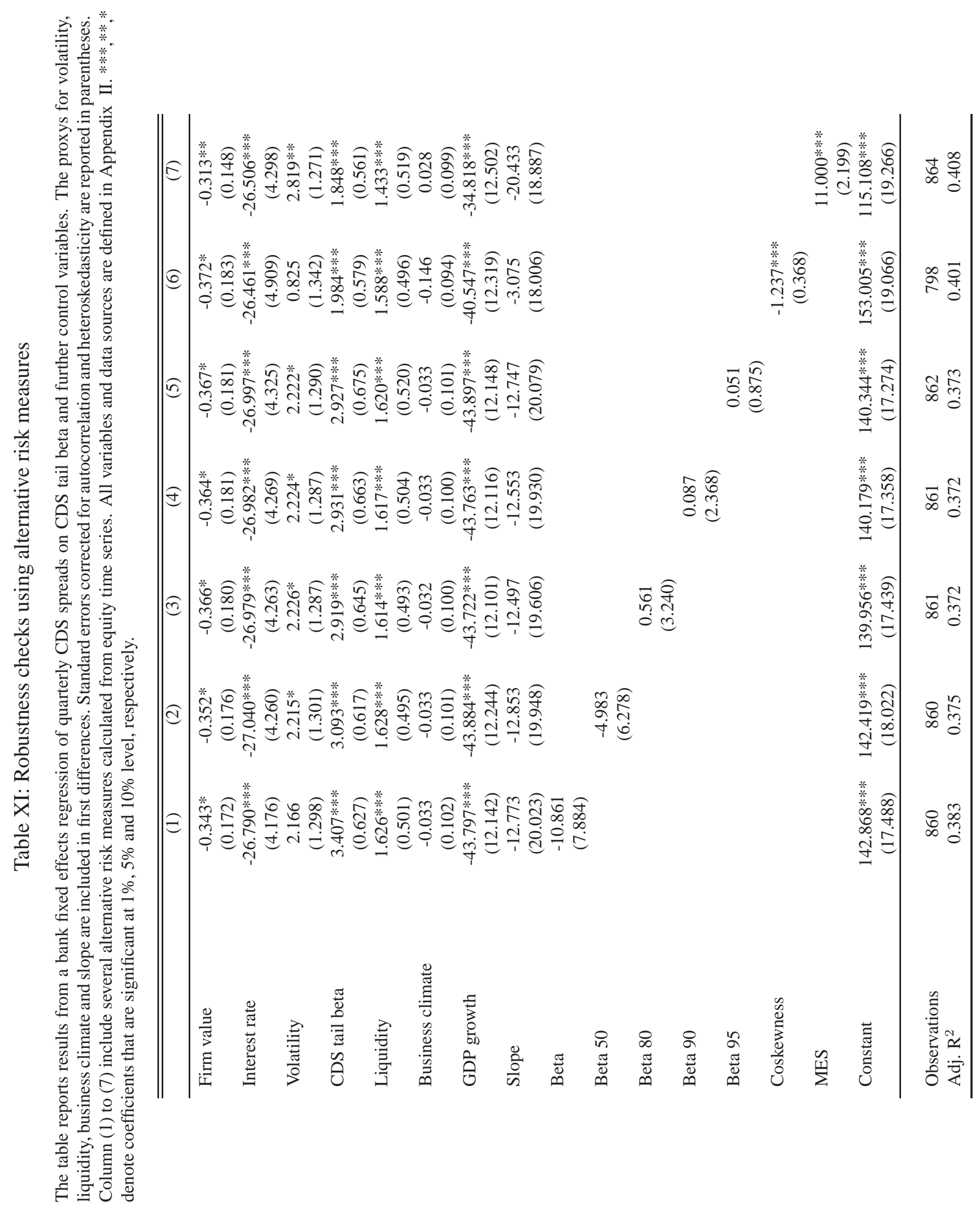


Table XII: Dependent portfolio sorts: CDS tail beta and equity MES.

This table reports average daily CDS spreads double-sorted on CDS tail beta and different specifications of Marginal Expected Shortfall (MES), respectively. In a first step, we rank the time series of CDS spread observations into quintiles (1-5) with respect to MES for each bank in the sample. Then, within each of these quintiles, we sort the corresponing CDS spreads by CDS tail beta resulting in a total of 875 quintiles. In the last step, we calculate the mean CDS spread for each quintile and finally average across all banks in the sample. The last row reports the difference between the average CDS spreads of the fifth and the first tail beta quintile for each MES quintile with corresponding significance levels, where $t$-statistics are in parantheses and ${ }^{* * *},{ }^{* *}$, and ${ }^{*}$ indicate significance at the $1 \%, 5 \%$ and $10 \%$ significance level, respectively. CDS tail betas are simulated from the DAC model, MES is calculated from alternative models including the static MES according to Acharya et al. (2010) as well as various dynamic model specifications proposed in Brownlees and Engle (2012). Static MES is computed non-parametrically from rolling windows of 100 data points, and the dynamic MES models include the VCT model, the Dynamic Conditional Beta model as well as the Dynamic Conditional Copula model that is based on Patton's (2006) dynamic $t$-copula (see Brownlees and Engle, 2012, for details). To account for daily fluctuations, the double-sorts are based on smoothed versions of the original variables, obtained by applying a simple moving average filter with a lag of 20 trading days. The sample period contains daily data from January 2004 to October 2010 for 35 European banks.

Panel A: CDS tail beta vs. static MES (Acharya et al., 2010).

\begin{tabular}{c|ccccc|c}
\hline \hline & 1 Low MES & 2 & 3 & 4 & 5 High MES & Average \\
\hline 1 Low tail beta & 23.03 & 21.16 & 29.44 & 93.85 & 173.03 & 68.10 \\
2 & 21.65 & 25.35 & 34.29 & 116.55 & 177.15 & 75.00 \\
3 & 21.05 & 36.31 & 51.48 & 143.23 & 195.85 & 89.58 \\
4 & 22.78 & 38.27 & 99.94 & 161.67 & 244.80 & 113.49 \\
5 High tail beta & 25.78 & 42.08 & 109.79 & 171.11 & 225.98 & 114.95 \\
\hline \multirow{2}{*}{ High - Low } & 2.75 & $20.92^{* * *}$ & $80.34^{* * *}$ & $77.26^{* * *}$ & 52.95 & 46.85 \\
& $(0.92)$ & $(3.47)$ & $(6.75)$ & $(4.76)$ & $(1.68)$ & \\
\hline
\end{tabular}

Panel B: CDS tail beta vs. dynamic MES (VCT; Brownlees and Engle, 2012).

\begin{tabular}{c|ccccc|c}
\hline \hline & 1 Low MES & 2 & 3 & 4 & 5 High MES & Average \\
\hline 1 Low tail beta & 38.28 & 25.93 & 37.46 & 65.87 & 107.39 & 54.99 \\
2 & 35.10 & 35.69 & 41.70 & 76.89 & 168.59 & 71.59 \\
3 & 46.88 & 44.85 & 55.80 & 118.42 & 181.69 & 89.53 \\
4 & 49.89 & 71.75 & 113.45 & 154.18 & 188.50 & 115.55 \\
5 High tail beta & 59.05 & 87.18 & 138.68 & 169.25 & 227.19 & 136.27 \\
\hline \multirow{2}{*}{ High - Low } & $20.77^{*}$ & $61.25^{* * *}$ & $101.22^{* * *}$ & $103.38^{* * *}$ & $119.80^{* * *}$ & \multirow{2}{*}{81.28} \\
& $(2.03)$ & $(5.35)$ & $(8.23)$ & $(4.48)$ & $(4.28)$ & \\
\hline
\end{tabular}


Panel C: CDS tail beta vs. dynamic MES (Conditional Beta; Brownlees and Engle, 2012).

\begin{tabular}{c|ccccc|c}
\hline \hline & 1 Low MES & 2 & 3 & 4 & 5 High MES & Average \\
\hline 1 Low tail beta & 26.15 & 33.24 & 37.92 & 58.03 & 115.84 & 54.24 \\
2 & 33.29 & 39.57 & 35.26 & 72.39 & 165.09 & 69.12 \\
3 & 47.00 & 51.42 & 53.55 & 113.34 & 175.37 & 88.14 \\
4 & 63.09 & 52.89 & 108.53 & 129.68 & 212.67 & 113.37 \\
5 High tail beta & 75.46 & 84.81 & 146.15 & 162.14 & 228.19 & 139.35 \\
\hline \multirow{2}{*}{ High - Low } & $49.32^{* * *}$ & $51.57^{* * *}$ & $108.23^{* * *}$ & $104.11^{* * *}$ & $112.35^{* * *}$ & \multirow{2}{*}{85.11} \\
& $(2.83)$ & $(4.62)$ & $(8.46)$ & $(4.12)$ & $(3.70)$ & \\
\hline
\end{tabular}

Panel D: CDS tail beta vs. dynamic MES (Conditional Copula; Brownlees and Engle, 2012).

\begin{tabular}{c|ccccc|c}
\hline \hline & 1 Low MES & 2 & 3 & 4 & 5 High MES & Average \\
\hline 1 Low tail beta & 19.74 & 17.33 & 38.87 & 83.34 & 172.20 & 66.29 \\
2 & 21.06 & 21.17 & 35.13 & 106.82 & 185.97 & 74.03 \\
3 & 21.26 & 24.57 & 55.63 & 145.43 & 198.25 & 89.03 \\
4 & 20.21 & 30.14 & 70.85 & 161.01 & 216.93 & 99.83 \\
5 High tail beta & 24.39 & 38.91 & 104.33 & 167.42 & 234.07 & 113.82 \\
\hline \multirow{2}{*}{ High - Low } & $4.65^{* * *}$ & $21.58^{* * *}$ & $65.46^{* * *}$ & $84.08^{* * *}$ & $61.87^{*}$ & \multirow{2}{*}{47.53} \\
& $(2.76)$ & $(4.63)$ & $(3.87)$ & $(4.22)$ & $(1.71)$ & \\
\hline
\end{tabular}




\section{Internet Appendix to "Is Tail Risk Priced in Credit Default Swap \\ Premia?"*}

This Internet Appendix contains several additional Figures and Tables that present the results of further analyses and robustness checks.

*Authors: Christian Meine, Ruhr-University Bochum; Hendrik Supper, TU Dortmund University; Gregor N.F. Weiß, TU Dortmund University. 
Figure IA.1: Cross-country copula correlations and CDS tail betas.

The panels of this figure show the time evolution of average daily copula correlations and CDS tail betas as well as their quarterly cumulations for each country included in the sample. The sample period contains daily data from January 2004 to October 2010 and the average is taken across all banks in a specific country. The banks included in the sample cover the following European countries: Austria, Belgium, France, Germany, Greece, Ireland, Italy, Netherlands, Portugal, Spain. In the panels on the left-hand side, the dark-gray lines refer to average daily CDS tail betas, the lightgray lines depict average daily copula correlations. Analogously, in the right-hand side panels the dark-gray bars refer to quarterly cumulative CDS tail betas, whereas the light-gray bars illustrate quarterly cumulative copula correlations. Copula correlations and CDS tail betas are estimated from the Dynamic Asymmetric Copula (DAC) model, where the tail betas are approximated by numerical integration using $\xi=0.001$ (see Christoffersen et al., 2012, for details).

\section{Austria}
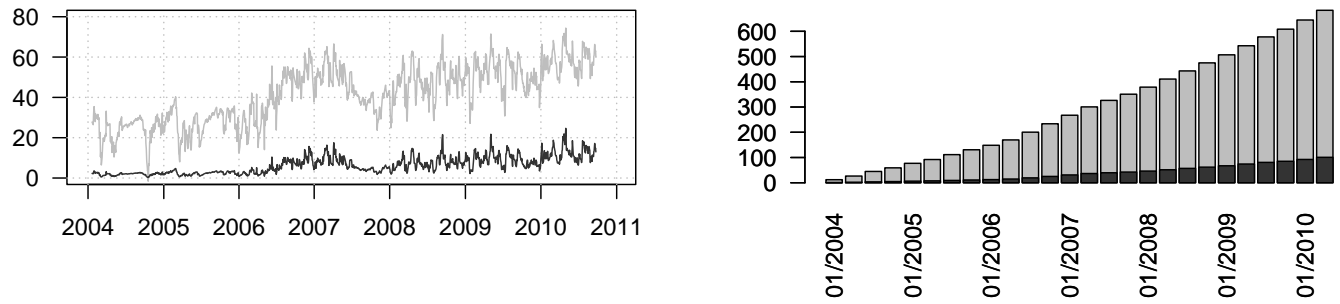

\section{Belgium}
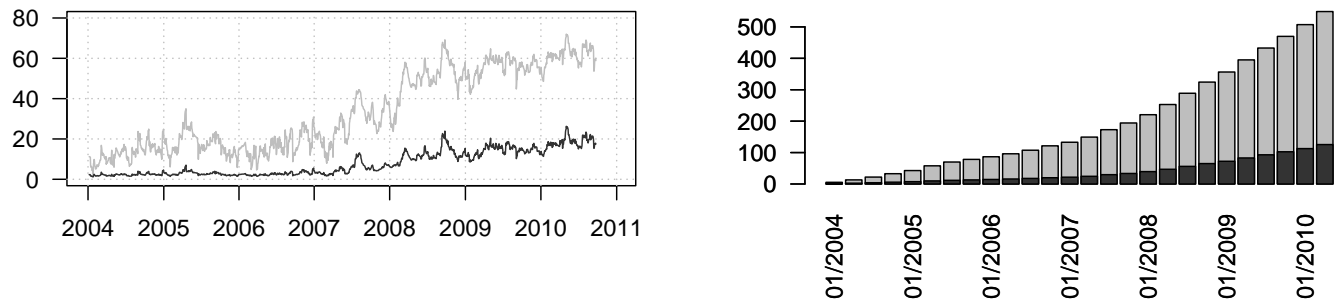

\section{France}
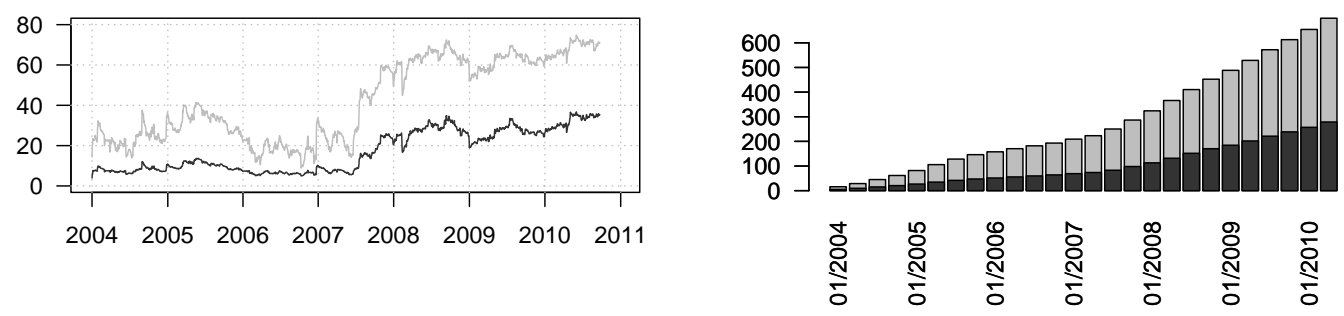
Figure IA.1: Cross-country copula correlations and CDS tail betas (continued).

\section{Germany}
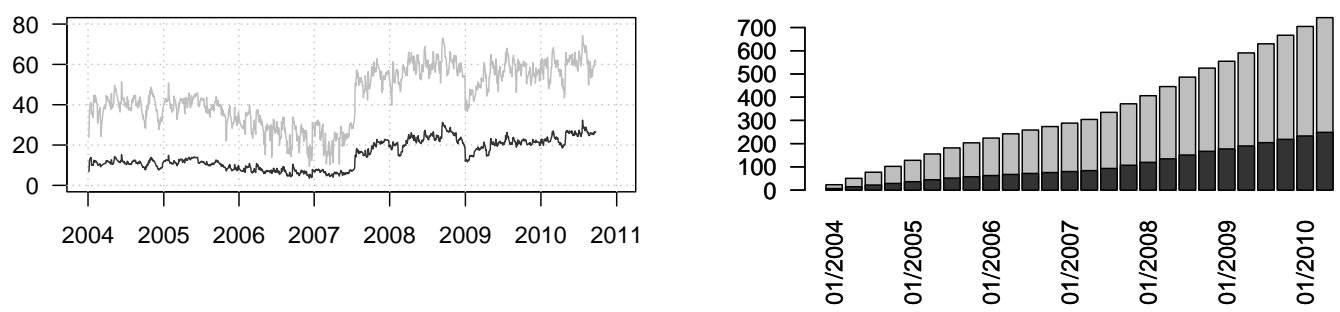

\section{Greece}
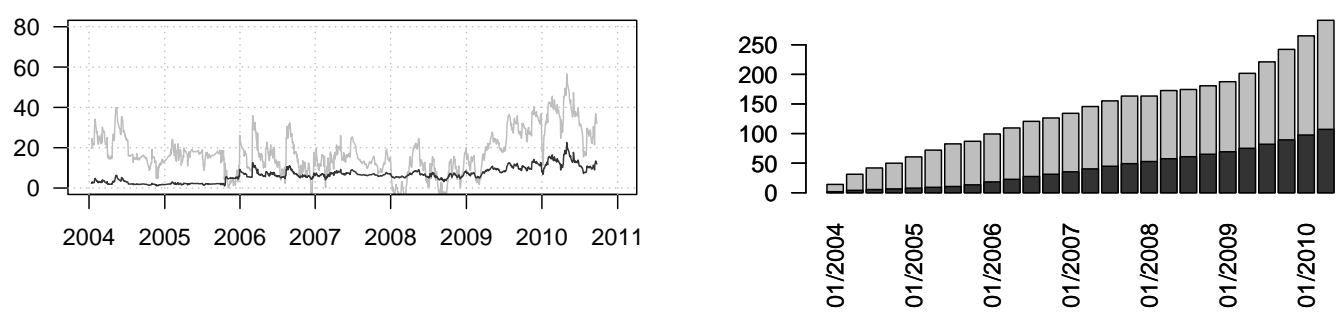

\section{Ireland}
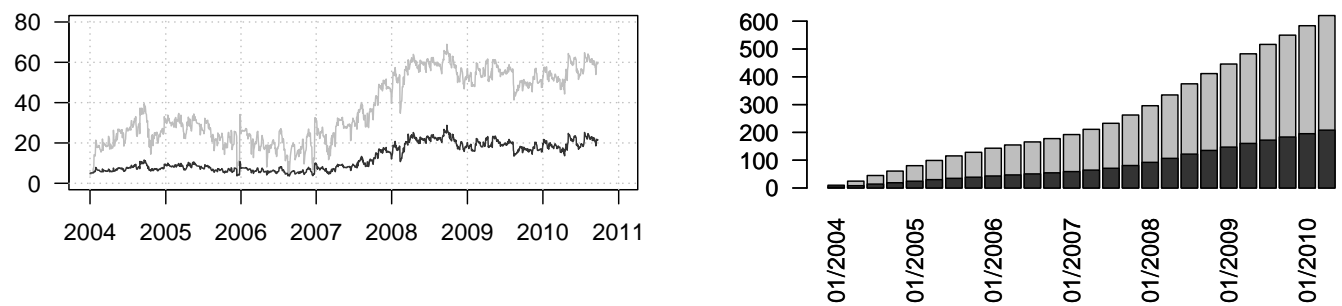

Italy
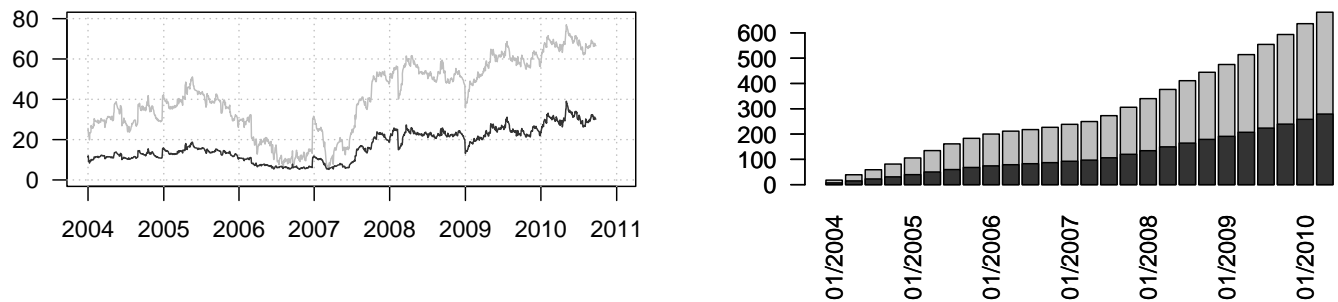
Figure IA.1: Cross-country copula correlations and CDS tail betas (continued).

\section{Netherlands}
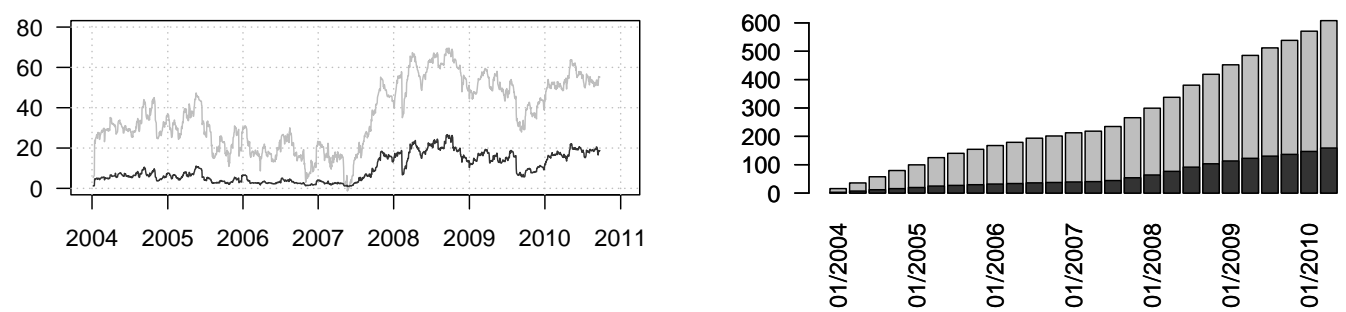

\section{Portugal}
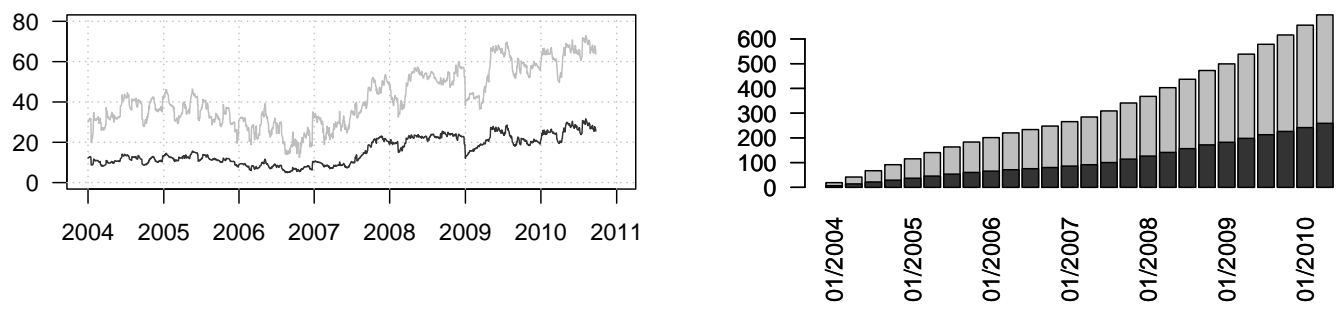

\section{Spain}
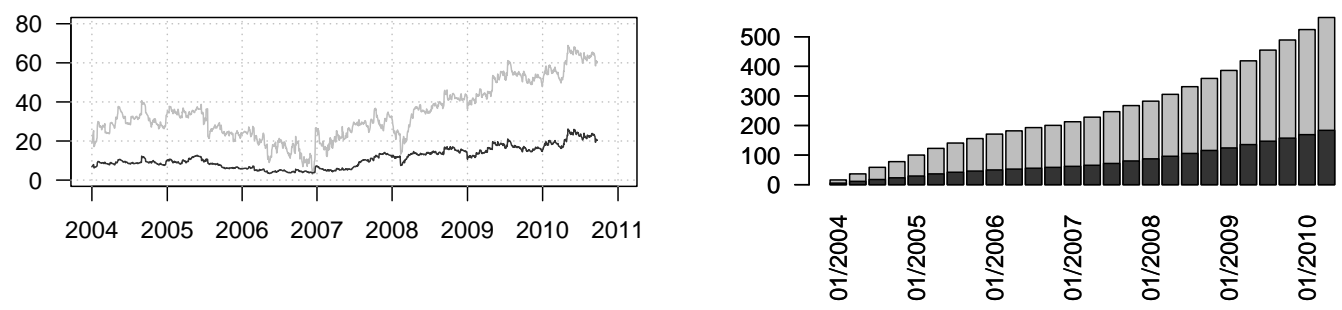

$$
\begin{aligned}
& \text { Average daily tail betas (in \%) } \\
& \text { Average daily copula correlations (in \%) }
\end{aligned}
$$




\section{Figure IA.2: Scatter plots of CDS premia against CDS tail risk/liquidity/firm value.}

The figure shows scatter plots of the credit default swap premia of banks against the banks' CDS tail betas, CDS liquidity, and changes in firm value. CDS tail betas are estimated from the Dynamic Asymmetric Copula (DAC) model, where the tail betas are approximated by numerical integration using $\xi=0.001$ (see Christoffersen et al. 2012, for details). Liquidity is measured by bid-ask spreads, and changes in firm value are proxied by arithmetic stock returns. Variable definitions and data sources are provided in Appendix 凹. The sample consists of 902 bank-quarters.

(a) CDS tail beta predicts CDS premia

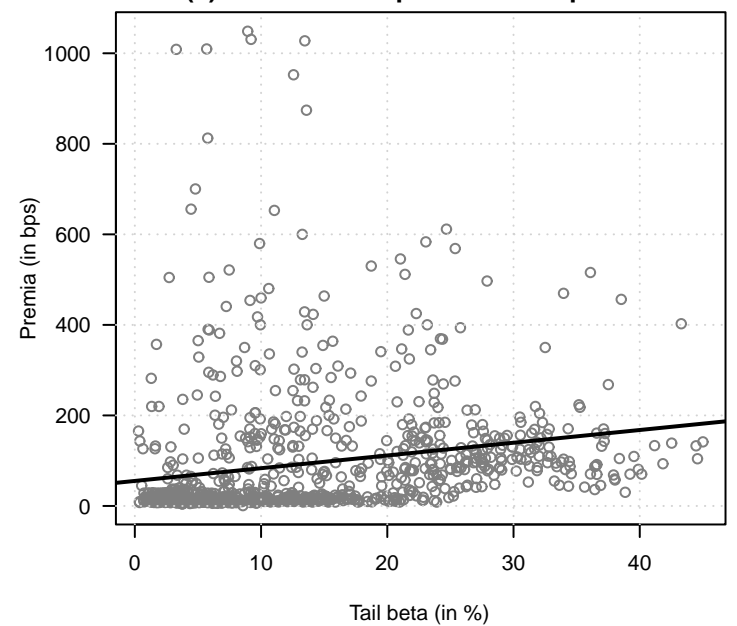

(b) Liquidity predicts CDS premia

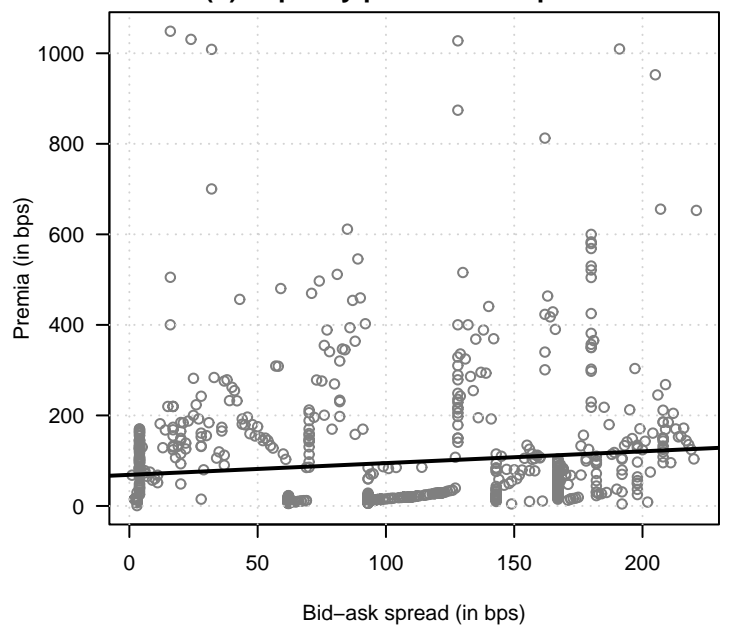

(c) Changes in firm value predict CDS premia

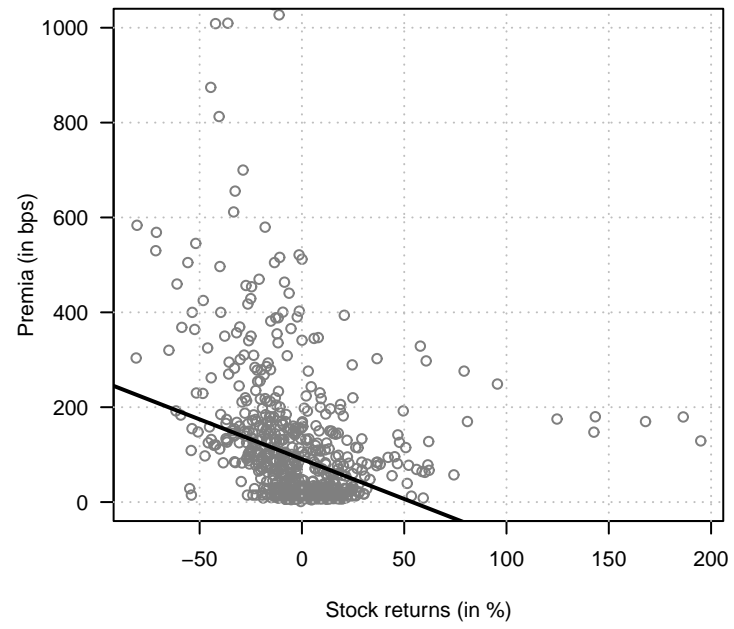


春

늘.

은 专 氖

을

○

궁

宁言

ठํำ

○ స

ป ฮ

ᄋㅇํ요

त 월

胥经 


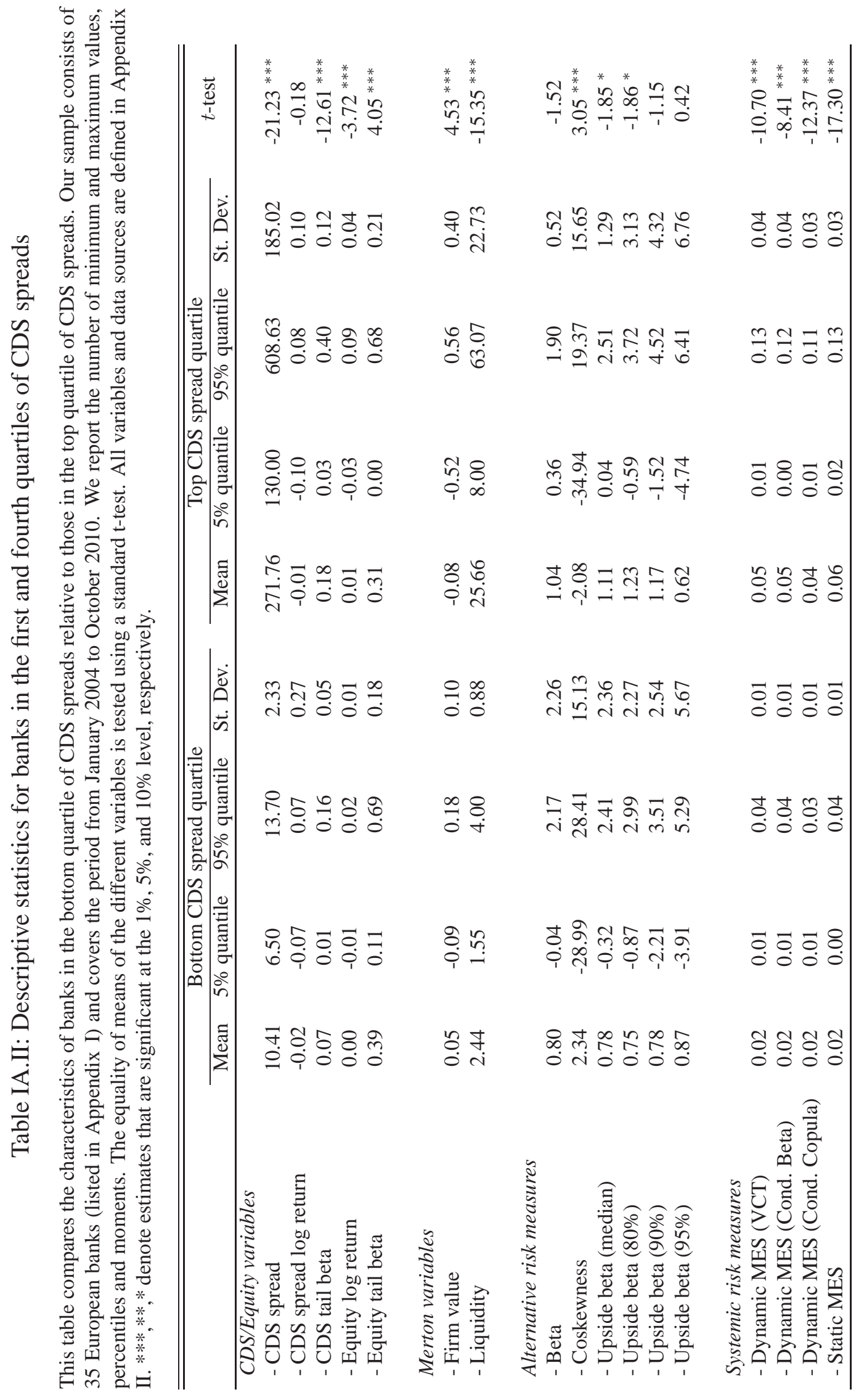


Table IA.III: Univariate sorts.

This table reports average daily CDS spreads sorted by CDS tail beta. For each bank in the sample, we rank the time series of CDS spread observations into quintiles (1-5) with respect to realized CDS tail beta and compute the average spread for each tail beta quintile. CDS tail betas are simulated from the DAC model, where the tail betas are approximated by numerical integration using $\xi=0.001$ (see Christoffersen et al., 2012, for details). To account for daily fluctuations, the univariate CDS spread sortings are based on a smoothed version of the CDS tail beta estimates, which is calculated by applying a simple moving average filter with a lag of 20 trading days to the original tail beta estimates. The last column of the table reports the difference between the average CDS spread of the fifth and the first tail beta quintile, whereas the last column calculates the average spread for each tail beta quintile across all 35 sample banks, with the $t$-statistic of the $t$-test on the average high-low difference in parantheses and with significance at the $1 \%, 5 \%$ and $10 \%$ being indicated by ${ }^{* * *},{ }^{* *}$, and ${ }^{*}$, respectively. The sample period contains daily data from January 2004 to October 2010 for 35 European banks. Company names are abbreviated by their corresponding Bloomberg ticker symbols listed in Appendix [

\begin{tabular}{|c|c|c|c|c|c|c|}
\hline & \multicolumn{5}{|c|}{ Average quintile spreads } & \multirow[b]{2}{*}{ High - Low } \\
\hline & 1 Low tail beta & 2 & 3 & 4 & 5 High tail beta & \\
\hline ACA & 8.10 & 9.58 & 29.53 & 85.54 & 104.77 & 96.67 \\
\hline AIBSF & 9.29 & 10.07 & 41.22 & 260.54 & 265.37 & 256.07 \\
\hline ALPHA & 27.11 & 27.13 & 26.38 & 143.27 & 331.72 & 304.61 \\
\hline BBPI & 50.43 & 38.50 & 40.92 & 44.58 & 182.23 & 131.80 \\
\hline BBVA & 9.50 & 11.32 & 44.46 & 93.15 & 115.70 & 106.20 \\
\hline BCPSF & 78.27 & 81.92 & 52.23 & 141.96 & 324.26 & 245.99 \\
\hline BILMI & 312.38 & 465.43 & 779.18 & 256.45 & 183.39 & -128.99 \\
\hline BKESF & 11.42 & 17.79 & 51.63 & 137.07 & 196.52 & 185.10 \\
\hline BKT & 39.17 & 80.76 & 69.83 & 88.37 & 220.39 & 181.21 \\
\hline BMDPF & 10.66 & 19.81 & 42.21 & 91.01 & 99.49 & 88.84 \\
\hline BNP & 7.21 & 9.90 & 28.33 & 64.36 & 75.50 & 68.29 \\
\hline BPCGF & 13.45 & 14.96 & 40.62 & 107.34 & 190.44 & 177.00 \\
\hline BPESF & 13.08 & 21.51 & 19.54 & 143.35 & 240.03 & 226.95 \\
\hline BPI & 24.21 & 37.34 & 110.85 & 118.93 & 135.71 & 111.50 \\
\hline BPMLF & 26.56 & 27.74 & 47.62 & 70.22 & 80.96 & 54.40 \\
\hline CBK & 11.60 & 20.36 & 44.93 & 85.18 & 85.75 & 74.15 \\
\hline CRIH & 12.56 & 13.85 & 42.64 & 93.98 & 113.26 & 100.70 \\
\hline DBK & 11.72 & 15.94 & 42.47 & 91.77 & 102.31 & 90.59 \\
\hline DEXB & 7.10 & 9.82 & 27.00 & 241.54 & 239.64 & 232.54 \\
\hline EBKOF & 17.85 & 20.93 & 87.54 & 126.76 & 157.36 & 139.51 \\
\hline EFG & 19.25 & 17.16 & 18.38 & 117.63 & 459.07 & 439.82 \\
\hline FSVVF & 19.39 & 25.33 & 52.11 & 78.86 & 170.01 & 150.62 \\
\hline GLE & 9.49 & 9.27 & 25.63 & 87.92 & 104.33 & 94.84 \\
\hline IITSF & 9.74 & 17.46 & 37.13 & 63.72 & 92.32 & 82.58 \\
\hline IKB & 293.67 & 181.26 & 188.57 & 232.92 & 227.83 & -65.84 \\
\hline ILB & 26.26 & 24.00 & 40.71 & 208.45 & 289.49 & 263.23 \\
\hline ING & 6.40 & 10.71 & 28.01 & 93.79 & 92.39 & 85.99 \\
\hline IRLBF & 9.81 & 9.81 & 75.70 & 229.95 & 250.91 & 241.10 \\
\hline $\mathrm{KBC}$ & 17.49 & 17.09 & 39.60 & 141.48 & 166.01 & 148.53 \\
\hline $\mathrm{KN}$ & 11.68 & 10.01 & 64.98 & 153.82 & 173.20 & 161.52 \\
\hline MDIBF & 21.24 & 20.85 & 40.40 & 65.71 & 90.72 & 69.48 \\
\hline SAB & 93.98 & 188.35 & 259.49 & 196.83 & 271.35 & 177.37 \\
\hline SAN & 10.38 & 12.70 & 39.62 & 96.34 & 107.26 & 96.88 \\
\hline UBI & 26.09 & 40.88 & 55.55 & 37.52 & 105.94 & 79.85 \\
\hline UNBLF & 32.64 & 40.90 & 130.13 & 158.22 & 165.31 & 132.67 \\
\hline Average & 37.41 & 45.16 & 79.00 & 127.10 & 177.46 & $\begin{array}{c}140.05^{* * *} \\
(8.15)\end{array}$ \\
\hline
\end{tabular}




